Desenvolvimento e avaliação de algoritmos para composição dinâmica de web services baseada em QoS

Pedro Felipe do Prado 

Data de Depósito:

Assinatura:

\title{
Desenvolvimento e avaliação de algoritmos para composição dinâmica de web services baseada em QoS
}

\author{
Pedro Felipe do Prado
}

Orientador: Prof. Dr. Marcos José Santana

Dissertação apresentada ao Instituto de Ciências Matemáticas e de Computação - ICMC-USP, como parte dos requisitos para obtenção do título de Mestre em Ciências - Ciências de Computação e Matemática Computacional. VERSÃO REVISADA

USP - São Carlos

Agosto de 2012 
Ficha catalográfica elaborada pela Biblioteca Prof. Achille Bassi e Seção Técnica de Informática, ICMC/USP, com os dados fornecidos pelo(a) autor(a)

do96d Prado, Pedro Felipe
Desenvolvimento e avaliação de algoritmos para
composição dinâmica de web services baseada em Qos /
Pedro Felipe do Prado; orientador Marcos José
Santana. -- São Carlos, 2012 .
85 p.
Dissertação (Mestrado - Programa de Pós-Graduação en
Ciências de Computação e Matemática Computacional) --
Instituto de Ciências Matemáticas e de Computação,
Universidade de São Paulo, 2012.
1. Composição de Web services. 2. Avaliação de
Desempenho. 3. QoS. 4. Sistemas de Tempo-Real. 5. e-
commerce. I. Santana, Marcos José, orient. II. Título.




\section{Agradecimentos}

Gostaria de agradecer primeiramente a Deus, por eu existir. Também gostaria de agradecer aos meus pais e em especial ao meu próprio brother Rodrigo do Prado, pelo apoio financeiro e moral que me deram durante todo o mestrado.

Aos professores do LaSDPC - Laboratório de Sistemas Distribuídos e Programação Concorrente, em especial ao meu orientador Professor Doutor Marcos José Santana, pela ajuda em relação ao projeto e também aos processos burocráticos que envolvem o mestrado. Um agradecimento especial também a Professora Doutora Regina Helena Carlucci Santana, pelas sugestões de melhoria dadas nos seminários do grupo e algumas vezes também fora dos seminários.

Aos meus colegas do LaSDPC, pelas sugestões relacionadas ao meu projeto e pelas trocas de experiências no decorrer do mestrado, em especial ao meu amigo Luís Hideo Vasconcelos Nakamura, que me ajudou na implementação do ambiente de testes deste projeto, além de fornecer várias sugestões relevantes ao projeto.

Ao CNPq - Conselho Nacional de Desenvolvimento Científico e Tecnológico pela bolsa de mestrado que permitiu que eu pagasse minhas despesas durante o mestrado. 
Introdução. 1

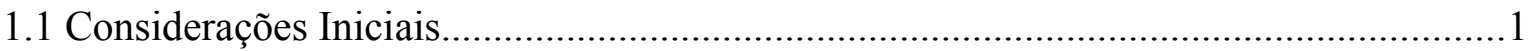

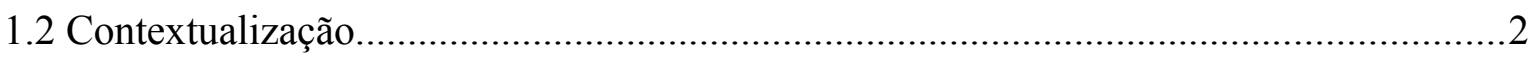

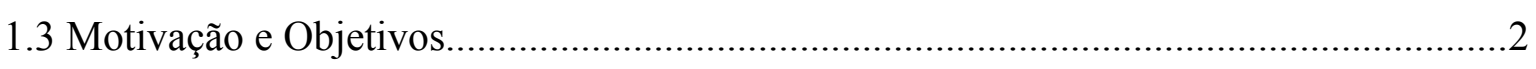

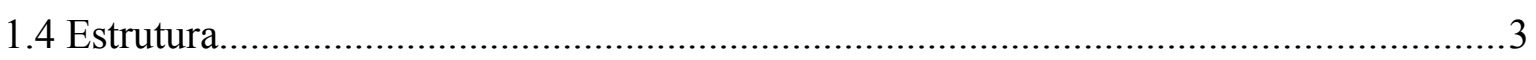

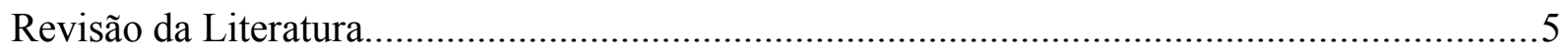

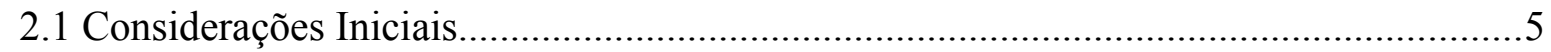

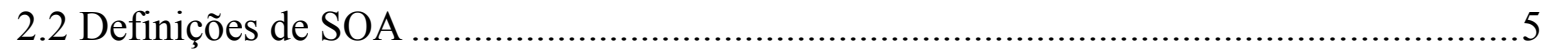

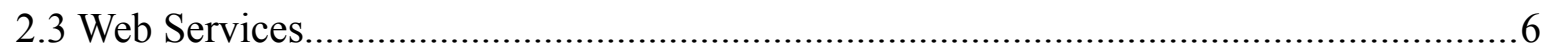

2.3.1 Modelo de Web Services..............................................................................6

2.3.2 Composição de Web services............................................................................... 7

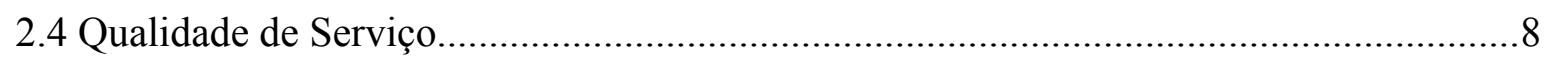

2.4.1 Composição de Web services com qualidade de serviço.......................................10

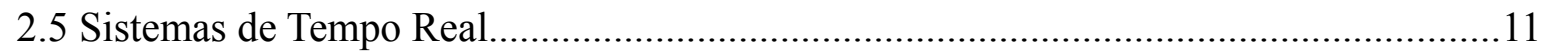

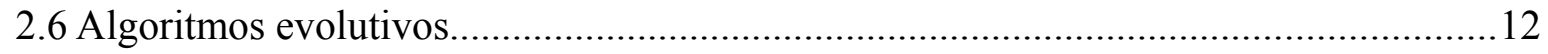

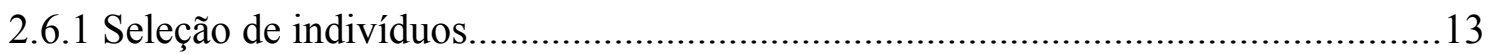

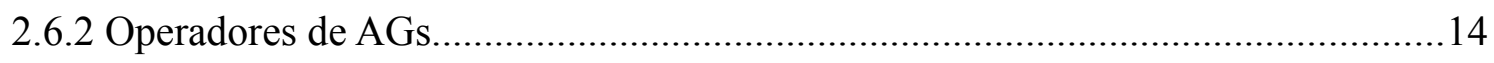

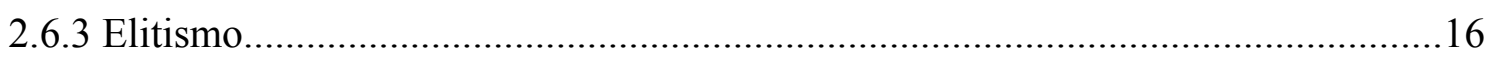

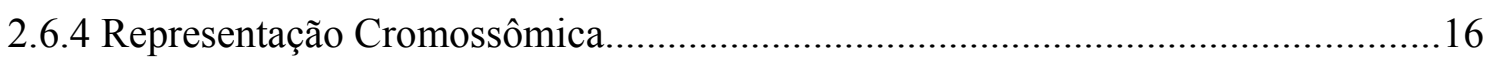

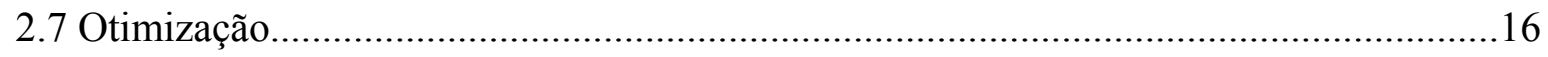

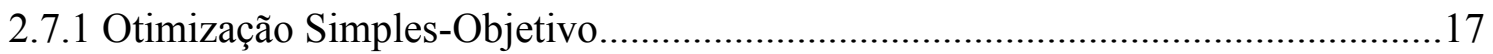

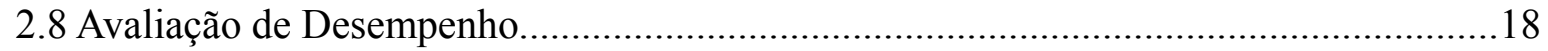

2.8.1 Seleção da Técnica de Avaliação........................................................................20

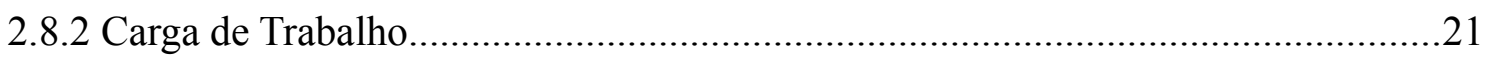

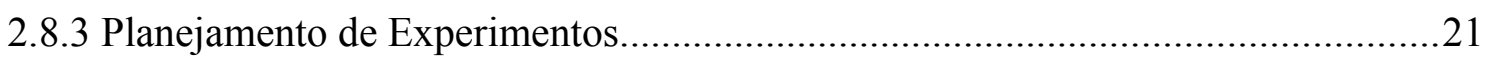

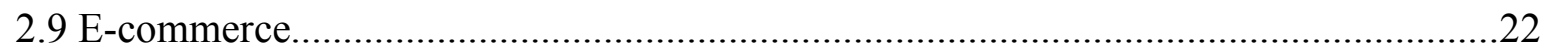

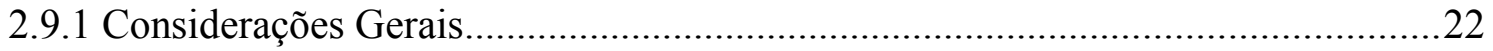

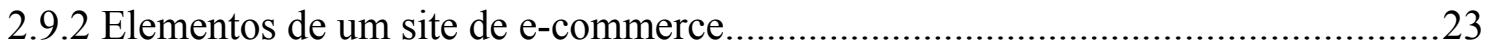

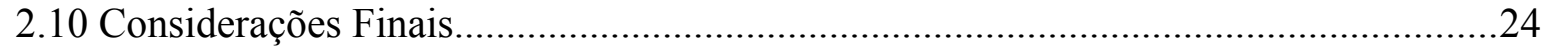

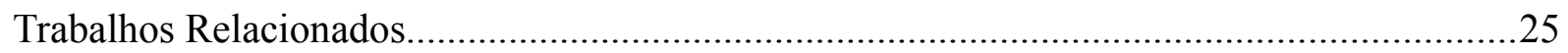

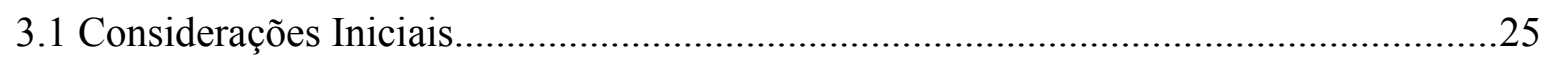

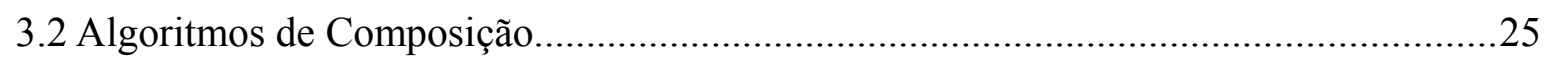




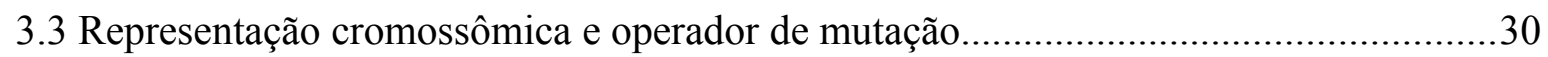

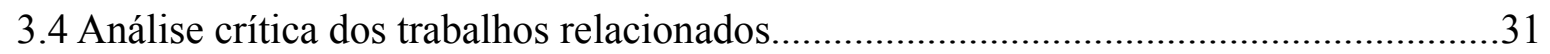

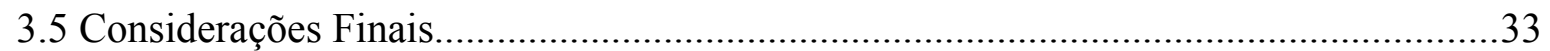

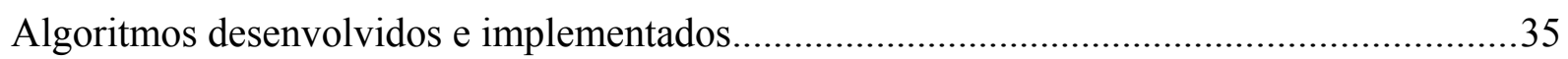

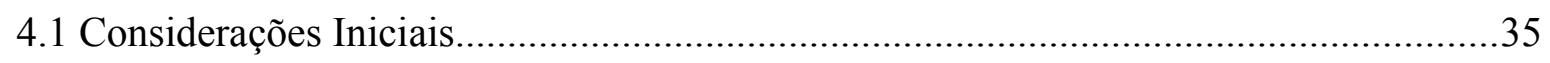

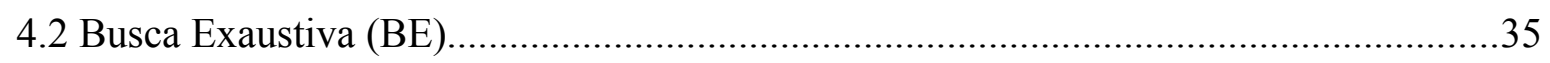

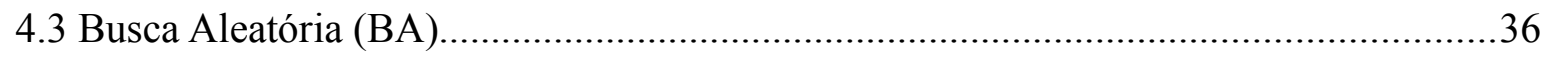

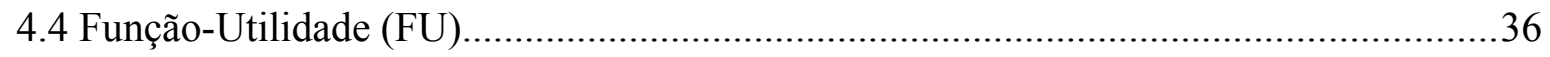

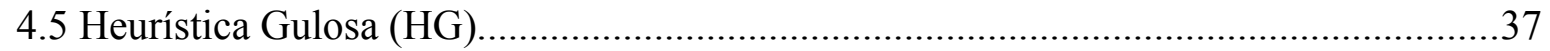

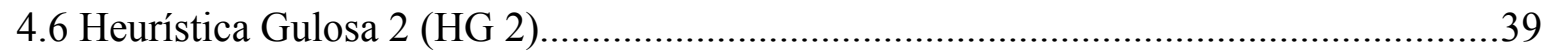

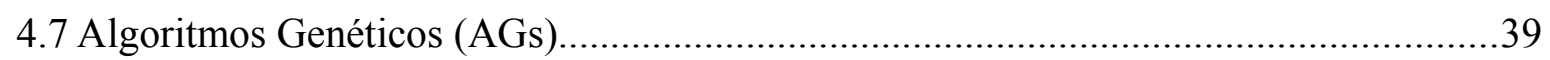

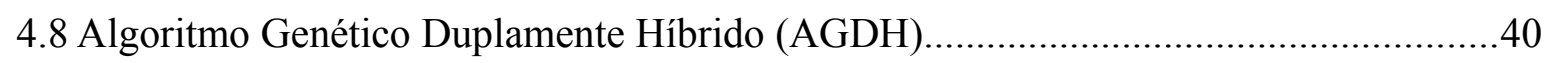

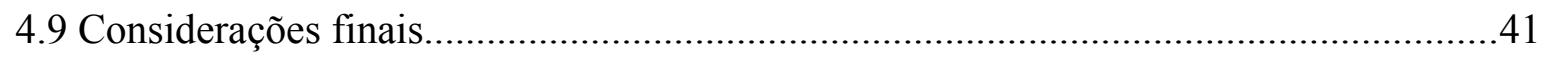

Ambiente de testes e planejamento de experimentos...........................................................43

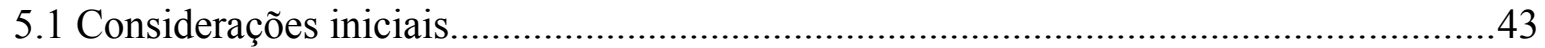

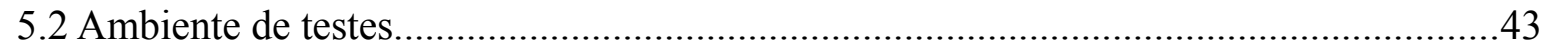

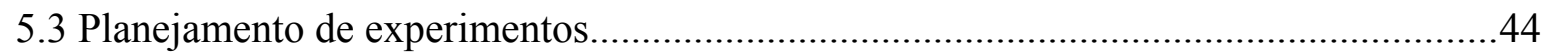

5.3.1 Criação e normalização dos atributos de QoS......................................................45

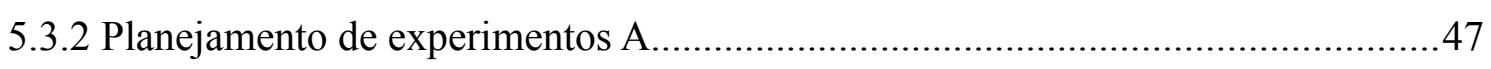

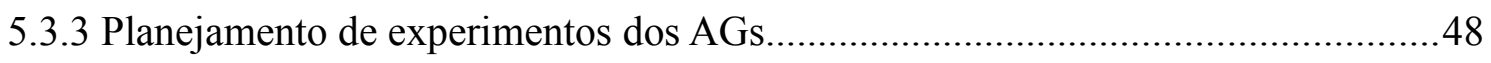

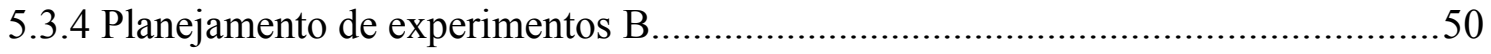

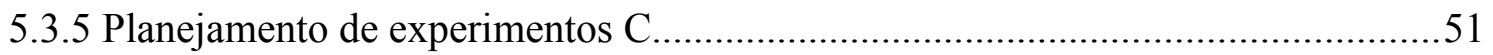

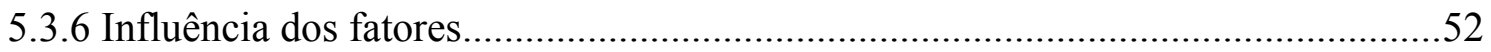

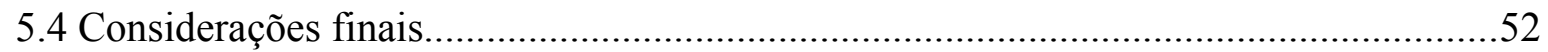

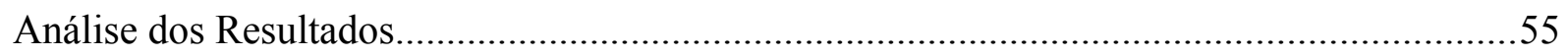

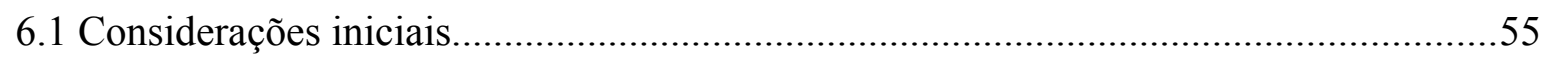

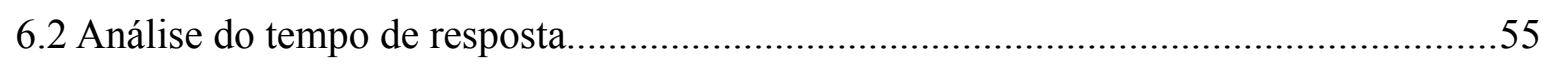

6.2.1 Análise do tempo de resposta do planejamento de experimentos A......................55

6.2.2 Análise do tempo de resposta do planejamento de experimentos dos AGs............56

6.2.3 Análise do tempo de resposta do planejamento de experimentos B......................58

6.2.4 Análise do tempo de resposta do planejamento de experimentos C.....................60

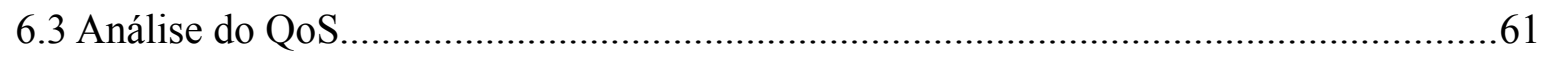

6.3.1 Análise do QoS do planejamento de experimentos A..........................................61

6.3.2 Análise do QoS do planejamento de experimentos dos AGs.................................62

6.3.3 Análise do QoS do planejamento de experimentos B.........................................65 


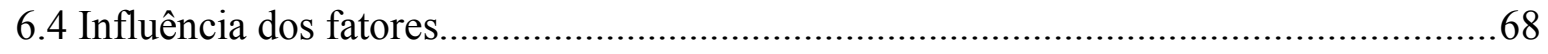

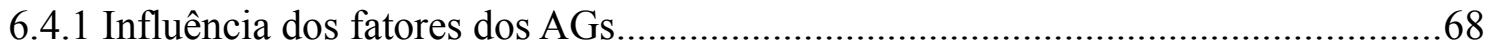

6.4.2 Influência dos fatores do FU e HG.......................................................................69

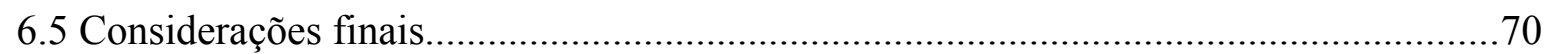

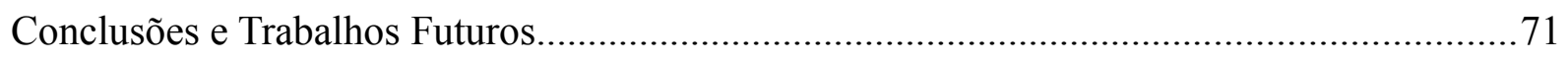

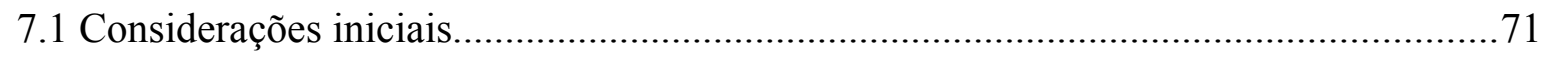

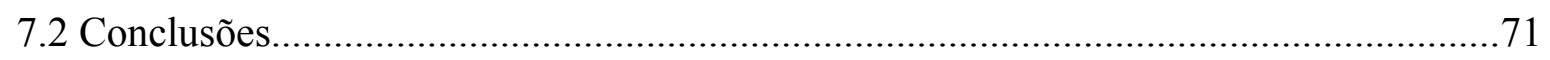

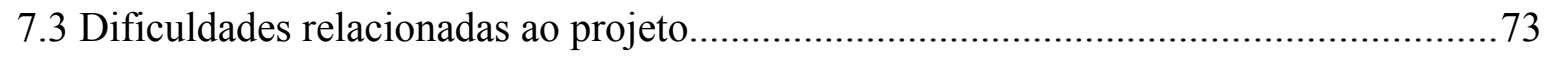

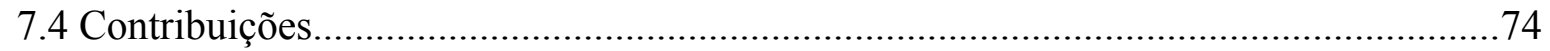

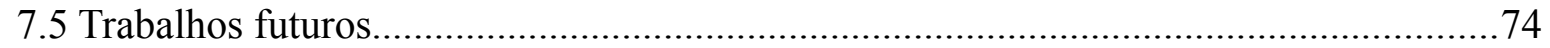

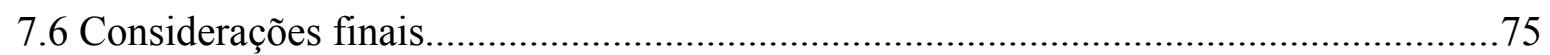

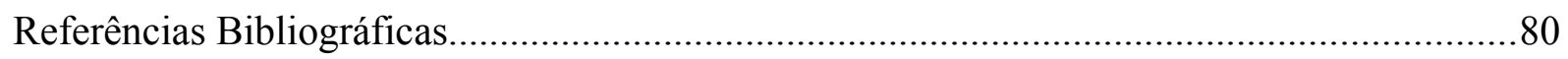




\section{Lista de Figuras}

Figura 1: Modelo de Web services. 7

Figura 2 Diferentes aspectos da Composição de Web services................................................................11

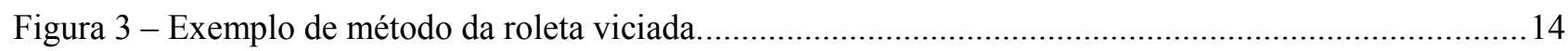

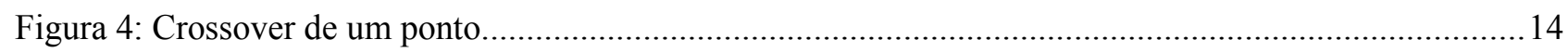

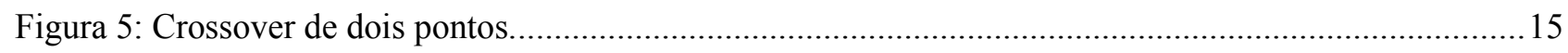

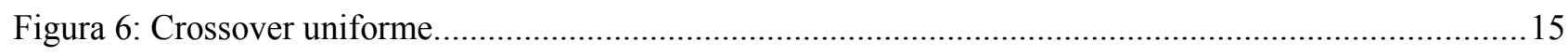

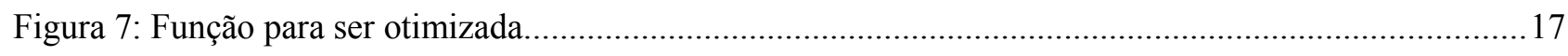

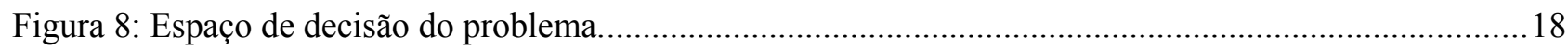

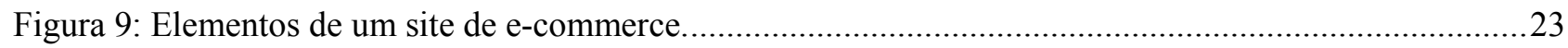

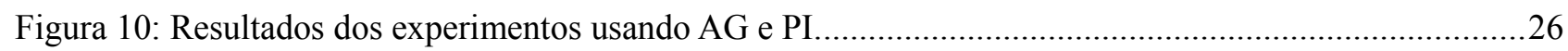

Figura 11: Resultados dos experimentos de acordo com o tamanho do espaço de busca...............................27

Figura 12: Resultados dos experimentos usando-se o algoritmo híbrido....................................................28

Figura 13: Resultados dos experimentos usando-se o algoritmo baseado em PI........................................28

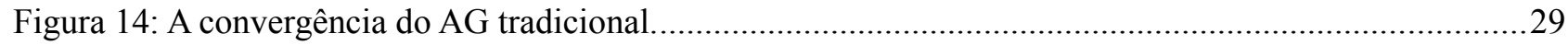

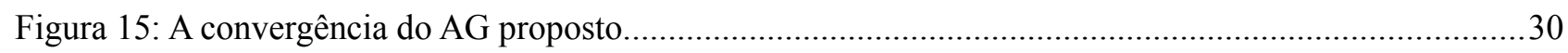

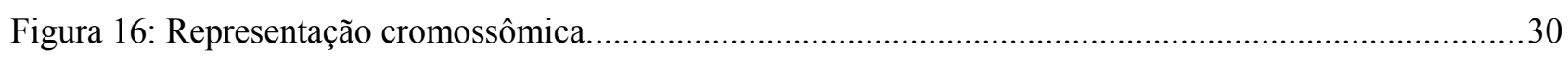

Figura 17: Operador de mutação............................................................................................. 31

Figura 18: Diferentes aspectos do problema abordado nesta dissertação......................................................33

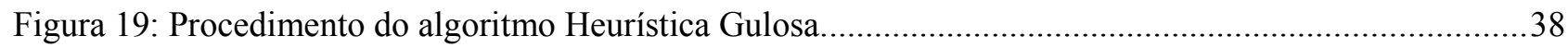

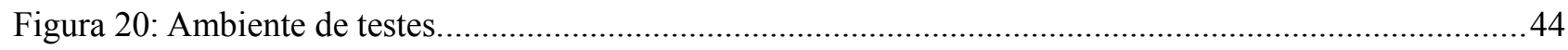

Figura 21: Tempos médios de resposta (em ms) dos algoritmos avaliados no planejamento de experimentos A

Figura 22: Tempos médios de resposta (em ms) do planejamento de experimentos dos AGs, com deadline de

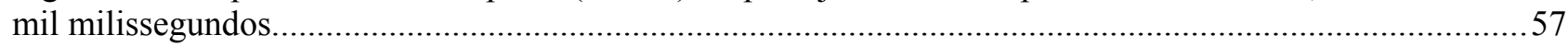

Figura 23: Tempos médios de resposta (em ms) do planejamento de experimentos dos AGs, com deadline de

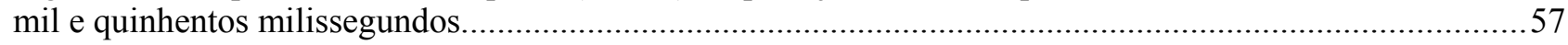

Figura 24: Tempos médios de resposta (em ms) para o Planejamento de Experimentos B, com deadline de

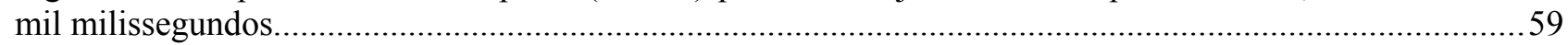

Figura 25: Tempos médios de resposta (em ms.) para o Planejamento de Experimentos B, com deadline de

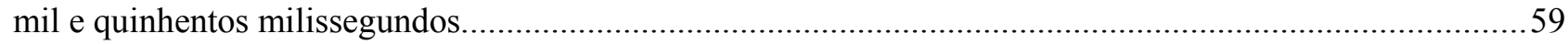

Figura 26: Tempos médios de resposta (em ms.) para o Planejamento de Experimentos C..........................60

Figura 27: QoS obtido pelo planejamento de experimentos A................................................................61 
Figura 28: QoS médio dos algoritmos avaliados no planejamento de experimentos dos AGs, para o deadline de mil milissegundos.

Figura 29: QoS médio dos algoritmos avaliados pelo planejamento de experimentos dos AGs, para o deadline de mil e quinhentos milissegundos.

Figura 30: Tempo médio dispendido na troca de mensagens entre as máquinas do ambiente de testes e na normalização de atributos de QoS.....

Figura 31: QoS médio dos algoritmos avaliados no planejamento de experimentos B, para o deadline de mil milissegundos......

Figura 32: QoS médio dos algoritmos avaliados no planejamento de experimentos B, para o deadline de mil e quinhentos milissegundos.

Figura 33: Influência dos fatores do algoritmo FU....... .69

Figura 34: Influência dos fatores do algoritmo HG. .69 


\section{Lista de Tabelas}

Tabela 1: Atributos de QoS e suas funções de agregação.....................................................................10

Tabela 2: Tempo de resposta de diferentes técnicas para Composição de Web services.......................26

Tabela 3: Parâmetros dos operadores genéticos dos Ags implementados............................................40

Tabela 4: Configuração de hardware do ambiente de testes....................................................................44

Tabela 5: Diferentes tamanhos de espaço de busca definidos..................................................................45

Tabela 6: Intervalo fechado de cada atributo de QoS gerado aleatoriamente.......................................46

Tabela 7: Fatores e níveis do planejamento de experimentos A........................................................... 47

Tabela 8: Fatores e níveis do planejamento de experimentos dos AGs..............................................48

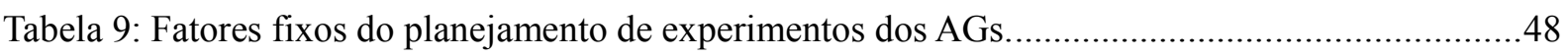

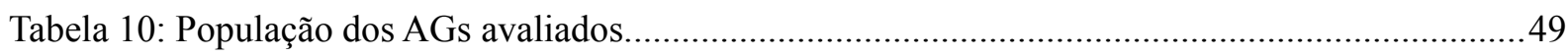

Tabela 11: Fatores e níveis do planejamento de experimentos B........................................................50

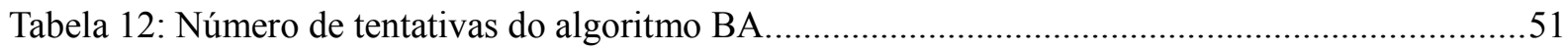

Tabela 13: Fatores e níveis do planejamento de experimentos C.......................................................51

Tabela 14: Fatores e níveis usados no cálculo da influência dos fatores dos algoritmos FU e HG.......52

Tabela 15: Diferenças no QoS do algoritmo BA para os dois deadlines definidos...............................67

Tabela 16: Análise da influência dos fatores para o planejamento de experimentos dos AGs...............68 


\section{Lista de Equações}

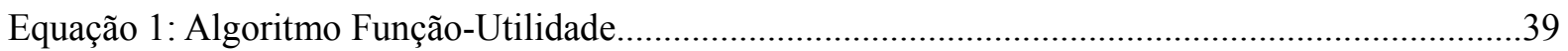

Equação 2: Normalização dos atributos que devem ser minimizados.....................................................48

Equação 3: Normalização dos atributos que devem ser maximizados..................................................48 


\section{Lista de Símbolos}

\begin{tabular}{|c|c|}
\hline$A E$ & Algoritmo Evolutivo. \\
\hline$A G$ & Algoritmo Genético. \\
\hline$A G D H$ & Algoritmo Genético Duplamente Híbrido. \\
\hline ATM & Asynchronous Transfer Mode. \\
\hline $\boldsymbol{B} \boldsymbol{A}$ & Busca Aleatória. \\
\hline$B E$ & Busca Exaustiva. \\
\hline CPU & Central Processing Unit - Unidade Central de Processamento. \\
\hline$C W S b Q$ & Composição de Web Services baseada em QoS. \\
\hline $\boldsymbol{E} \boldsymbol{E}$ & Estratégias Evolutivas. \\
\hline $\boldsymbol{F U}$ & Função-Utilidade. \\
\hline$H G$ & Heurística Gulosa. \\
\hline$H G 2$ & Heurística Gulosa 2. \\
\hline $\boldsymbol{H P}$ & Hewlett-Packard. \\
\hline HRT & Hard Real-Time - Tempo Real Rígido. \\
\hline HTTP & Hyper Text Transfer Protocol. \\
\hline IBM & International Business Machines. \\
\hline IP & Internet Protocol. \\
\hline$N P$ & Non-Deterministic Polynomial Time. \\
\hline$P E$ & Programação Evolutiva. \\
\hline$P G$ & Programação Genética. \\
\hline$P I$ & Programação Inteira. \\
\hline$Q o S$ & Quality of Service. \\
\hline$S G B D$ & Sistema Gerenciador de Banco de Dados. \\
\hline SMTP & Simple Mail Transfer Protocol. \\
\hline$S O A$ & Service-Oriented Architecture - Arquitetura Orientada à Serviços. \\
\hline$S O A P$ & Simple Object Acces Protocol. \\
\hline$T I$ & Tecnologia da Informação. \\
\hline$U D D I$ & Universal Description Discovery and Integration. \\
\hline URI & Uniform Resource Identifier. \\
\hline W3C & World Wide Web Consortium. \\
\hline$W S D L$ & Web Service Definition Language. \\
\hline$X M L$ & eXtensible Markup Language. \\
\hline
\end{tabular}




\section{Resumo}

Esta dissertação de mestrado aborda a Composição de Web services baseada em atributos de Qualidade de Serviço (CWSbQ). Foi selecionado o domínio de sistemas de e-commerce, por se tratar de uma área em franca expansão, tanto no cenário nacional como internacional. Além disso, os sistemas de e-commerce podem se beneficiar da CWSbQ devido à sua interoperabilidade e atendimento aos requisitos de qualidade de serviço de seus clientes. Foram implementados dez algoritmos para resolver esse problema, usando várias técnicas diferentes, sendo elas: busca aleatória, busca exaustiva, busca heurística, busca meta-heurística e um algoritmo híbrido. Foram realizados experimentos de avaliação de desempenho, considerando tamanhos de espaço de busca diferentes e dois deadlines estabelecidos. As principais contribuições deste trabalho foram 0 desenvolvimento de três novos algoritmos: Heurística Gulosa (HG), Heurística Gulosa 2 (HG2) e Algoritmo Genético Duplamente Híbrido $(\mathrm{AGDH})$; o uso de planejamento de experimentos e avaliação de desempenho para aperfeiçoar Algoritmos Genéticos (AGs) usados no problema de CWSbQ; e o estudo de adequação dos algoritmos de CWSbQ para diferentes situações. 


\begin{abstract}
This MSc dissertation addresses the QoS-aware Web services composition (QWSC) problem. The field of e-commerce systems was selected because it comprises an area in wide expansion, both in national and international scenarios. Furthermore, e-commerce systems can benefit from QWSC due to its interoperability and compliance to the requirements of quality of service of the customers. Ten algorithms were implemented to solve this problem by using several different techniques, namely: random search, exhaustive search, heuristic search, meta-heuristic and a hybrid algorithm. Performance evaluation was made considering different search space sizes for two different established deadlines. The main contributions of this work were the development of three new algorithms: Greedy Heuristic $(\mathrm{GH})$, Greedy Heuristic 2 (GH2) and Doubly Hybrid Genetic Algorithm (DHGA); the use of planning of experiments and performance evaluation to improve the genetic algorithms (GAs) used in QWSC problem; and a suitability study of QWSC algorithms for different situations.
\end{abstract}




\section{Capitulo 1}

\section{Introdução}

\subsection{Considerações Iniciais}

Até a década de 1990, a Internet era usada primordialmente por pesquisadores, acadêmicos e estudantes universitários para se interligar a hospedeiros remotos, transferir arquivos de hospedeiros locais para hospedeiros remotos e vice-versa, enviar e receber notícias, e enviar e receber correio eletrônico. (KUROSE \& ROSS, 2007).

Entretanto, no início da década de 1990, entrou em cena uma nova aplicação importantíssima - a World Wide Web (BERNERS-LEE,2000).

O paradigma de computação orientada a serviços - Services Oriented Architecture (SOA) - fornece suporte às aplicações desenvolvidas em ambientes heterogêneos. Além da flexibilidade, permite a adaptação automática para mudanças dos requisitos ou do contexto. (FOSTER et. al., 2004).

Com o surgimento dos chamados Web Services (que são uma implementação da arquitetura SOA), tem sido possível que aplicações executando em diferentes plataformas e desenvolvidas em diferentes linguagens de programação possam se comunicar pela Web através de uma interface denominada Web Service Description Language (WSDL), toda composta em eXtensible Markup Language (XML), uma linguagem interoperável e independente de plataforma e sistema operacional.

Segundo SNELL et. al. (2001), Web Services podem ser definidos como aplicações que são acessíveis pela Web usando uma combinação de protocolos como Hyper Text Transfer Protocol (HTTP), XML, Simple Mail Transfer Protocol (SMTP) ou Jabber.

Com a crescente popularidade dos Web Services, um suporte geral a Qualidade de Serviço (Quality of Service - QoS) é uma questão fundamental para o sucesso dessa solução emergente (ERRADI \& MAHESHWARI,2005). Infelizmente, os ambientes de Web Services 
atuais não oferecem um suporte adequado à qualidade de serviço e apresentam diversas limitações (TIAN et. al., 2003).

\subsection{Contextualização}

O surgimento dos Web Services tem provocado uma mudança de paradigma na integração de aplicações, onde serviços podem ser compartilhados para permitir a otimização de processos de negócios numa ampla estrutura de Tecnologia de Informação (TI). A adoção efetiva dos Web Services é atualmente uma realidade, uma vez que a indústria vem considerando duas frentes: padrões e produtos (KREGER, 2001). A IBM tem investido tempo, talento e recursos financeiros em ambas as frentes, em projetos que envolvem arquiteturas orientadas a serviços, composição de serviços e computação em nuvem (cloud computing). Conforme SNELL et. al. (2001), muitos fabricantes de softwares como IBM e Microsoft estão adotando Web Services em larga escala. IBM, por exemplo, está integrando suporte a Web Services em seu WebSphere, Tivoli, Lotus e DB2. E a nova plataforma de desenvolvimento .NET da Microsoft foi construída com base em Web Services.

Segundo Wang et. al. (2009), grandes empresas estão disponibilizando serviços através da composição de Web Services, como Google, Microsoft e Yahoo.

\subsection{Motivação e Objetivos}

Segundo CERAMI (2002), Web Services podem ser definidos como qualquer serviço que está disponível na Internet e utiliza um padrão de mensagens baseado em XML, e não está preso a nenhum sistema operacional ou linguagem de programação. Além disso, é uma promessa para a integração de aplicações $W e b$, sendo um tópico amplamente pesquisado pela comunidade acadêmica e por empresas como IBM, HP e Microsoft (SIBLINI; MANSOUR, 2005).

De acordo com SNELL et al (2001) interoperabilidade é um dos principais benefícios de se utilizar Web Services. Para permitir maior interação nos processos de negócios, é vital que as aplicações interajam entre si de um modo flexível. Isso pode ser facilitado pela adoção de padrões de Web Services, para aplicações serem parte do processo de negócios. O gerenciamento de processos de negócios também oferece a real capacidade de incluir Web 
Services em uma arquitetura genérica orientada a serviço numa larga escala empresarial, utilizando para esta finalidade, um processo de composição de serviços (Janssen et al., 2005).

Conforme DUSTDAR \& SCHREINER (2004), quando ocorre a composição de Web Services, a lógica de negócio do cliente é desenvolvida por vários serviços. Isso é similar ao gerenciamento do fluxo de trabalho em que a lógica das aplicações é realizada através da composição de aplicações autônomas.

A composição de Web Services tem se mostrado como o desafio mais interessante e um dos principais temas de estudo na área de Web Services (LI \& CHEN, 2010; LIU ET. AL., 2010; FANJIANG ET. AL., 2010).

Conforme Bravetti et. al. (2004), e-commerce é uma das aplicações mais críticas da Internet, e é fundamental empregar tecnologias que garantam não apenas transações seguras, mas também QoS.

De acordo com Menascé et. al. (2001), QoS de sites de e-commerce tem um papel crucial na atração e retenção de clientes. Clientes frustrados deixam esses sites e não retornam, causando perdas de receita.

Portanto, o objetivo deste projeto de mestrado é realizar um levantamento dos atributos de QoS relevantes na composição manual e dinâmica de Web Services voltados a sistemas de e-commerce e desenvolvimento de algoritmos para seleção dinâmica de Web Services, levando-se em conta os atributos de QoS definidos e avaliação de desempenho dos algoritmos desenvolvidos.

As contribuições esperadas com o desenvolvimento deste projeto vão desde permitir um melhor mapeamento dos atributos de QoS relevantes para Web Services voltados a sistemas de e-commerce, como também avaliar o desempenho dos algoritmos desenvolvidos, o que permitirá para empresas e provedores de serviços, identificar quais são as alternativas mais interessantes para suas necessidades de negócios, levando-se em conta os algoritmos analisados.

\subsection{Estrutura}

Esta dissertação está organizada da seguinte forma:

No Capítulo 2 são apresentadas informações sobre todos os conceitos relacionados ao 
projeto. Esses conceitos incluem: Web Services, SOA, otimização, e-commerce, QoS, sistemas de tempo-real, algoritmos evolutivos e avaliação de desempenho.

No Capítulo 3 são apresentados os trabalhos relacionados. Isso permite uma visão mais ampla do problema abordado neste projeto.

No Capítulo 4 são apresentados os algoritmos de composição de Web Services desenvolvidos. Foram desenvolvidos dez algoritmos, sendo três deles baseados em ideias originais que surgiram durante a execução do projeto.

No Capítulo 5 é apresentada a avaliação de desempenho dos algoritmos desenvolvidos. Este capítulo inclui a configuração do ambiente de testes e o planejamento dos experimentos.

No Capítulo 6 é apresentada a análise dos resultados.

O Capítulo 7 apresenta as conclusões e sugestões para trabalhos futuros.

As Referências são apresentadas em seguida. 


\section{Capítulo}

\section{Revisão da Literatura}

\subsection{Considerações Iniciais}

Este capítulo tem o intuito de fornecer a fundamentação teórica necessária para a compreensão dos conceitos relacionados a este projeto de mestrado, bem como formar o arcabouço de sustentação para os desenvolvimentos aqui formulados. Os temas abordados são: SOA, Web Services, QoS, sistemas de tempo-real, algoritmos evolutivos, otimização, avaliação de desempenho e e-commerce.

Este capítulo não visa a aprofundar-se nesses temas, mas sim fornecer, de forma clara e sucinta, a base necessária para a compreensão do que foi realizado neste projeto de mestrado.

\subsection{Definições de SOA}

De acordo com Erl (2008), SOA (Service-Oriented Architeture) ou Arquitetura Orientada a Serviços, estabelece um modelo de arquitetura que visa a aumentar a eficiência, agilidade e produtividade de uma empresa, fazendo com que os serviços sejam o principal meio através do qual a solução lógica é representada, visando a apoiar os objetivos estratégicos da empresa.

Serviços são unidades de trabalho criadas por um fornecedor de serviço, para alcançar os resultados finais desejados por um consumidor de serviços. Ambos, fornecedor e consumidor, são regrados por agentes de software de acordo com o interesse de seus proprietários (HE \& HASS, 2003). 


\subsection{Web Services}

A W3C define um Web Service como uma aplicação identificada por uma Uniform Resource Identifier (URI), cujas interfaces e ligações são definidas, descritas e descobertas utilizando-se uma linguagem padrão, XML (FERRIS; FARREL, 2003).

Web Services constituem uma implementação de SOA (ERRADI; MAHESHWARI, 2005). Pelas definições apresentadas, pode-se observar que diferentes explicações sobre Web Services estão disponíveis. Uma delas menciona que as interações entre Web Services ocorrem tipicamente com chamadas SOAP (Simple Object Access Protocol), um protocolo de comunicação baseado em XML para a interação de aplicações (PAPAZOGLOU; GEORGAKOPOULOS, 2001). SOAP é apresentado como um arcabouço para uma nova geração de aplicações de computação distribuída, independente de plataforma e de linguagens de programação.

A principal função desse protocolo é encapsular as chamadas aos métodos remotamente distribuídos, que serão transportados, por sua vez, por algum protocolo, tal como o HTTP, utilizado para comunicação entre um browser e um servidor Web (COMER, 2000). Além disso, as descrições de interfaces dos WS são expressas usando a linguagem denominada WDSL (THOMAS; THOMAS; GHINEA, 2003). Na literatura sobre Web Services é apresentado também um protocolo para serviços de diretório, que contém as descrições dos Web Services, denominado Universal Description Discovery and Integration (UDDI). Esse protocolo funciona como um registro de serviços sendo um importante componente da arquitetura orientada a serviços (FARKAS; CHARAF, 2003). Uma arquitetura orientada a serviço é uma maneira lógica de construção de um sistema de software para prover serviços, ou para aplicações de usuários finais, ou para outros serviços distribuídos em uma rede, por meio de interfaces públicas disponíveis (nesse contexto destaca-se o WSDL) (PAPAZOGLOU, 2003). O UDDI habilita, ainda, os clientes de Web Services a localizarem serviços ou descobrirem seus detalhes, permitindo que registros operacionais sejam mantidos para diferentes propósitos em diferentes contextos (LEAVITT, 2004).

\subsubsection{Modelo de Web Services}

A arquitetura de Web Services é baseada nas interações entre três entidades que são o provedor de serviços, o registro de serviços e o consumidor de serviços. As interações 
envolvem a publicação, a pesquisa e a ligação.

O provedor de serviços define uma descrição de serviços para o Web Services e o publica nos registros de pesquisa ou a disponibiliza diretamente para serviços consumidores. Os serviços consumidores utilizam operações de pesquisa para localizar a descrição do serviço localmente ou nos registros de pesquisa e usa a descrição do serviço para conectar-se ao provedor de serviço e invocar, ou interagir, com a implementação do Web Service. O provedor de serviços é uma construção lógica uma vez que um serviço pode ter características de provedor de serviço e de consumidor de serviço (KREGER, 2001).

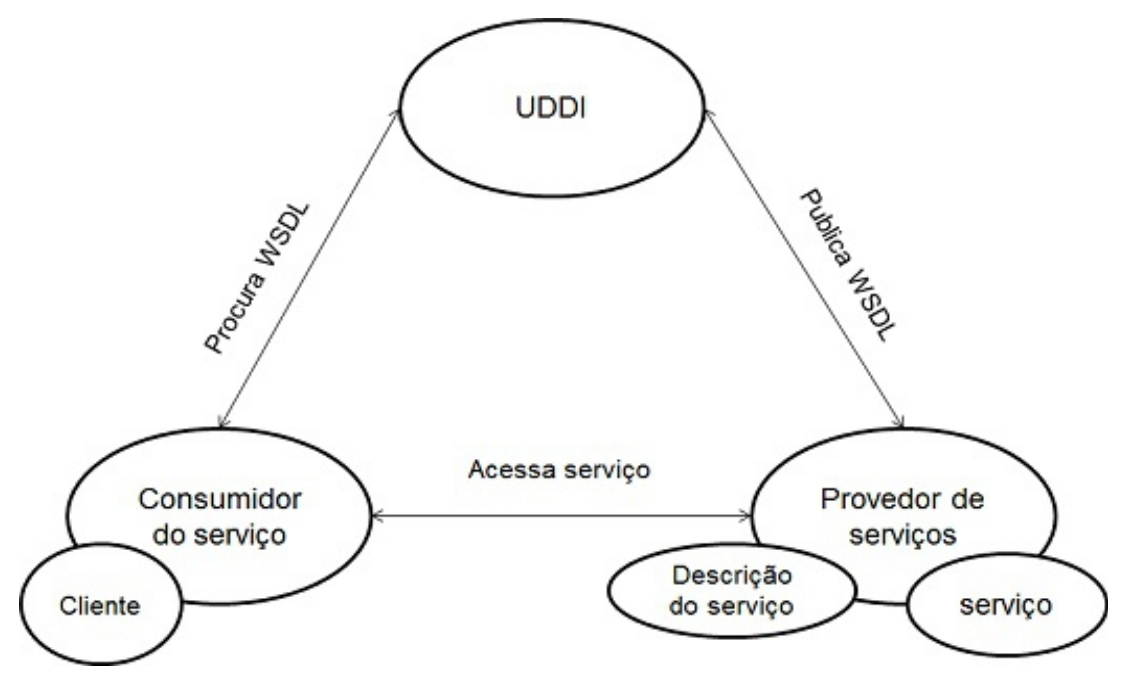

Figura 1: Modelo de Web Services.

Fonte: Kreger (2001).

\subsubsection{Composição de Web Services}

Composição de software não é um conceito novo. Muitos programas e sistemas foram compostos de arquivos e componentes unidos para formar algo útil em tempo de execução. Composição foi um aspecto chave para a evolução da TI (ERL, 2008).

De acordo com Snell et al. (2001), interoperabilidade é um dos principais benefícios ao se utilizar Web Services. Para permitir maior interação nos processos de negócios, é vital que as aplicações interajam entre si de modo flexível. Isso pode ser facilitado pela adoção de padrões de Web Services, para as aplicações serem parte do processo de negócios. O gerenciamento de processos de negócios também oferece a real capacidade de incluir Web Services em uma arquitetura genérica orientada a serviço numa larga escala empresarial, utilizando para essa finalidade, por exemplo, um processo de composição de serviços 
(JANSSEN et al., 2005).

Conforme Dustdar \& Schreiner (2004), quando ocorre a composição de Web Services, a lógica de negócio do cliente é desenvolvida por vários serviços. Isso é similar ao gerenciamento do fluxo de trabalho em que a lógica das aplicações é realizada através da composição de aplicações autônomas.

Segundo Peltz (2003), os termos orquestração e coreografia são utilizados para descrever diferentes formas de se criar processos de negócio através da composição de Web Services.

Orquestração se refere a um processo de negócio executável, que pode interagir com Web Services internos e externos. As interações ocorrem em nível de mensagens. Orquestração sempre representa o controle de uma das partes envolvidas. Isso o difere da coreografia que é mais colaborativa e permite que cada parte envolvida possa descrever sua participação na interação (PELTZ, 2003).

Na literatura é comum haver confusão sobre os tipos de composição de Web Services, que podem ser manual ou automática, e estática ou dinâmica. Trabalhos como Rao \& Su (2004) e Dustdar \& Schreiner (2004) descrevem sobre uma classificação dos tipos de composição. A partir dessas classificações é possível chegar-se à conclusão de forma sucinta, de que composição manual e automática são duas grandes classificações onde, na composição manual um grafo contendo a descrição de execução de fluxo e referência lógica a Web Services é planejado por um desenvolvedor. Na composição automática o fluxo é definido automaticamente, através de técnicas como inteligência artificial e Web semântica, usando como referência apenas as entradas e saídas fornecidas ao processo pelo usuário para definir o fluxo. Já a composição dinâmica e estática são classificações que podem ser aplicadas dentro de composição automática e manual. Composição estática se refere à associação de cada implementação de serviço em tempo de projeto. Na composição dinâmica os serviços são selecionados para serem executados em tempo de execução (KUEHNE, 2009).

\subsection{Qualidade de Serviço}

O termo qualidade de serviço pode ser visto de diversas formas de acordo com a área de aplicação. Por exemplo, do ponto de vista de uma rede de comutação de circuitos, refere-se à probabilidade de sucesso em estabelecer uma ligação a um determinado destino. Do ponto de 
vista de uma rede de comutação de pacotes a qualidade de serviço (QoS) refere-se à capacidade de uma rede prover melhores serviços para um dado tráfego selecionado, podendo utilizar várias tecnologias incluindo Frame Relay, Asynchronous Transfer Mode (ATM), Ethernet, redes 802.11, Synchronous Optical Networking (SONET) e redes Internet Protocol (IP) (VESEGNA, 2001).

Entretanto, este projeto de mestrado tem em foco a Composição de Web Services baseada em atributos de QoS (CWSbQ), por isso a qualidade de serviço em nível de rede não será explorada.

No contexto de Web Services, qualidade de serviços é referenciada como um conjunto de propriedades não-funcionais, tais como desempenho, confiabilidade, disponibilidade e segurança. Com a difusão dos Web Services, medidas de qualidade de serviço são utilizadas como uma aferição para diferenciar serviços (Kalepu et al. 2003). No entanto, garantir QoS em aplicações Web não é uma tarefa trivial devido às características imprevisíveis da Internet (Farkas \& Charaf, 2003).

Assim, alguns parâmetros de qualidade de serviço, de acordo com Kalepu (2003) são:

Disponibilidade: é um aspecto de qualidade de serviço no qual um Web Service está presente, ou pronto, para uso imediato, representado como uma porcentagem de tempo disponível de um serviço em um período de observação e está relacionado com sua confiabilidade. Para serviços frequentemente acessados, um pequeno valor de período de observação fornece uma aproximação mais precisa para sua disponibilidade.

Custo: o valor monetário cobrado pelo provedor de serviços pelo acesso feito ao serviço.

Tempo de resposta: corresponde ao tempo que uma requisição demora a partir do momento em que ela é iniciada para ser atendida até o momento em que o requisitante recebe a resposta dessa requisição. Esse tempo inclui toda a sobrecarga e possíveis atrasos que ocorram na rede.

Reputação: corresponde a um parâmetro medido pela avaliação que os clientes do serviço atribuem a ele. No final de cada acesso isso pode ser coletado por meio de uma enquete sobre a satisfação do usuário.

Confidencialidade: de acordo com Kurose \& Ross (2006) esse atributo de QoS faz parte da segurança do sistema (ou rede) e significa que somente o remetente e o destinatário 
pretendido devem poder entender o conteúdo da mensagem transmitida.

\subsubsection{Composição de Web Services com qualidade de serviço}

De acordo com Wang et. al. (2009) a popularidade crescente do uso de Web Services para sistemas distribuídos contribui para a importância da descoberta de serviços. No entanto, podem existir vários Web Services com a mesma funcionalidade, de forma que é necessário utilizarem-se de critérios adicionais para a seleção dos Web Services que serão considerados em uma composição. Como selecionar a melhor composição de Web Services baseando-se em atributos de QoS é uma questão prática bastante atrativa e desafiadora.

Tendo em vista que cada Web Service possui seus próprios atributos de QoS, são necessárias funções de agregação para tais atributos, de forma que seja possível avaliar os valores de QoS da composição como um todo (KO ET. AL., 2008; ZHI-PENG ET. AL., 2009). A Tabela 1 apresenta um exemplo desses atributos de agregação:

Tabela 1: Atributos de QoS e suas funções de agregação.

\begin{tabular}{|c|c|}
\hline Atributo de QoS & Função de Agregação \\
\hline Custo & $\sum_{i=1}^{i=n}$ custo $\left(W S_{i}\right)$ \\
\hline Disponibilidade & $\prod_{i=1}^{i=n}$ disponibilidade $\left(W S_{i}\right)$ \\
\hline Reputação & $\sum_{i=1}^{i=n}$ reputacao $\left(W S_{i}\right) * 1 / n$ \\
\hline Tempo de Resposta & $\sum_{i=1}^{i=n}$ tempo $\left(W S_{i}\right)$ \\
\hline Confidencialidade & $\sum_{i=1}^{i=n} \operatorname{conf}\left(W S_{i}\right) * 1 / n$ \\
\hline
\end{tabular}

Fonte: Adaptado de Ko et. al. (2008)

Na Tabela 1 pode-se observar que os atributos de QoS custo e tempo de resposta da composição são apenas a somatória dos valores individuais de cada Web Service. O atributo disponibilidade é dado pela multiplicação dos valores de cada Web Service. Finalmente os atributos de reputação e confidencialidade representam uma média dos valores de cada Web Service. 
Essas funções de agregação são utilizadas quando o fluxo de execução da composição é sequencial, sendo que para diferentes tipos de fluxos são utilizadas outras funções de agregação.

De acordo com Canfora et. al. (2005) e Ardagna \& Pernici (2006) o problema de composição de Web Services baseando-se em atributos de QoS, é um problema de otimização combinatória, com complexidade NP - difícil, pois é equivalente ao problema da mochila multidimensional com múltiplos objetivos.

Segundo Zhang \& Ma (2009) alguns Web Services candidatos (Web Services concretos) com as mesmas funções e diferentes valores de atributos de QoS são descobertos para cada tarefa a ser executada (Web Services abstratos). Se o fluxo tiver 10 Web Services abstratos e 15 Web Services concretos para cada Web Service abstrato, têm-se $15^{10}$ possíveis composições.

De acordo com o trabalho de Ko et. al. (2008) é esperado que existissem centenas de Web Services concretos com as mesmas funcionalidades e diferentes valores para os atributos de QoS. Além disso, o uso de Web Services vem crescendo a cada ano, dessa forma, seria razoável imaginar um cenário com cerca de 150 Web Services concretos para cada Web Service abstrato, supondo-se um fluxo com $10 \mathrm{Web}$ Services abstratos se teria $150^{10}$ possíveis composições, algo claramente inviável de se calcular através de algoritmos de busca exaustiva.

Em Fanjiang et. al. (2010), a composição de Web Services é separada em seleção baseada em QoS e criação da orquestração, porém este projeto de mestrado está focado apenas na seleção baseada em QoS. A Figura 2 exemplifica essa separação: 


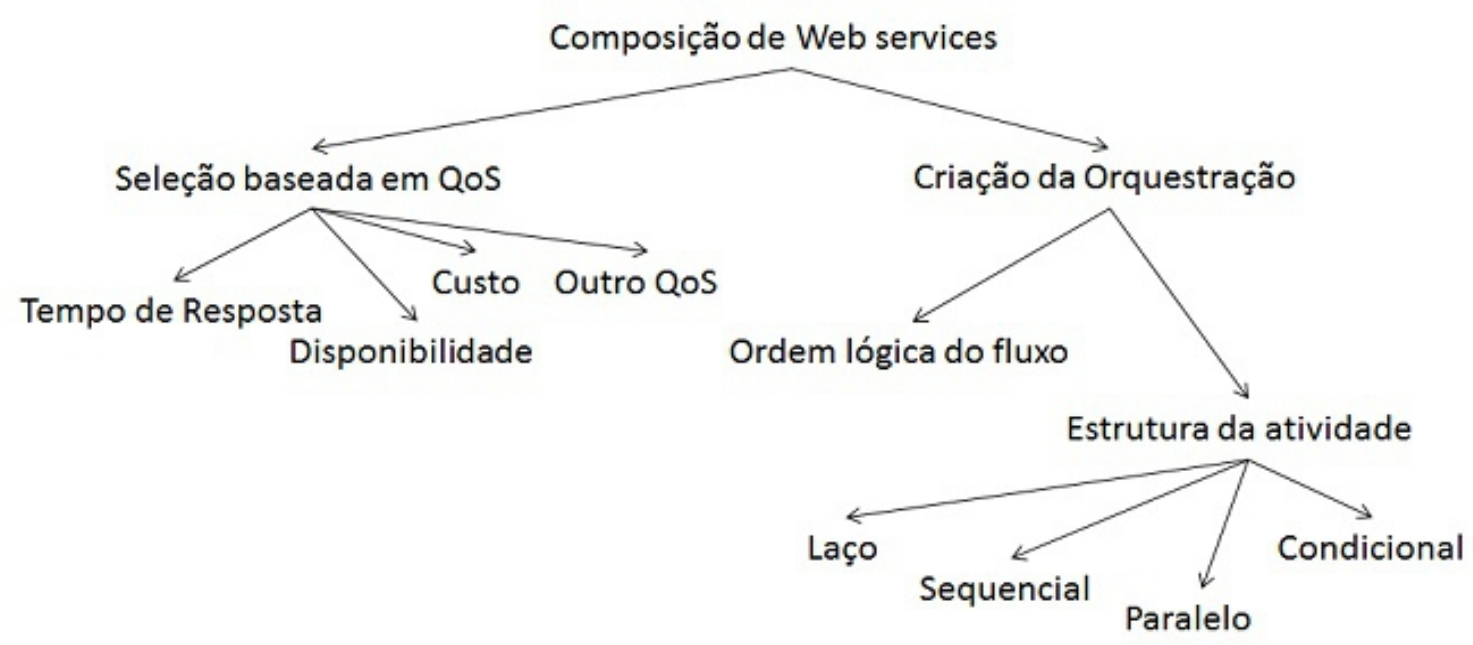

Figura 2 Diferentes aspectos da Composição de Web services.

Fonte: Adaptado de Fanjiang et. al. (2010).

\subsection{Sistemas de Tempo Real}

De acordo com Liu (2000), sistemas de tempo-real (real-time systems) podem ser definidos como aqueles que devem completar suas tarefas de maneira correta e dentro de um intervalo de tempo preestabelecido (deadline). Essa segunda característica é o que os diferencia dos sistemas que não são de tempo-real. Os sistemas convencionais não possuem um deadline para executar suas tarefas.

Segundo Liu (2000) os sistemas de tempo-real podem ainda ser classificados de duas formas: Hard Real-Time (HRT) e Soft Real-Time (SRT). Uma definição usualmente utilizada é que o não cumprimento de um deadline em um sistema HRT pode ocasionar uma falta grave. Por grave, pode-se definir como perdas catastróficas, como por exemplo, um acidente em uma usina nuclear ou ainda a falha em um mecanismo eletrônico de um automóvel que pode ocasionar um acidente de trânsito.

Os sistemas SRT são aqueles em que atrasos no deadline são indesejados, mas que não trazem consequências graves. Nesses sistemas, seus desenvolvedores raramente precisam de provas rigorosas de que seus sistemas atendem aos deadlines estabelecidos. Exemplos desses sistemas incluem sistemas de transações on-line e switches de telefones, bem como jogos eletrônicos.

Dessa forma, como este projeto de mestrado foca em sistemas de e-commerce fica 
evidente que se devem levar em conta as características dos sistemas SRT no planejamento de experimentos e nas avaliações de desempenho dos algoritmos desenvolvidos.

\subsection{Algoritmos evolutivos}

Algoritmos evolutivos (AEs) é uma subárea dos algoritmos meta-heurísticos, que são utilizados em problemas de otimização. Alguns exemplos de algoritmos evolutivos são: algoritmos genéticos (AGs), programação evolutiva (PE), estratégias evolutivas (EE) e programação genética (PG) (LINDEN, 2008).

Algoritmos evolutivos usam modelos computacionais dos processos naturais de evolução como uma ferramenta para resolver problemas. Apesar de haver uma grande variedade de modelos computacionais propostos, todos eles têm em comum o conceito de simulação da evolução das espécies através da seleção, mutação e reprodução, processos estes que dependem do "desempenho" dos indivíduos dessa espécie dentro do "ambiente" (LINDEN, 2008).

De acordo com Fogel (2006) os AGs são geralmente desenvolvidos da seguinte forma:

1. O problema a ser abordado é definido e capturado em uma função objetivo que indica a adequação de uma solução em potencial.

2. Uma população de soluções candidatas é inicializada sujeita a certas limitações. Normalmente, cada indivíduo é codificado como um vetor $x$ denominado um cromossomo, com elementos que estão sendo descritos como genes e os valores variam em posições específicas, chamadas alelos.

3. Cada cromossomo, $x_{\mathrm{i}}, i=1, \ldots, P$, na população é decodificado em uma forma apropriada para a avaliação e é atribuída uma pontuação de fitness, $u\left(x_{i}\right)$ de acordo com a função objetivo.

4. Cada cromossomo recebe uma probabilidade de reprodução $p_{i}, i=1, \ldots, P$, de modo que sua probabilidade de ser selecionado é proporcional à aptidão relativa para os outros cromossomos na população. Se a aptidão de cada cromossomo é um número estritamente positivo a ser maximizado, esta é tradicionalmente realizada pelo método da roleta viciada, embora outras técnicas estejam disponíveis.

5. De acordo com as probabilidades atribuídas à reprodução de $p_{i}, i=1, \ldots, P$, uma nova 
população de cromossomos é gerada probabilisticamente selecionando indivíduos da população atual. Os cromossomos selecionados geram descendentes, através do uso de operadores genéticos específicos, tais como cruzamento e mutação de bit.

6. O processo é interrompido se uma solução desejável for encontrada ou se o tempo computacional disponível tiver expirado. De outra forma, o processo retoma ao passo 3 onde os novos cromossomos são avaliados e continuam a iteração.

\subsubsection{Seleção de indivíduos}

De acordo com Silva (2001), uma série de técnicas diferentes tem sido utilizada para a seleção dos indivíduos que sofrerão cruzamento, entretanto, uma das mais utilizadas é o método da roleta viciada. Cada indivíduo da população é representado de forma proporcional ao seu valor de aptidão (função de avaliação ou função fitness). Dessa forma, a roleta é "rodada" tantas vezes quanto o número de indivíduos da população, escolhendo-se assim aqueles que darão origem à próxima geração. A Figura 3 mostra um exemplo de uma roleta criada para uma população com cinco indivíduos:

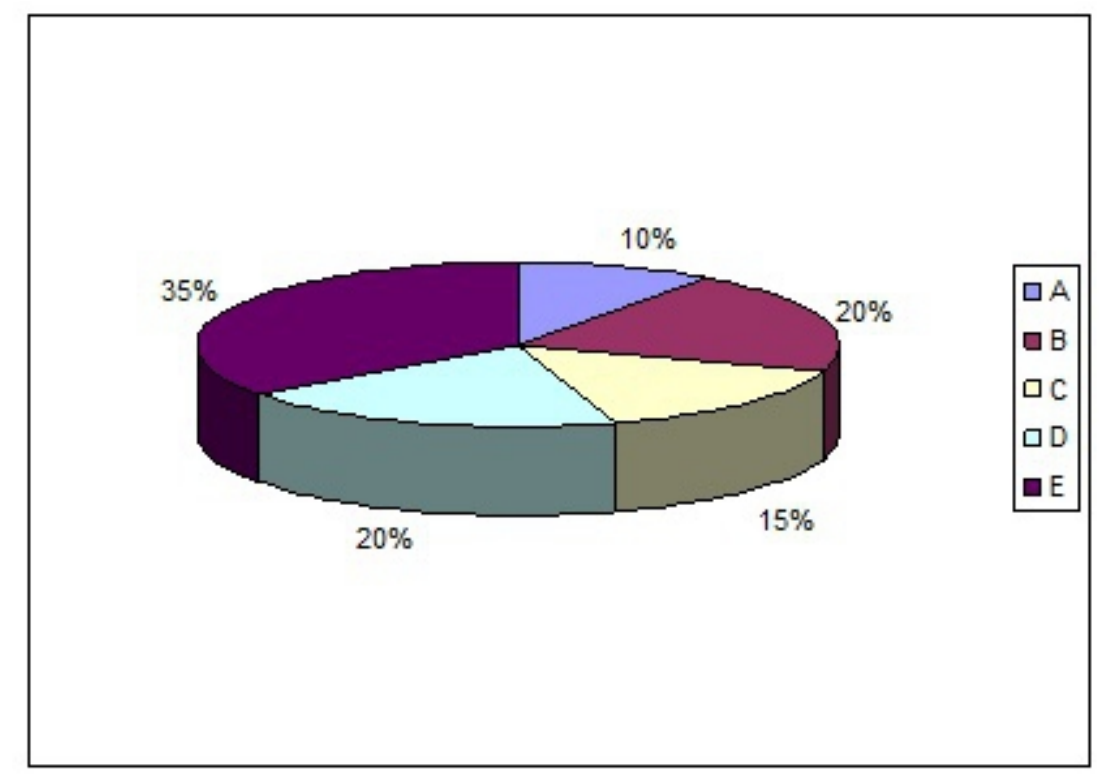

Figura 3 - Exemplo de método da roleta viciada. 


\subsubsection{Operadores de AGs}

\section{. Cruzamento de um ponto}

De acordo com Linden (2008), o operador de cruzamento mais simples é chamado de cruzamento de um ponto. Depois de selecionados dois pais pelo módulo de seleção, um ponto de corte é selecionado. Um ponto de corte constitui uma posição entre dois genes de um cromossomo. Cada indivíduo de $n$ genes contém $n-1$ pontos de corte, e este ponto de corte é o ponto de separação entre cada um dos genes que compõem o material genético de cada pai. A Figura 4 exemplifica o funcionamento do cruzamento de um ponto:

\begin{tabular}{|l|lllll|lllll|}
\hline Pai 1: & $\mathbf{1}$ & $\mathbf{0}$ & $\mathbf{1}$ & $\mathbf{1}$ & $\mathbf{1}$ & 0 & $\mathbf{0}$ & $\mathbf{0}$ & $\mathbf{1}$ & $\mathbf{1}$ \\
\hline Pai 2: & 1 & 1 & 0 & 1 & 0 & 0 & 1 & 0 & 0 & 1 \\
\hline Filho 1: & $\mathbf{1}$ & $\mathbf{0}$ & $\mathbf{1}$ & $\mathbf{1}$ & $\mathbf{1}$ & 0 & 1 & 0 & 0 & 1 \\
\hline Filho 2: & 1 & 1 & 0 & 1 & 0 & 0 & 0 & 0 & 1 & 1 \\
\hline
\end{tabular}

Figura 4: Cruzamento de um ponto.

Fonte: Silva (2001).

\section{. Cruzamento de dois pontos}

Segundo Silva (2001), no cruzamento de dois pontos, dois pontos de corte são selecionados aleatoriamente e as secções entre os dois cortes são trocadas entre os pais. Isso pode ser observado na Figura 5:

\begin{tabular}{|c|c|c|c|}
\hline Pai 1: & $\begin{array}{lll}1 & 0 & 1\end{array}$ & $\begin{array}{lllll}1 & 1 & 0 & 0 & 0\end{array}$ & 11 \\
\hline Pai 2: & 110 & $\begin{array}{lllll}1 & 0 & 0 & 1 & 0\end{array}$ & $\begin{array}{ll}0 & 1\end{array}$ \\
\hline Filho 1 : & $\begin{array}{lll}1 & 0 & 1 \\
\end{array}$ & $\begin{array}{lllll}1 & 0 & 0 & 1 & 0\end{array}$ & 11 \\
\hline Filho 2: & 110 & $\begin{array}{lllll}1 & 1 & 0 & 0 & 0 \\
\end{array}$ & 01 \\
\hline
\end{tabular}

Figura 5: Cruzamento de dois pontos.

Fonte: Silva (2001). 


\section{. Cruzamento uniforme}

Conforme Silva (2001), para cada par de pais é gerada uma máscara de bits aleatórios. Se o primeiro bit da máscara possuir o valor 1, então o primeiro bit do Pail é copiado para o primeiro bit do filho1. Caso contrário, o primeiro bit do Pai2 é copiado para o primeiro bit do filho1. O processo se repete para os bits restantes do filho1. Na geração do filho2 o processo é invertido. Esse processo pode ser observado na Figura 6:

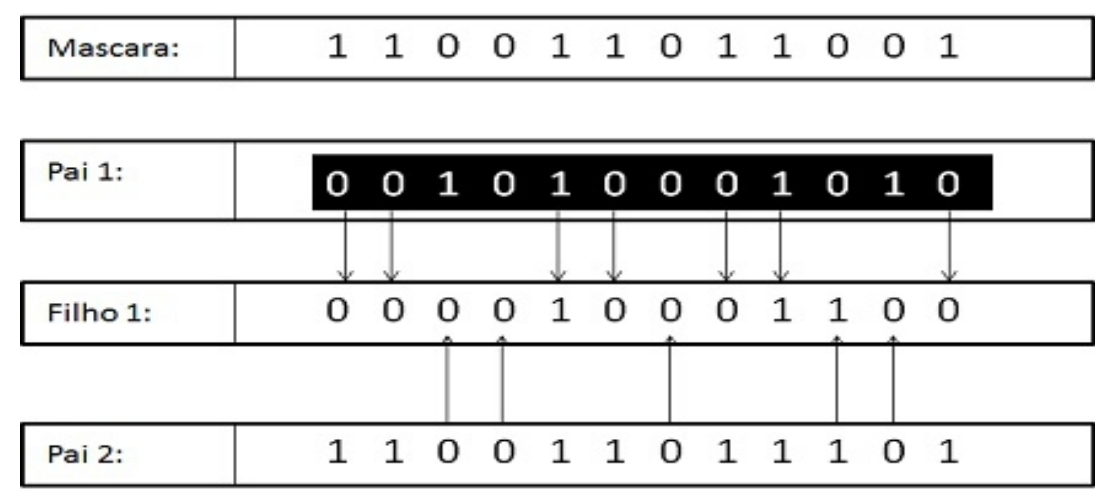

Figura 6: Cruzamento uniforme.

Fonte: Silva (2001).

\section{. Operador de mutação}

O operador de mutação é necessário para a introdução e manutenção da diversidade genética da população, alterando arbitrariamente um ou mais componentes de uma estrutura escolhida, fornecendo assim, meios para a introdução de novos elementos na população. Dessa forma, a mutação assegura que a probabilidade de se chegar a qualquer ponto do espaço de busca nunca será zero, além de contornar o problema de mínimos locais (SILVA, 2001).

\subsubsection{Elitismo}

De acordo com Linden (2008), o elitismo é uma pequena modificação no módulo de população que quase não altera o tempo de processamento, mas que garante que o desempenho do AG sempre cresce com o decorrer das gerações. A ideia básica por trás do elitismo é a seguinte: os $\mathrm{n}$ melhores indivíduos de cada geração não devem "morrer" junto com a sua geração, mas sim passar para a próxima visando a garantir que seus genomas sejam 
preservados. Dessa forma, garante-se que o gráfico da avaliação do melhor indivíduo como função do número de gerações decorridas é uma função monotonamente crescente.

\subsubsection{Representação Cromossômica}

De acordo com Rothlauf (2006), o uso de algoritmos evolutivos para muitos problemas de otimização nas organizações tem dado bons resultados e soluções de alta qualidade. Entretanto, é necessário obter uma boa representação cromossômica para o problema e desenvolver operadores de busca apropriados que trabalhem bem com a representação adotada.

A Figura 4 apresentou um exemplo de representação cromossômica, onde cada indivíduo foi representado por um vetor de inteiros que podiam assumir valores zero ou um. Existe uma infinidade de representações possíveis e Rothlauf (2006) dedicou um livro inteiro a esse tema.

\subsection{Otimização}

Otimização é um processo que, dado um conjunto de objetivos e restrições, visa a encontrar uma ou mais soluções que maximizem (ou minimizem) os objetivos e, ao mesmo tempo, respeitem as restrições impostas. Problemas de otimização existem nos mais variados domínios, sendo frequentemente resultantes do mapeamento de uma situação do mundo real para um modelo matemático. Por exemplo, uma fábrica pode empregar otimização para descobrir a melhor estratégia de produção e venda, buscando obter lucro máximo. Ou então uma equipe de administradores pode empregar otimização para decidir a melhor forma de aplicar recursos (GIUSTI, 2010).

\subsubsection{Otimização Simples-Objetivo}

No caso mais simples, o problema de otimização é modelado como um conjunto de variáveis de decisão e uma função objetivo. As variáveis de decisão são parâmetros relacionados ao problema em questão, por exemplo: número de peças fabricadas ou montante investido em um fundo. A função objetivo é uma função que associa variáveis de decisão a um valor real. Uma solução é um vetor de valores associados às variáveis de decisão que 
descreve uma possível estratégia de resolução do problema de otimização, sendo uma solução ótima aquela para qual a função objetivo assume o máximo ou mínimo valor possível, dependendo do problema em questão. Soluções que não são ótimas são chamadas subótimas (GIUSTI, 2010). Um exemplo de modelo para esse tipo de problema de otimização é dado na Figura 7.

$$
\begin{array}{ll}
(\min ) & f(x, y)=x^{2}+y^{2} \\
& x, y \in \Re \\
& f: \Re^{2} \rightarrow \Re
\end{array}
$$

Figura 7: Função para ser otimizada.

Fonte: Giusti (2010).

A leitura desse modelo é a seguinte: deseja-se encontrar um par de valores reais $(x, y)$ tal que o valor da função $f$ seja o menor possível para esse par. Em outras palavras, deseja-se minimizar a função $f$ (GIUSTI, 2010).

Duas possíveis soluções para o problema modelado através da Figura 7 são, por exemplo, $S 1=(2,2)$ e $S 2=(0,0)$. Observe que $f(S 1)=4$ e $f(S 2)=0$. Como se trata de um problema de minimização, então a solução $S 2$ é melhor - ou mais eficiente ou de melhor qualidade - que a solução $S 1$ e, consequentemente, pode-se afirmar que a solução $S 1$ é subótima. É possível verificar também que não existe solução mais eficiente que $S 2$, o que significa que $S 2$ é a solução ótima, como pode ser facilmente observado na Figura 8 (GIUSTI,2010): 


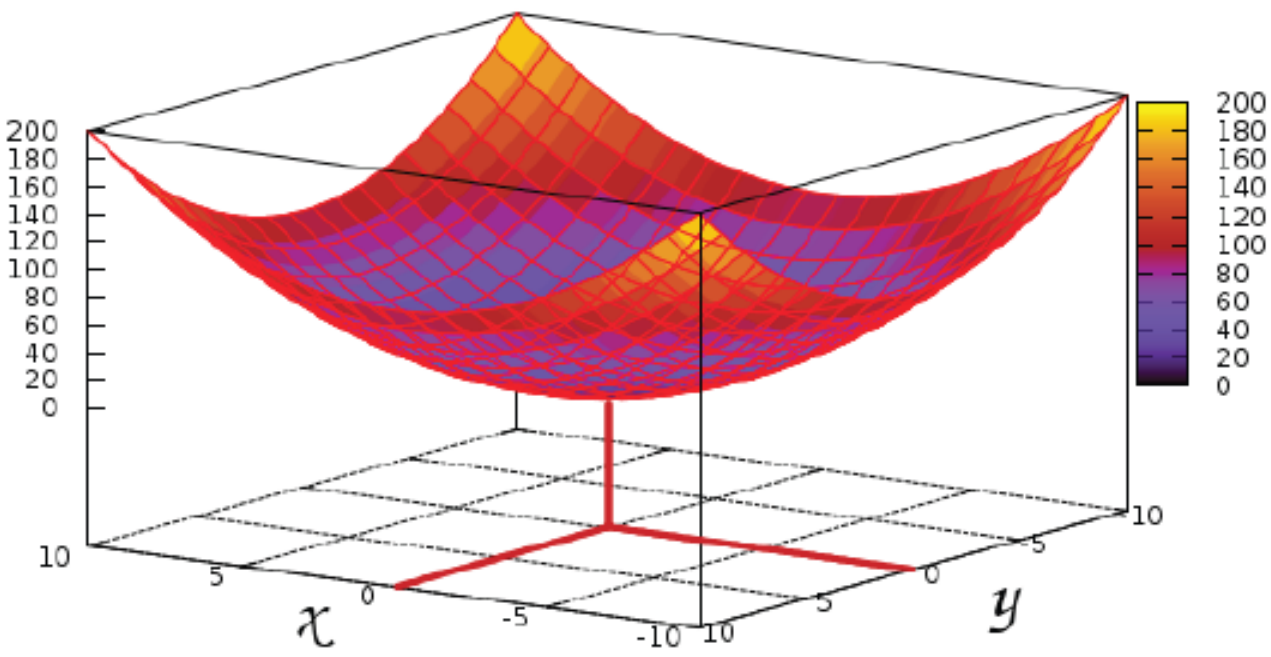

Figura 8: Espaço de decisão do problema.

Fonte: Giusti (2010).

A figura retrata o espaço de decisão do problema de otimização modelado na Figura 7. As coordenadas $x$ e $y$ indicam valores das variáveis de decisão. A terceira coordenada indica o valor assumido pela função objetivo quando as variáveis de decisão assumem os valores relacionados. As linhas vermelhas contínuas na base da figura indicam as coordenadas e a "altura" da solução ótima.

\subsection{Avaliação de Desempenho}

Usuários de computadores, administradores e projetistas demonstram interesse em avaliação de desempenho, uma vez que o objetivo da técnica é obter resultados que possibilitem atingir ou prover o maior desempenho possível com o menor custo. A avaliação de desempenho é necessária em todos os estágios do ciclo de vida de um software, incluindo o projeto, manufatura, vendas, uso, atualização e assim por diante. Ela também é necessária quando o projetista de software deseja comparar um número de alternativas para o projeto e escolher a melhor entre elas (JAIN, 1991). Segundo Jain (1991) os passos necessários para se realizar uma avaliação de desempenho sistemática são:

- Definir os objetivos e o sistema: O primeiro passo em qualquer avaliação de desempenho é definir os objetivos do estudo e definir o que constitui o sistema, definindo suas fronteiras. Levando-se em conta o mesmo conjunto de hardware e 
softwares, a definição do sistema pode variar dependendo dos objetivos que se quer alcançar com o estudo.

- Listar serviços e saídas: Quando um usuário solicita qualquer um desses serviços, existe uma série de saídas possíveis. Algumas dessas saídas são desejáveis e outras não. Por exemplo, um Sistema Gerenciador de Banco de Dados (SGBD) pode responder a uma consulta corretamente, incorretamente (devido a atualizações inconsistentes), ou nenhum dos dois (devido a deadlocks ou problemas do gênero). Uma lista de serviços e possíveis saídas serão úteis posteriormente, para selecionar as métricas e cargas de trabalho corretas.

- Selecionar Métricas: O próximo passo é selecionar os critérios para comparar a performance. Esses critérios são chamados métricas. Em geral, as métricas são relacionadas com velocidade, precisão e disponibilidade dos serviços.

- Listar Parâmetros: O próximo passo em projetos de avaliação de desempenho é criar uma lista de todos os parâmetros que afetam a performance. A lista pode ser dividida em parâmetros do sistema e parâmetros de carga de trabalho. A lista de parâmetros pode não estar completa. Isto é, após o primeiro passo da análise, pode-se descobrir que existem parâmetros adicionais que podem afetar o desempenho. Pode-se então adicionar esses parâmetros na lista, mantendo-a sempre o mais coerente possível. Isso permite ao analista e aos tomadores de decisão discutir o impacto de vários parâmetros e determinar quais dados precisam ser coletados antes ou durante a análise.

- Selecionar Fatores para Estudo: A lista de parâmetros pode ser dividida em duas partes: aqueles que serão variados durante a avaliação e aqueles que permanecerão constantes. Os parâmetros que serão variados são denominados fatores e seus valores são denominados níveis. Em geral, a lista de fatores, e seus possíveis níveis são maiores do que os recursos disponíveis permitem.

- Selecionar a Técnica de Avaliação: As três abordagens para avaliação de desempenho são: modelagem com solução analítica ou por simulação e aferições em sistemas reais. A seleção da técnica correta depende do tempo e recursos disponíveis para resolver o problema e o nível desejado de precisão.

- Selecionar a Carga de Trabalho: A carga de trabalho consiste de uma lista de requisições de serviços ao sistema. Por exemplo, a carga de trabalho para comparar diferentes SGBDs pode se constituir de uma série de consultas. Dependendo da técnica 
de avaliação escolhida, a carga de trabalho pode ser expressa de diferentes formas.

- Projeto de Experimentos: Uma vez que se tenha uma lista de fatores e seus níveis, é necessário decidir a sequência de experimentos que forneça o máximo de informação com o mínimo de esforço.

- Analisar e Interpretar Dados: É importante reconhecer que os resultados das medidas e simulações são quantidades aleatórias em que os resultados poderão ser diferentes cada vez que a experiência for repetida.

- Apresentar Resultados: O passo final para todos os projetos de desempenho é comunicar os resultados para outros membros do time de tomadores de decisão. É importante que os resultados sejam apresentados de uma forma que seja fácil de entender. Isso geralmente necessita que os resultados sejam apresentados em forma de gráficos e sem jargões estatísticos. Os gráficos devem ser apropriadamente escalados.

\subsubsection{Seleção da Técnica de Avaliação}

As três técnicas de avaliação de desempenho existentes, podem ser sintetizadas como modelagem com solução analítica, modelagem com solução por simulação e aferição. A aferição pode ser realizada tanto em sistemas reais, como também em protótipos. Por exemplo, pode-se aferir o tempo de execução de uma instrução de máquina em uma placa de hardware e isso seria uma aferição em um sistema real. Pode-se também, desenvolver um protótipo de um sistema e aferir o tempo de execução do mesmo e isso seria aferição em protótipo. Existe um número de considerações que auxiliam na decisão sobre qual técnica deve ser usada.

\subsubsection{Carga de Trabalho}

Uma carga de trabalho pode ser real ou sintética. Uma carga de trabalho real é aquela observada em um sistema sendo usado para operações normais. Ela não pode ser repetida e, portanto, não é recomendada para o uso como carga de trabalho de testes. Em vez disso, uma carga de trabalho sintética, cujas características são semelhantes às da carga de trabalho real e podem ser aplicadas várias vezes de forma controlada, é desenvolvida e utilizada para estudos (JAIN, 1991). 
A carga de trabalho é a parte mais crucial de qualquer projeto de avaliação de desempenho. É possível chegar a conclusões equivocadas, se a carga de trabalho não for devidamente selecionada.

\subsubsection{Planejamento de Experimentos}

O objetivo de um planejamento de experimentos adequado é obter o máximo de informação com o mínimo de experimentos. Isso economiza um trabalho considerável que teria sido gasto com a coleta dos dados. A análise adequada de experimentos também ajuda a separar os efeitos de vários fatores que podem afetar o desempenho. Além disso, permite determinar se um fator tem um efeito significativo ou se a diferença observada é simplesmente devido a variações aleatórias causadas por erros de medição e parâmetros que não foram controlados (JAIN, 1991).

Os seguintes termos são comumente utilizados no projeto e análise de experimentos: variável de resposta, fatores, níveis, fatores primários, fatores secundários, replicação, projeto, unidade de experimento e interação.

Existem inúmeras variedades de projetos de experimentos. Os três modelos mais utilizados são: projeto simples, fatorial completo e fatorial parcial. Suas vantagens e desvantagens serão explicadas a seguir (JAIN, 1991):

- Fatorial simples: Em um projeto fatorial simples, começa-se com uma configuração típica e varia-se um fator de cada vez para ver como esse fator afeta o desempenho. Esse tipo de projeto é o mais fácil de se utilizar, porém não é estatisticamente eficiente.

- Fatorial completo: Um planejamento fatorial completo utiliza todas as combinações possíveis em todos os níveis de todos os fatores. A vantagem de um planejamento fatorial completo é que todas as combinações possíveis e cargas de trabalho são examinadas.

- Fatorial parcial: Algumas vezes, o número de experimentos necessários para um planejamento fatorial completo é muito grande. Isso pode acontecer se o número de fatores ou níveis é muito grande. Nesses casos, pode-se usar apenas uma fração do planejamento fatorial completo. Para cada vantagem existe uma desvantagem 
correspondente. Fatoriais parciais podem economizar tempo e despesas em relação ao fatorial completo.

\subsection{E-commerce}

\subsubsection{Considerações Gerais}

Desde o surgimento do comércio eletrônico (e-commerce) viabilizado pela Internet, na segunda metade da década de 1990, seu desenvolvimento se deu a alta velocidade. Em geral, e-commerce trata-se de uma alternativa para o consumidor com os mesmos benefícios do comércio tradicional, porém com redução de custos de operação e fornecimento de produtos e serviços a preços mais baixos (CUI-MEI, 2009).

De acordo com Cui-Mei (2009) e-commerce envolve atividades de negócios que lidam com troca de valores de bens e serviços, onde todas as transações são realizadas através da Internet. E-commerce cria um enorme potencial econômico que é viável devido ao acesso global e livre proporcionado pela Internet e às interfaces gráficas amigáveis que as ferramentas Web oferecem.

Segundo Wang \& Tian (2009), o e-commerce tornou-se o meio casual de nossas atividades diárias, devido à sua disponibilidade e facilitação. No entanto, o processo de serviço do comércio eletrônico é mais complexo. A colaboração entre empresas é necessária e isso requer o uso de Web Services. Dessa forma, é importante que exista uma forma inteligente e eficiente para controlar a composição dos Web Services.

Segundo Canfora et. al. (2005), é importante que a CWSbQ seja rápida. Especialmente para sistemas interativos, atrasos longos são inaceitáveis. Por exemplo, um usuário de um sistema de reserva de bilhetes não ficaria satisfeito em ter que ficar vários minutos esperando que o algoritmo faça a melhor composição, para no final, economizar alguns centavos.

\subsubsection{Elementos de um site de e-commerce}

De acordo com Chu et. al. (2007) o órgão de administração do Website pode ser visto como um hospedeiro que presta serviços diretamente ou facilita a colaboração entre os 
participantes. A separação dos participantes e do hospedeiro é inerente à arquitetura da Internet. Na Figura 9 pode-se visualizar que ambos os participantes e hospedeiro têm elementos que são universais:

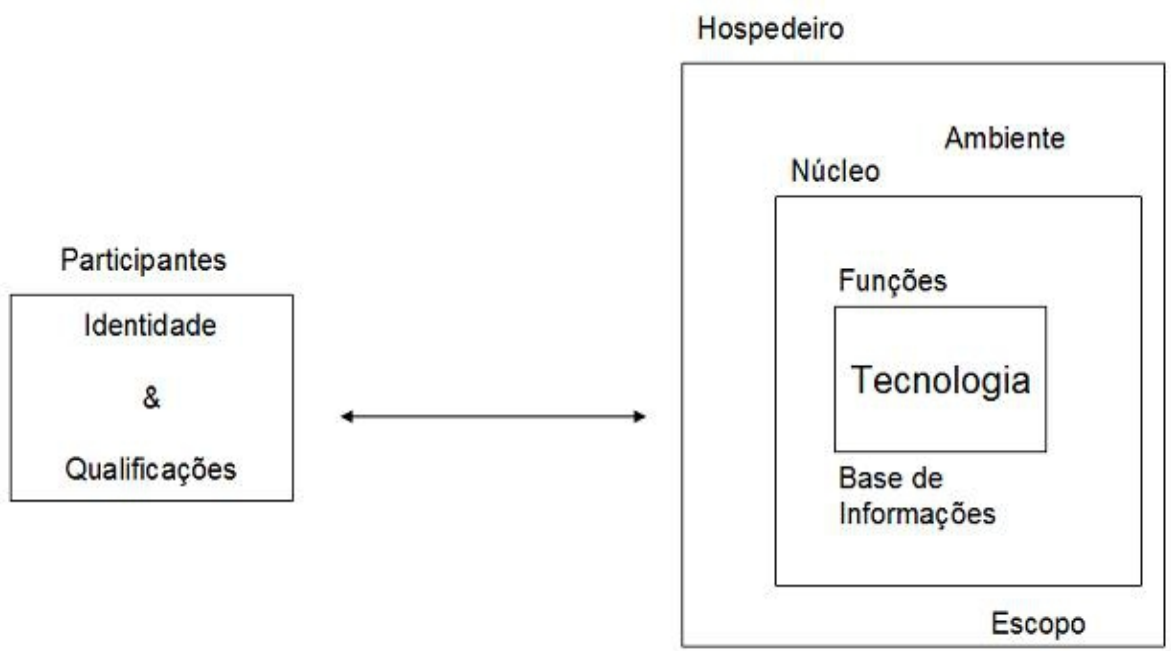

Figura 9: Elementos de um site de e-commerce.

Fonte: Adaptado de Chu et. al. (2007).

Participantes podem ser compradores ou vendedores que utilizam o site para realizar atividades comerciais. Os atributos identidade e qualificações (estado ou condições, como registrado ou licenciado) descrevem os participantes. É claro que os participantes podem ter várias identidades e qualificações (CHU ET. AL., 2007).

De acordo com Chu et. al. (2007) o hospedeiro coordena as atividades no site e possui dois atributos: ambiente e escopo. $\mathrm{O}$ ambiente define as fronteiras entre o e-commerce e sua natureza de negócio, como mercado, broker ou shopping. Além disso, as atividades comerciais podem ser estruturadas de acordo com o relacionamento (como cooperativa, colaborativa ou neutra, etc.) entre os participantes e o hospedeiro. $\mathrm{O}$ escopo descreve essas relações ou propriedades. Um hospedeiro pode possuir múltiplos escopos e ambientes.

Conforme Chu et. al. (2007) as funções do núcleo (por ex., registro, navegação e busca) são aquelas que essencialmente definem as capacidades e inteligência do site. A tecnologia do núcleo é dividida em quatro áreas: apresentação e representação da informação, comunicação, linguagem de programação de processo de negócio e armazenamento e recuperação de informações. A base de informações contém as informações de conteúdo do site, que inclui 
dados persistentes e transitórios e informações sobre todas as atividades do $e$-commerce.

\subsection{Considerações Finais}

Este capítulo apresentou os conceitos básicos necessários para o desenvolvimento deste projeto de mestrado e também uma descrição do problema a ser estudado. A CWSbQ tem se mostrado uma área de pesquisa bastante ativa tanto no meio acadêmico, como em grandes empresas, tais como Google e Microsoft.

A CWSbQ é um problema de otimização combinatória, sendo assim, diversos pesquisadores tem usado meta-heurísticas para resolvê-lo. Os sistemas de e-commerce são interativos e SRT, portanto devem-se procurar algoritmos que não ultrapassem um deadline pré-determinado. 


\section{Trabalhos Relacionados}

\subsection{Considerações Iniciais}

O objetivo deste capítulo é apresentar alguns resultados obtidos em trabalhos relacionados, que permitem uma visão mais ampla do problema que é abordado neste projeto de mestrado. Também é feita uma análise crítica dos trabalhos relacionados, indicando quais lacunas desses trabalhos foram abordadas nesta dissertação de mestrado.

\subsection{Algoritmos de Composição}

Os algoritmos utilizados para realizar a composição de Web Services podem ser classificados da seguinte forma: busca aleatória (KUEHNE, 2009), busca exaustiva (KUEHNE, 2009; WEISE ET. AL., 2008), busca heurística (WEISE ET. AL., 2008; MORAES, 2010; LIN ET. AL., 2011), métodos numéricos (CANFORA ET. AL., 2005; ARDGNA \& PERCINI, 2006; KO ET. AL., 2008), meta-heurísticas (CANFORA ET. AL., 2005; WANG ET. AL., 2007; WEISE ET. AL., 2008; ZHANG ET. AL., 2007; MA \& ZHANG, 2008; CLARO ET. AL., 2005; SU ET. AL., 2007; ZHANG \& MA, 2009; ZHANG ET. AL., 2010; LI \& CHEN, 2010, BATOUCHE ET. AL., 2010; YU ET. AL., 2011) e algoritmos híbridos (WANG ET. AL., 2010; ZHI-PENG ET. AL., 2009; KO ET. AL., 2008; TANG \& AI, 2010, LIU ET. AL., 2010, FANJIANG ET. AL., 2010; LIU ET. AL., 2011).

Alguns desses trabalhos focam em comparar duas ou mais abordagens diferentes para realizar a composição de Web Services. Em Weise et. al. (2008), são avaliados um algoritmo que usa busca exaustiva, um algoritmo heurístico e um algoritmo genético (meta-heurístico).

Na Tabela 2 pode-se observar que o algoritmo de busca exaustiva se torna inviável rapidamente, quando se aumenta a quantidade de Web Services abstratos e a quantidade de Web Services concretos. O algoritmo heurístico obteve um tempo de execução cerca de uma 
ordem de grandeza menor do que o algoritmo genético. Entretanto, nesse trabalho não são levados em conta atributos de QoS e o autor cita que caso isso fosse levado em conta, provavelmente o algoritmo genético teria um desempenho superior.

Tabela 2: Tempo de resposta de diferentes técnicas para Composição de Web Services.

\begin{tabular}{|l|l|l|l|l|l|}
\hline Teste & WS abstratos & WS concretos & $\begin{array}{l}\text { Busca } \\
\text { exaustiva } \\
(\mathbf{m s})\end{array}$ & $\begin{array}{l}\text { Busca } \\
\text { heurística } \\
(\mathbf{m s})\end{array}$ & $\begin{array}{l}\text { Algoritmo } \\
\text { genético (ms) }\end{array}$ \\
\hline 1 & 5 & 1000 & 241 & 34 & 376 \\
\hline 2 & 12 & 1000 & - & 51 & 1011 \\
\hline 3 & 10 & 10000 & - & 46 & 1069 \\
\hline 4 & 15 & 2000 & - & 36 & 974 \\
\hline 5 & 30 & 4000 & - & 70 & 6870 \\
\hline 6 & 40 & 8000 & - & 63 & 24117 \\
\hline 7 & 1 & 118 & $<=16$ & $<=16$ & 290 \\
\hline
\end{tabular}

Fonte: Adaptado de Weise et. al. (2008).

Em Canfora et. al. (2005), é feita uma comparação entre um algoritmo usando programação inteira (PI) e um AG. Pode-se observar o resultado dos experimentos na Figura 10 .

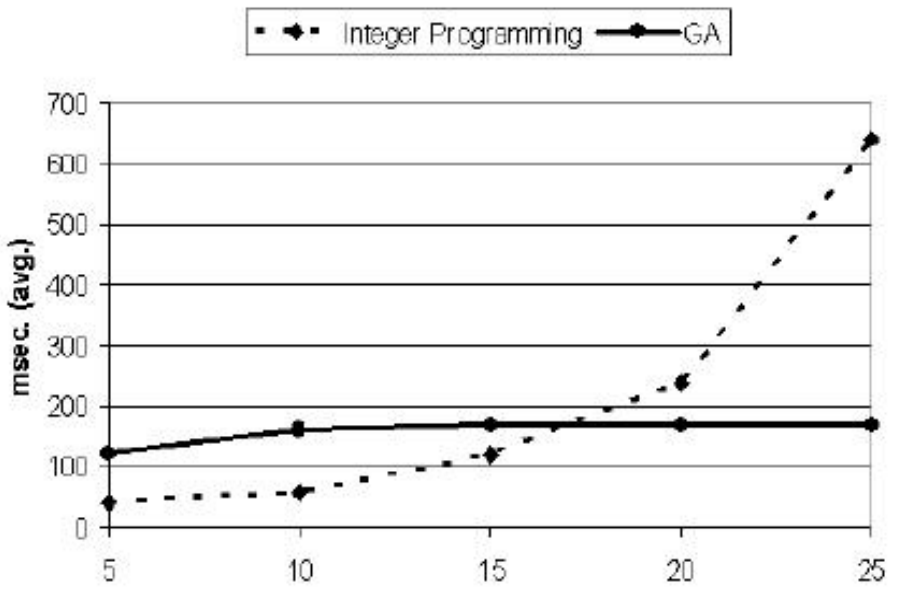

Figura 10: Resultados dos experimentos usando AG e PI.

Fonte: Claro et. al. (2005). 
O eixo horizontal representa a quantidade de Web Services concretos por Web Services abstrato. O eixo vertical representa o tempo médio de execução dos algoritmos em milissegundos. Em todos os casos oito Web Services abstratos foram utilizados.

Em Alrifai \& Risse (2008), é feita uma comparação entre um algoritmo de programação inteira mista (método numérico) e um algoritmo híbrido, que utiliza uma heurística que é uma combinação de otimização global e local. Os resultados podem ser observados na Figura 11.

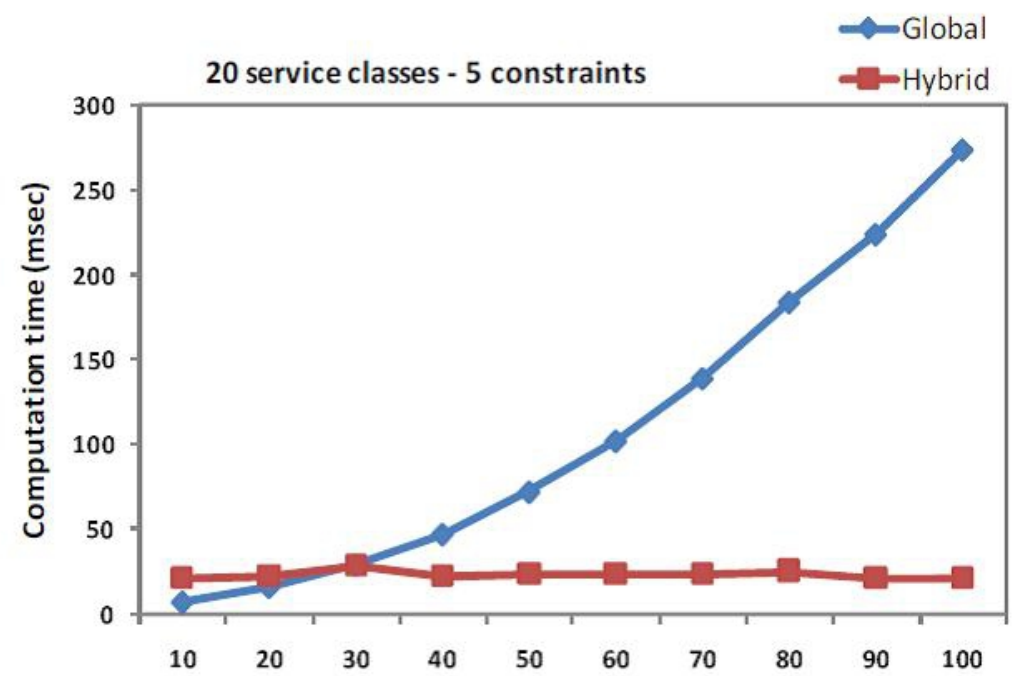

Figura 11: Resultados dos experimentos de acordo com o tamanho do espaço de busca.

Fonte: Alrifai \& Rise (2008).

O eixo horizontal representa o número de Web Services concretos para cada Web Service abstrato (foram utilizados vinte Web Services abstratos e cinco atributos de QoS) e o eixo vertical representa o tempo médio de execução do algoritmo.

Em Ko et. al. (2008) são comparados um algoritmo híbrido (uma combinação de busca tabu e têmpera simulada e um algoritmo usando programação inteira). A busca tabu é um método de otimização matemática, pertencente à classe de busca local (da mesma forma que subida de encosta). Ela é um algoritmo meta-heurístico que pode ser usado para resolver problemas de otimização combinatória, como o problema do caixeiro viajante. $\mathrm{O}$ algoritmo da têmpera simulada é um algoritmo meta-heurístico de busca global, da área da matemática aplicada e visa encontrar uma boa aproximação para o ótimo global de uma função, em um espaço de busca muito grande. O resultado do algoritmo híbrido pode ser observado na Figura 
12.

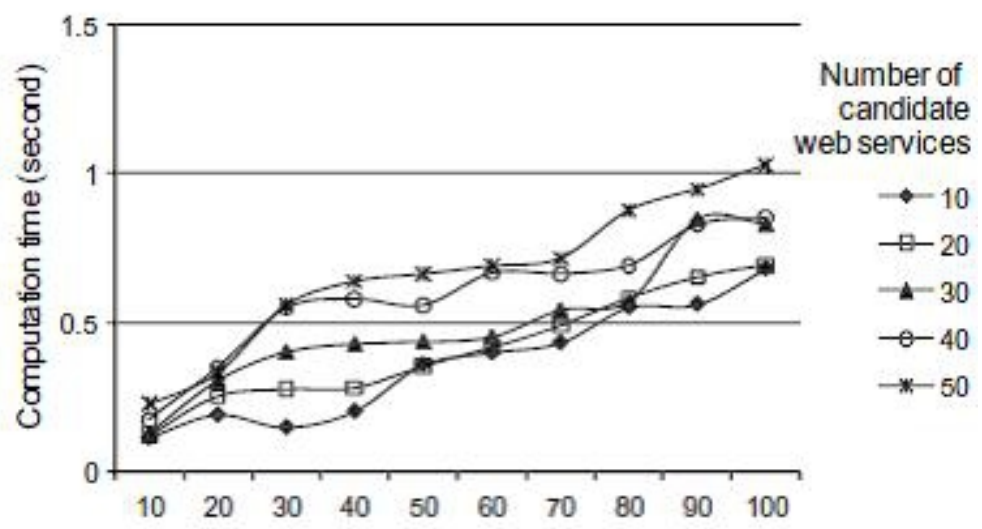

Figura 12: Resultados dos experimentos usando-se o algoritmo híbrido.

Fonte: Ko et. al. (2008).

O eixo horizontal representa o número de Web Services abstratos da composição, o eixo vertical representa o tempo médio de execução do algoritmo (em segundos) e a legenda do lado direito da figura representa a quantidade de Web Services concretos para cada Web Service abstrato. Também foi executado o algoritmo baseado em programação inteira, como pode ser observado na Figura 13.

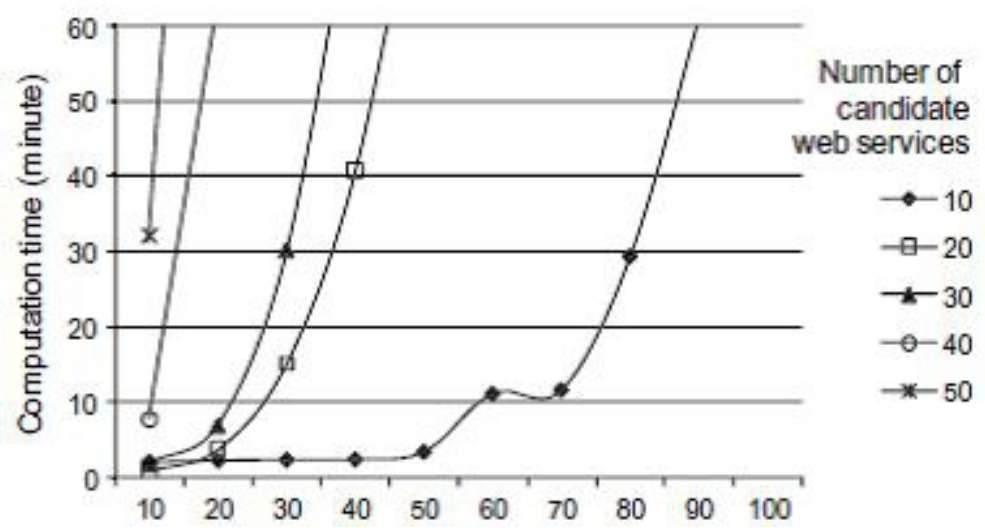

Figura 13: Resultados dos experimentos usando-se o algoritmo baseado em PI.

Fonte: Ko et. al. (2008).

É interessante atentar-se ao fato de que a Figura 13 possui o eixo vertical em escala de minutos e não de segundos, como acontece na Figura 12. Além disso, pode-se observar o 
crescimento exponencial do tempo de execução, quando se aumenta a quantidade de Web Services abstratos e/ou concretos.

Em Liang \& Huang (2009), é feita uma comparação entre um algoritmo genético tradicional e um algoritmo genético que incorpora a teoria dos conjuntos aproximativos. Esse algoritmo conseguiu ser mais eficiente do que o AG tradicional, através da redução do domínio da população inicial e uma restrição no operador de cruzamento, usando a teoria dos conjuntos aproximativos. A Figura 14 apresenta os resultados obtidos com o AG tradicional.

O eixo horizontal representa o número de gerações decorridas, o eixo vertical representa o valor de fitness alcançado, normalizado para estar no intervalo entre zero e um. A Figura 15 mostra o desempenho do $\mathrm{AG}$ proposto, notadamente mais rápido do que o $\mathrm{AG}$ tradicional.

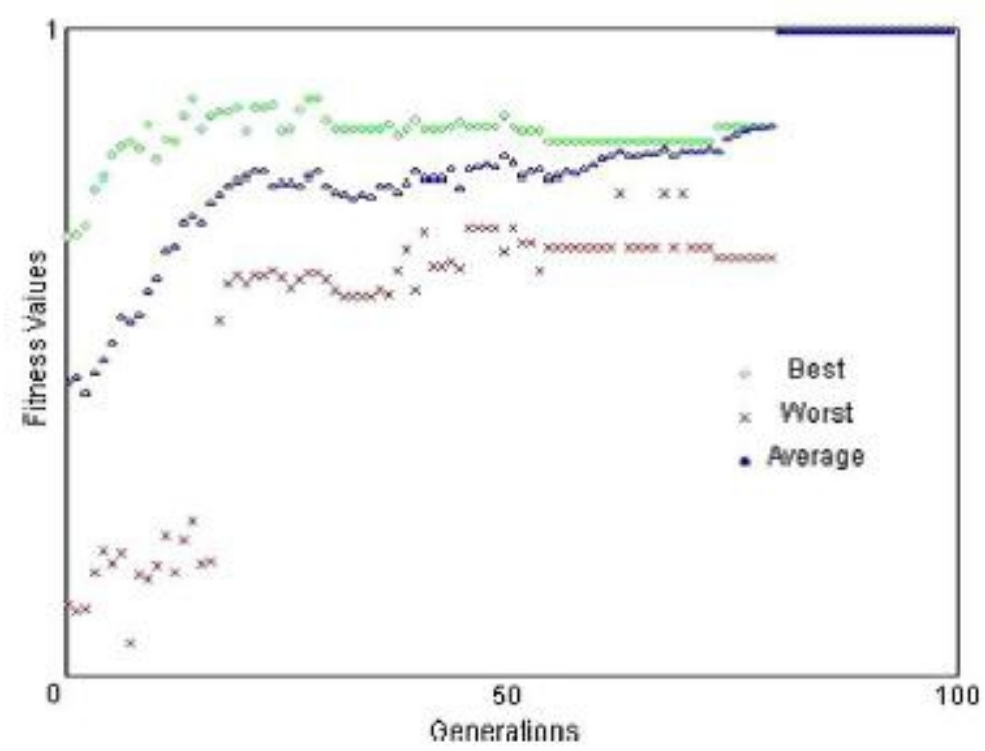

Figura 14: A convergência do AG tradicional.

Fonte: Liang \& Huang (2008). 


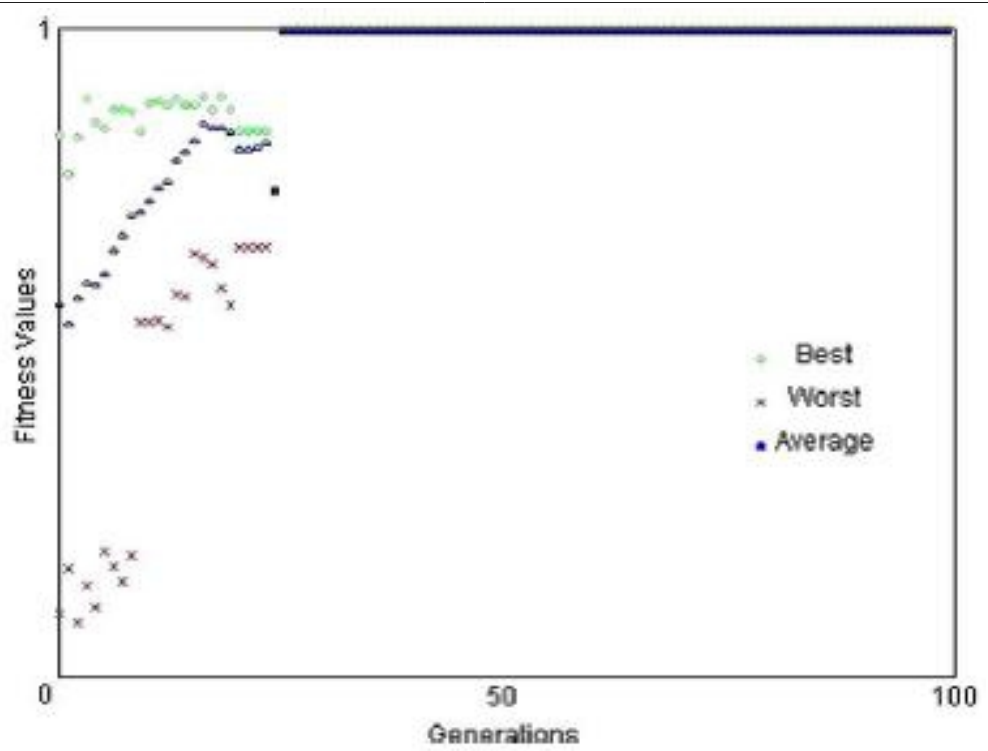

Figura 15: A convergência do AG proposto.

Fonte: Liang \& Huang (2008).

\subsection{Representação cromossômica e operador de mutação}

Em Tang \& Ai (2010) foi proposto um algoritmo genético híbrido, que combinava as características de um AG simples com um algoritmo de otimização local. O conjunto de Web Services abstratos foi representado por um vetor de inteiros, onde a quantidade de elementos do vetor era igual à quantidade de Web Services abstratos da composição. Para cada posição no vetor de Web Services abstratos (que representa um cromossomo), é atribuído um inteiro que representa o Web Service concreto selecionado. A Figura 16 apresenta esse cromossomo:

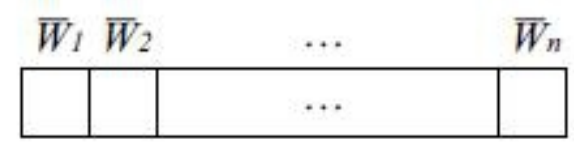

Figura 16: Representação cromossômica.

Fonte: Tang \& Ai (2010).

Dessa forma, o algoritmo de mutação simplesmente escolhe aleatoriamente uma posição nesse vetor e modifica o Web Service concreto selecionado para aquele Web Service abstrato. Isso pode ser visualizado na Figura 17: 


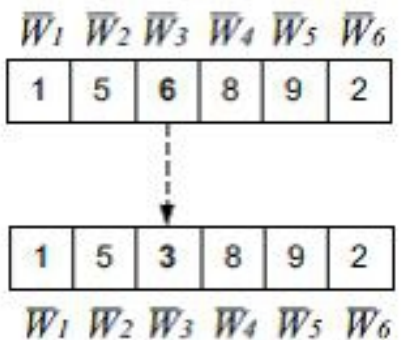

Figura 17: Operador de mutação.

Fonte: Tang \& Ai (2010).

\subsection{Análise crítica dos trabalhos relacionados}

É interessante notar que de todos os trabalhos citados nesta dissertação, apenas o trabalho de Kuenhe (2009) realmente utilizou uma técnica de avaliação de desempenho. Nesse trabalho foram calculados: média, desvio-padrão intervalo de confiança e influência dos fatores.

A falta da utilização de técnicas de avaliação de desempenho torna-se ainda pior no caso de meta-heurísticas, devido ao seu caráter probabilístico (estocástico), sendo que em cada execução do algoritmo é possível que se obtenha uma resposta diferente (QoS da composição obtido). Em casos extremos como o trabalho de Batouche et. al. (2010), os experimentos foram executados apenas quatro vezes e foi calculada a média, uma análise possivelmente superficial.

Outro fato observado na literatura estudada é que alguns artigos apenas citam como foi desenvolvido um determinado algoritmo, não o comparando com outros algoritmos para demonstrar seus pontos fortes e/ou fracos. Esse tipo de comparação é importante porque permite avaliar em quais situações determinados algoritmos é uma escolha melhor do que outros. Alguns dos trabalhos que não fazem essa comparação são: Fanjiang et. al. (2010), Wang et. al. (2010) e Claro et. al. (2005).

Também foi observado que em alguns trabalhos relacionados, o número de Web Services abstratos e concretos parece ter sido definido ao acaso, sem um critério que vise a representar o funcionamento dos sistemas no mundo real. Como foi citado em Ko et. al. (2008), atualmente existem centenas de Web Services com as mesmas funcionalidades e este número está crescendo cada vez mais. Em casos extremos como o trabalho de Liu et. al. (2010), são usados: dois, três, cinco, dois, cinco e oito, Web Services concretos 
respectivamente, para cada Web Service abstrato no fluxo de composição. Como foi explicado no capítulo dois desta dissertação, o número de Web Services concretos está diretamente ligado com a quantidade de possíveis combinações de Web Services para a composição.

Em Liu et. al. (2010) é citado o fato de que a composição dinâmica de WS é um problema de tempo-real, portanto deve-se buscar a melhor solução possível dentro do limite superior de tempo estabelecido. Entretanto ele não define diferentes deadlines para que seja possível avaliar qual o melhor algoritmo em cada caso. Por ex: o algoritmo A pode obter uma melhor solução se o deadline for 2 segundos, mas aumentando o deadline para 5 segundos pode ser que o algoritmo $\mathrm{B}$ tenha melhores resultados.

Em nenhum dos trabalhos citados nesta dissertação foi usada à avaliação de desempenho para aperfeiçoar os AGs. Isso será abordado nos capítulos quatro e cinco.

Nos trabalhos relacionados estudados, os autores focaram-se na otimização dos algoritmos de composição de Web Services, melhorando as respostas dos algoritmos em termos de tempo de resposta e/ou QoS. Como foi citado anteriormente em Liang \& Huang (2008), obteve-se um tempo de resposta menor usando-se uma técnica de hibridização. Em outros trabalhos, buscaram-se um melhor QoS (ZHANG ET. AL., 2007; TANG \& AI, 2010; LIU ET. AL, 2010).

Neste projeto de mestrado, além de focar-se em melhorar o tempo de resposta e/ou QoS dos algoritmos, também buscou-se descobrir quais algoritmos eram melhores para os diferentes tamanhos de espaços de busca e deadlines definidos. A Figura 18 ajuda a ilustrar essa ideia.

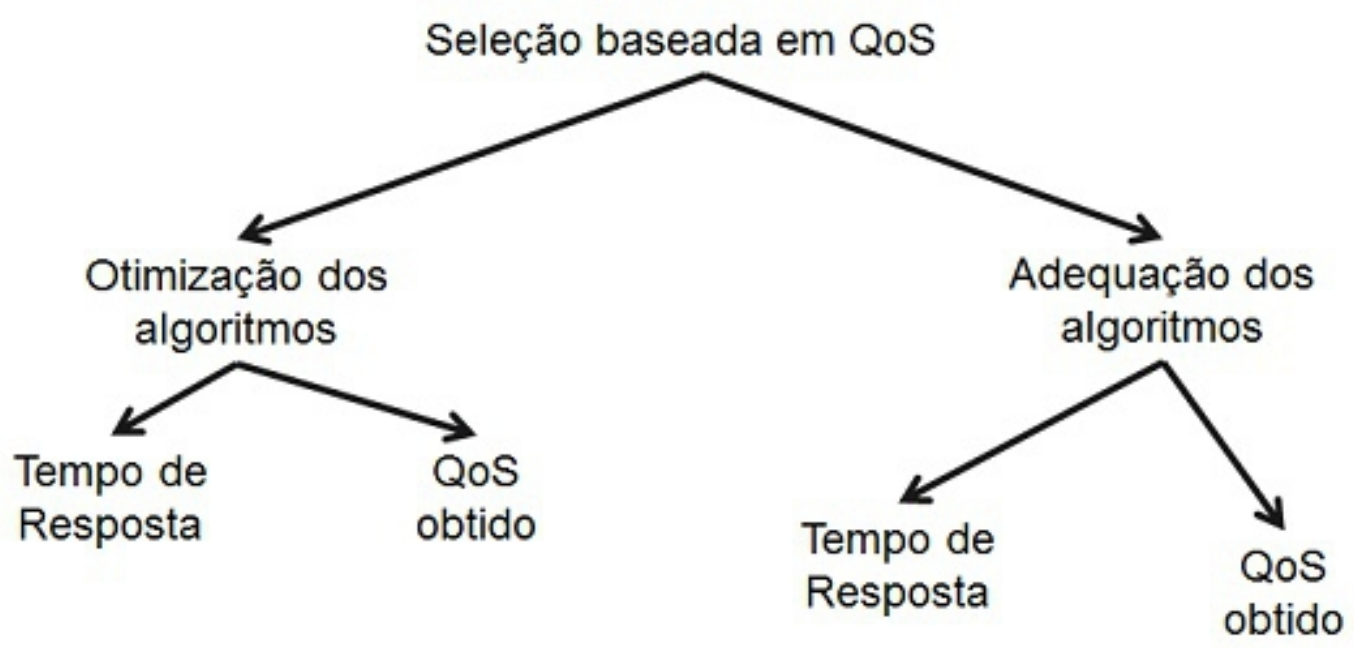

Figura 18: Diferentes aspectos do problema abordado nesta dissertação. 


\subsection{Considerações Finais}

Neste capítulo foram citados os diferentes tipos de algoritmos que podem ser utilizados para a solução do problema CWSbQ. Também foram apresentados alguns resultados de experimentos realizados em trabalhos relacionados. Esses resultados mostraram que o uso de métodos numéricos não tem se mostrado uma boa opção, ao passo que os algoritmos híbridos obtiveram resultados interessantes.

Por fim, foi feita uma análise crítica dos trabalhos relacionados, identificando pontos que podem ser melhorados e lacunas que podem ser preenchidas. Isso é importante para definir de que forma este trabalho irá contribuir com a área de pesquisa estudada. 


\section{Algoritmos desenvolvidos e implementados}

\subsection{Considerações Iniciais}

Neste capítulo são apresentados os algoritmos de composição de Web Services que foram desenvolvidos durante o decorrer do projeto. Alguns algoritmos foram baseados em ideias presentes em outros trabalhos relacionados e outros são criações originais. O intuito deste capítulo é explicar o funcionamento de cada algoritmo e suas possíveis vantagens e desvantagens.

\subsection{Busca Exaustiva (BE)}

\section{- Procedimento}

Também conhecido como algoritmo "força-bruta" é assim denominado porque dado um determinado espaço de busca, avalia todos os pontos desse espaço de busca, garantindo encontrar o ótimo global. No caso do problema CWSbQ, cada possível plano de composição de Web Services é um ponto do espaço de busca. Supondo um fluxo de composição com doze Web Services abstratos e cem Web Services concretos por abstrato, tem-se $100^{12}$ possíveis planos de composição de Web Services, ou seja, $100^{12}$ pontos no espaço de busca.

\section{- Vantagens}

A vantagem desse algoritmo é que sempre encontra o ótimo global. Portanto, se for possível executá-lo é sempre a melhor opção. 
- Desvantagens

Como ele avalia todos os pontos no espaço de busca, ele possui complexidade assintótica exponencial, ou seja, $\mathrm{O}\left(n^{\mathrm{k}}\right)$, sendo $k$ o número de Web Services abstratos no fluxo e $n$ o número de Web Services concretos por abstrato (supondo que $n$ seja igual para todos os Web Services abstratos). Dessa forma, ele se torna muito lento para alguns tamanhos de espaço de busca, algo inviável dada à característica de tempo-real das aplicações de $e$ commerce.

\subsection{Busca Aleatória (BA)}

\section{- Procedimento}

Este algoritmo utiliza a técnica de busca denominada Random Walk (LINDEN, 2008). Isso significa que o algoritmo fica percorrendo aleatoriamente o espaço de busca, mantendo sempre a melhor resposta encontrada e termina sua execução quando atinge o critério de parada (nesse caso, o deadline estabelecido).

\section{- Vantagens}

A única vantagem deste algoritmo é que ele utiliza todo o deadline disponível. Ele foi desenvolvido apenas para comprovar que os demais algoritmos possuem uma qualidade superior do que uma simples busca aleatória nos espaços de busca estabelecidos.

\section{- Desvantagens}

Como se trata de um algoritmo aleatório, a qualidade das respostas obtidas varia bastante. Além disso, para tamanhos de espaço de busca entre médio e grande, seus resultados são bem inferiores a todos os demais algoritmos desenvolvidos.

\subsection{Função-Utilidade (FU)}

\section{- Procedimento}

Este algoritmo heurístico foi originalmente proposto em Yu et. al. (2007) e foi adaptado 
para este projeto de mestrado. Ele associa a cada implementação do Web Service disponível um único valor que o representará de acordo com seus parâmetros de QoS, sendo $\mu$ e $\sigma$ a média e o desvio padrão de cada atributo de QoS. Supondo $k$ sendo o número de atributos de QoS e $q$ o atributo de QoS (por exemplo, custo) obtém-se a Equação 1, que representa este algoritmo adaptado:

$$
F u=\sum_{i=1}^{i=k} \frac{q_{i}-\mu}{\sigma_{i}} \text { Equação 1 }
$$

Sendo assim, todos os Web Services concretos concretos recebem uma única nota que representa o seu QoS como um todo. Então o algoritmo seleciona as maiores notas de todos os Web Services concretos para o seu respectivo Web Service abstrato e monta o plano de composição de Web Services.

\section{- Vantagens}

Ele é bem mais rápido que o $\mathrm{BE}$, pois não percorre todo o espaço de busca. Isso permite que seja utilizado mesmo em tamanhos de espaço de busca muito grandes $\left(200^{12}\right)$. Também garante boas respostas, em alguns casos chegando bem próximo do ótimo global.

\section{- Desvantagens}

Por se tratar de um algoritmo determinístico, não consegue se beneficiar de um deadline maior. Por exemplo, se o deadline for um segundo ou um dia, a resposta do algoritmo será a mesma.

\subsection{Heurística Gulosa (HG)}

\section{- Procedimento}

Este algoritmo foi uma proposta original que surgiu durante o desenvolvimento deste projeto. Para todos os Web Services abstratos do fluxo, o algoritmo avalia todos os Web 
Services concretos disponíveis e seleciona o melhor, de acordo com os atributos de QoS. Dessa forma, o plano de composição de Web Services selecionado é formado pelos melhores Web Services concretos para todos os Web Services abstratos do fluxo. A Figura 19 ajuda a entender esse procedimento.

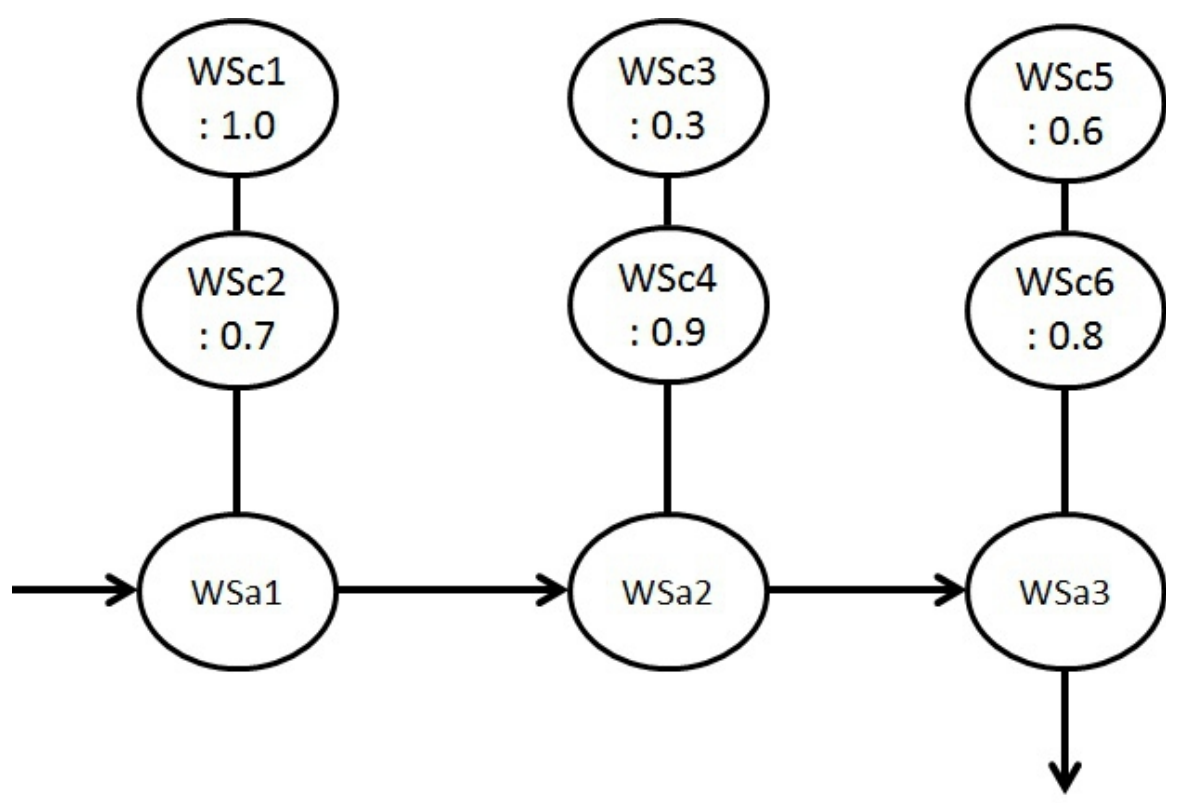

Figura 19: Procedimento do algoritmo Heurística Gulosa.

Os WSa1, WSa2 e WSa3 são os três WS abstratos do fluxo. Para cada Web Service abstrato do fluxo, existem dois Web Services concretos que podem ser selecionados. Neste exemplo, existe apenas um atributo de QoS que está normalizado entre 0 e 1. Então, para cada Web Service abstrato o algoritmo HG escolheu o Web Service concreto com o maior QoS (WSc1, WSc4 e WSc6). A seta antes do WSa1 representa o início do fluxo e a seta para baixo no WSa3 representa o fim do fluxo.

\section{- Vantagens}

Este algoritmo é muito rápido, sendo que sua complexidade assintótica é $\mathrm{O}\left(\begin{array}{lll}n & x k\end{array}\right)$, sendo $n$ o número de Web Services concretos e $k$ o número de Web Services abstratos (supondo $n$ igual para todos os Web Services abstratos). Possui bons resultados, em alguns casos encontra o ótimo global e pode ser executado em espaços de busca grandes $\left(200^{12}\right)$. 
- Desvantagens

Por se tratar de um algoritmo determinístico, não consegue se beneficiar de um deadline maior. Por exemplo, se o deadline for um segundo ou um dia, a resposta do algoritmo será a mesma.

\subsection{Heurística Gulosa 2 (HG 2)}

\section{- Procedimento}

Esse algoritmo é uma versão modificada do algoritmo HG. Ele permite um vetor de pesos para os atributos de QoS, permitindo que o usuário defina prioridades em relação aos atributos que julga mais importantes. Por exemplo, o usuário pode definir que o custo e o tempo de resposta tem peso 2, ao passo que os demais atributos tem peso 1, passando como parâmetro um vetor de pesos da seguinte maneira [2,2,1,1,1]. Além disso, esse algoritmo permite que o usuário defina uma restrição local, para um Web Service abstrato do fluxo. Por exemplo, o usuário pode definir que o primeiro Web Service abstrato do fluxo deve ser o mais rápido possível, passando como parâmetro o valor 1.0 para o atributo de QoS tempo daquele Web Service abstrato (esse valor é 1.0 porque todos os atributos de QoS são normalizados entre 0 e 1 , sendo que o 0 é sempre o pior valor encontrado e 1 é sempre o melhor).

\section{- Vantagens}

O usuário pode priorizar os atributos que julga mais importantes, além de poder definir uma restrição local para um de QoS de um único Web Service abstrato no fluxo. Nos casos em que foi testado, não apresentou um acréscimo relevante no tempo de execução em relação ao HG.

\section{- Desvantagens}

É um algoritmo determinístico, assim como o HG. Portanto, não aproveita um deadline maior para melhorar a solução encontrada. 


\subsection{Algoritmos Genéticos (AGs)}

Neste projeto foram desenvolvidos quatro AGs, para que fosse possível avaliar quais operadores de seleção e elitismo fornecem melhores resultados para o problema CWSbQ. Esses operadores foram explicados na Seção 2.6 e as combinações desenvolvidas podem ser observadas na Tabela 3:

Tabela 3: Parâmetros dos operadores genéticos dos Ags implementados.

\begin{tabular}{|c|c|c|}
\hline Nome & Operador de seleção & Elitismo \\
\hline AG 1 & Roleta viciada & Desativado \\
\hline AG 2 & Torneio com 16 participantes & Ativado \\
\hline AG 3 & Roleta viciada & Ativado \\
\hline AG 4 & Torneio com 16 participantes & Desativado \\
\hline
\end{tabular}

\section{- Procedimento}

Em todos os AGs foi utilizado o operador de cruzamento de um ponto, não foi usado operador de mutação e o número de gerações foi fixado em cinco. O tamanho da população varia de acordo com alguns critérios que serão explicados no próximo capítulo.

\section{- Vantagens}

A vantagem dos AGs é que eles aproveitam todo o deadline disponível. Aumentando-o é possível aumentar o tamanho da população e/ou o número de gerações o que provavelmente causará uma resposta melhor no final de sua execução.

\section{- Desvantagens}

Não há nenhuma garantia de que o ótimo global seja encontrado, mesmo que o deadline seja relativamente grande e o espaço de busca pequeno. Além disso, para alguns espaços de busca foram obtidos níveis de desempenho inferiores aos dos algoritmos heurísticos citados anteriormente. 


\subsection{Algoritmo Genético Duplamente Híbrido (AGDH)}

\section{- Procedimento}

Este algoritmo constitui uma proposta original deste trabalho de mestrado e trata-se da combinação de três algoritmos: HG, FU e AG 2. Primeiramente, é executado o algoritmo HG, sendo que sua resposta é salva em um cromossomo. Depois o algoritmo FU é executado e sua resposta também é salva em um cromossomo. Esses dois cromossomos são incluídos na população inicial do AGDH.

\section{- Vantagens}

Como esse algoritmo combina os três algoritmos citados, isso garante que sua resposta final seja pelo menos tão boa quanto a melhor resposta dos três individualmente. Outra vantagem é o fato de que quanto maior for o deadline maior a probabilidade de boas respostas.

\section{- Desvantagens}

Uma desvantagem desse algoritmo está relacionada ao fato de não garantir o ótimo global, sendo assim, para espaços de busca pequenos a BE é a melhor opção. Ele também não foi desenvolvido para aceitar pesos para os atributos de QoS e restrições, nesses casos deve-se usar o HG2.

\subsection{Considerações finais}

Este capítulo apresentou os dez algoritmos desenvolvidos durante o decorrer deste trabalho. Isso é interessante porque os trabalhos relacionados costumam focar-se em duas ou três técnicas diferentes, deixando de lado a oportunidade de comparar mais técnicas em um mesmo ambiente de testes.

Neste trabalho, foram desenvolvidos e avaliados uma busca aleatória (BA), três algoritmos heurísticos (FU, HG e HG2), um algoritmo de busca exaustiva (BE), quatro algoritmos genéticos (AG 1, AG 2, AG 3 e AG 4) e um algoritmo híbrido (AGDH). 


\section{Ambiente de testes e planejamento de experimentos}

\subsection{Considerações iniciais}

Este capítulo visa apresentar o ambiente de testes em que os experimentos foram realizados, as ferramentas utilizadas e o planejamento dos experimentos. Os dez algoritmos citados no Capítulo 4 foram avaliados de acordo com duas variáveis de resposta: tempo de resposta e QoS. O principal objetivo desses experimentos é descobrir quais algoritmos possuem melhor desempenho de acordo com os deadlines estabelecidos e os diferentes tamanhos de espaço de busca avaliados.

\subsection{Ambiente de testes}

O ambiente de testes é composto de três máquinas: uma representando um cliente, outra uma provedora de Web Service e uma terceira que executa um servidor MySQL que possui os dados sobre os atributos de QoS dos Web Services disponíveis. No ambiente de testes considerado, as três máquinas estão na mesma rede e são ligadas por um switch gigabit ethernet. A Figura 20 ilustra esse ambiente, em que as máquinas são heterogêneas e as suas configurações podem ser observadas na Tabela 4. As ferramentas utilizadas no ambiente de testes são:

- Apache Tomcat: um contêiner Web usado para a implantação do Web Service do provedor de Web Services.

- MySQL server: um SGBD usado para armazenar os dados dos atributos de QoS dos Web Services disponíveis.

Apache Axis2: é um motor de Web Services / SOAP / WSDL, usado para hospedar o Web Service responsável pelo atendimento das requisições do cliente (APACHE FOUNDATION, 2012). O WS recebe o pedido e, em seguida, executa o algoritmo de 
composição adequado e envia a resposta para o cliente.

Tabela 4: Configuração de hardware do ambiente de testes.

\begin{tabular}{|c|c|c|c|c|}
\hline \multicolumn{1}{|c|}{ Máquina } & CPU & Clock & Cache & RAM \\
\hline Provedor de WS & Intel ${ }^{\circ}$ Core $^{\mathrm{TM}} 2 \mathrm{Quad}$ & $2,66 \mathrm{GHz}$ & $3 \mathrm{MB}$ & $8 \mathrm{~GB}$ \\
\hline Servidor MySQL & Intel ${ }^{\circledR}$ Core & & \\
\hline Cliente & Intel ${ }^{\circledR}$ Core & $3,10 \mathrm{GHz}$ & $3 \mathrm{MB}$ & $4 \mathrm{~GB}$ \\
\hline
\end{tabular}

Os experimentos foram realizados usando a configuração padrão de todas as ferramentas citadas. A interação entre as máquinas é a seguinte: o cliente requisita um plano de composição de Web Services para o provedor de Web Services, o provedor de Web Services vasculha o servidor MySQL para obter os dados sobre os atributos de QoS dos Web Services disponíveis e então executa um dos algoritmos compositores (de acordo com a opção do cliente). O algoritmo selecionado informa qual foi o plano de composição de Web Services selecionado e seu respectivo QoS ao provedor de Web Services, que repassa essa informação para o cliente.

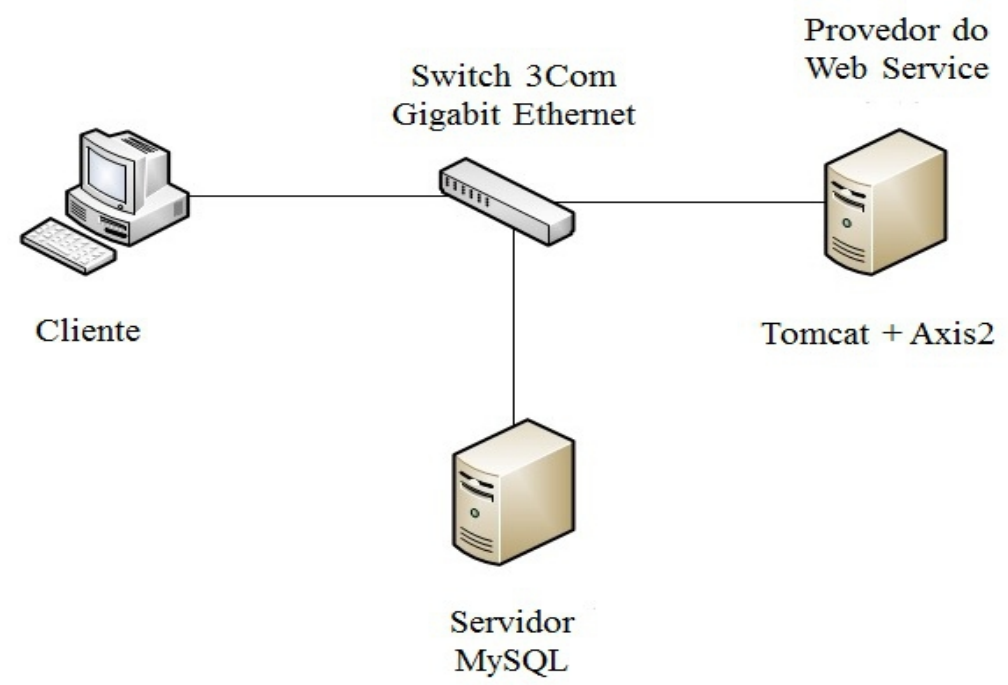

Figura 20: Ambiente de testes.

\subsection{Planejamento de experimentos}

Esta seção tem o intuito de esclarecer como foi realizado o planejamento dos 
experimentos realizados com os dez algoritmos desenvolvidos. Os diferentes tamanhos de espaço de busca avaliados podem ser observados na Tabela 5. Os dois deadlines definidos foram: 1.000 milissegundos e 1.500 milissegundos. O caractere \# representa o número de cada fator citado.

Tabela 5: Diferentes tamanhos de espaço de busca definidos.

\begin{tabular}{|c|c|c|}
\hline Espaço de busca & \# de WS abstratos & \# de WS concreto por WS abstrato \\
\hline 1 & 2 & 100 \\
\hline 2 & 2 & 200 \\
\hline 3 & 3 & 100 \\
\hline 4 & 3 & 200 \\
\hline 5 & 4 & 100 \\
\hline 6 & 4 & 200 \\
\hline 7 & 6 & 100 \\
\hline 8 & 6 & 200 \\
\hline 9 & 12 & 100 \\
\hline 10 & 12 & 200 \\
\hline
\end{tabular}

Se todos os algoritmos fossem avaliados em todos os espaços de busca estabelecidos, seriam cem experimentos realizados (cada algoritmo seria avaliado em todos os dez espaços de busca). Como foram definidos dois deadlines, o número total seria de duzentos experimentos realizados.

Felizmente, isso não foi necessário e um número menor de experimentos foi executado, sem a perda de nenhuma informação relevante. Por exemplo, o algoritmo BE, a partir do espaço de busca cinco, não atende a nenhum dos dois deadlines definidos. De fato, como o seu tempo de execução cresce exponencialmente, experimentos usando os dois últimos espaços de busca provavelmente levariam alguns bilhões de anos para serem executados.

\subsubsection{Criação e normalização dos atributos de QoS}

Os atributos de QoS foram gerados de forma aleatória e então inseridos no servidor MySQL. Alguns trabalhos relacionados também geram os atributos de QoS de forma aleatória (CLARO ET. AL., 2005; ARDAGNA \& PERNICI, 2006; SU ET. AL., 2007; FENG \& ZHEN-MING, 2009; TANG \& AI, 2010). A Tabela 6 apresenta os intervalos de valores de 
cada atributo de QoS. Em todos os experimentos, apenas 10\% dos dados de QoS nas tabelas do servidor MySQL estão relacionados aos Web Services candidatos. Por exemplo, no tamanho de espaço de busca um, existem duzentos Web Services candidatos e um total de dois mil disponíveis na tabela correspondente.

Tabela 6: Intervalo fechado de cada atributo de QoS gerado aleatoriamente.

\begin{tabular}{|c|c|c|c|c|c|c|c|c|c|}
\hline \multicolumn{2}{|c|}{ Custo } & \multicolumn{2}{c|}{ Tempo } & \multicolumn{2}{c|}{ Disponibilidade } & \multicolumn{2}{c|}{ Reputação } & \multicolumn{2}{c|}{ Confidencialidade } \\
\hline Min & Max & Min & Max & \multicolumn{1}{c|}{ Min } & Max & Min & Max & Min & Max \\
\hline 5 & 1000 & 10 & 300 & 0,991 & 0,999 & 0 & 10 & 0 & 10 \\
\hline
\end{tabular}

Para que todos os atributos de QoS tivessem o mesmo peso na avaliação dos possíveis planos de composição, foi necessária a utilização de duas fórmulas para normalizar todos os atributos entre 0 e 1 . Os atributos custo e tempo devem ser minimizados; já os demais devem ser maximizados. As fórmulas foram adaptadas de Su. et. al. (2007) e podem ser observadas nas Equações 2 e 3. A Equação 2 representa a fórmula para normalizar atributos que devem ser minimizados e a Equação 3 atributos que devem ser maximizados.

$$
\begin{aligned}
Q_{i} & =\frac{Q_{i}^{\text {max }}-Q_{i}}{Q_{i}^{\text {max }}-Q_{i}^{\text {min }}} \quad \text { Equação } 2 \\
Q_{i} & =\frac{Q_{i}-Q_{i}^{\min }}{Q_{i}^{\max }-Q_{i}^{\min }} \text { Equação } 3
\end{aligned}
$$

Dessa forma, para qualquer atributo de QoS, o melhor resultado é sempre representado pelo número 1 e o pior resultado sempre pelo número 0 .

Além de normalizar cada atributo de QoS individualmente, também foi feita a normalização do QoS agregado total da composição. Cada atributo de QoS possui sua própria função de agregação, como foi citado na Tabela 1. Por exemplo, suponha um fluxo com 2 WS abstratos. Somando-se todos os atributos de QoS agregados, o valor máximo seria 7. O custo seria a soma $1+1$, o tempo seria a soma $1+1$, a disponibilidade é o produto $1 * 1$, a 

reputação é a média $(1+1) / 2=1$ e a confidencialidade é a média $(1+1) / 2=1$. Portanto, para normalizar o QoS agregado total entre 0 e 1, basta dividir o valor obtido por 7 . No caso "2 100 " o algoritmo busca exaustiva obteve um QoS agregado total de 5,63 que dividido por 7 deu 0,804 . É por isso que os ótimos globais encontrados não são 1 , mas valores próximos a ele, pois trata-se de um ótimo global hipotético.

Existem outras formas de representar os atributos de QoS; o trabalho de Nakamura (2012) focou-se no uso de ontologias e Web semântica para representar os atributos de QoS, em Lin et. al. (2011) é citado o framework WS-QoS e Karunamurthy et. al. (2012) cita o uso de uma linguagem denominada Non-Functional Specification Language (NFSL) para descrever os atributos de QoS dos Web Services. Entretanto, as vantagens e desvantagens das diferentes formas de se representar os atributos de QoS estão fora do escopo desta dissertação.

\subsubsection{Planejamento de experimentos A}

Neste primeiro planejamento de experimentos, os menores espaços de busca foram abordados, ou seja, do primeiro ao quarto. Como o algoritmo BE conseguiu atender aos dois deadlines nesses experimentos, não seria necessário avaliar os demais algoritmos. Entretanto, mais algoritmos foram avaliados, objetivando-se conhecer melhor seu desempenho. Eles podem ser observados na Tabela 7:

Tabela 7: Fatores e níveis do planejamento de experimentos A.

\begin{tabular}{|l|l|l|}
\hline Espaço de busca & \multicolumn{1}{|c|}{ Algoritmo } & \multicolumn{1}{c|}{ Deadline (ms) } \\
\hline 1 & BE, FU e HG & 1.000 \\
\hline 2 & BE, FU e HG & 1.000 \\
\hline 3 & BE, FU e HG & 1.000 \\
\hline 4 & BE, FU e HG & 1.000 \\
\hline 1 & BE, FU e HG & 1.500 \\
\hline 2 & BE, FU e HG & 1.500 \\
\hline 3 & BE, FU e HG & 1.500 \\
\hline 4 & BE, FU e HG & 1.500 \\
\hline
\end{tabular}

Como se pode observar na Tabela 7, o número total de experimentos deste planejamento 
foi vinte e quatro.

\subsubsection{Planejamento de experimentos dos AGs}

Como citado anteriormente, o algoritmo BE conseguiu atender aos dois deadlines estabelecidos, nos espaços de busca um a quatro. Portanto não há necessidade de avaliar o desempenho dos AGs nestes casos, visto que o BE garante o ótimo global e, portanto, é o mais indicado. Nos demais espaços de busca, os AGs foram avaliados e agrupados em grupos de experimentos, como pode ser observado na Tabela 8. Como foram avaliados quatro AGs e doze grupos de experimentos, o número total de experimentos realizados foi quarenta e oito.

Tabela 8: Fatores e níveis do planejamento de experimentos dos AGs.

\begin{tabular}{|l|l|l|l|}
\hline$\#$ & Espaço de busca & \multicolumn{1}{c|}{ Deadline (ms) } & \multicolumn{1}{c|}{ Algoritmo } \\
\hline 1 & 5 & 1.000 & AG 1, AG 2, AG 3 e AG 4 \\
\hline 2 & 6 & 1.000 & AG 1, AG 2, AG 3 e AG 4 \\
\hline 3 & 7 & 1.000 & AG 1, AG 2, AG 3 e AG 4 \\
\hline 4 & 8 & 1.000 & AG 1, AG 2, AG 3 e AG 4 \\
\hline 5 & 9 & 1.000 & AG 1, AG 2, AG 3 e AG 4 \\
\hline 6 & 10 & 1.000 & AG 1, AG 2, AG 3 e AG 4 \\
\hline 7 & 5 & 1.500 & AG 1, AG 2, AG 3 e AG 4 \\
\hline 8 & 6 & 1.500 & AG 1, AG 2, AG 3 e AG 4 \\
\hline 9 & 7 & 1.500 & AG 1, AG 2, AG 3 e AG 4 \\
\hline 10 & 8 & 1.500 & AG 1, AG 2, AG 3 e AG 4 \\
\hline 11 & 9 & 1.500 & AG 1, AG 2, AG 3 e AG 4 \\
\hline 12 & 10 & 1.500 & AG 1, AG 2, AG 3 e AG 4 \\
\hline
\end{tabular}

Uma característica importante desses experimentos está relacionada aos fatores fixos. Esses fatores são os mesmos para os doze grupos de experimentos e podem ser observados na Tabela 9: 
Tabela 9: Fatores fixos do planejamento de experimentos dos AGs.

\begin{tabular}{|l|l|}
\hline Número de gerações & 5 \\
\hline Operador de mutação & Desativado \\
\hline Operador de crossover & Crossover de um ponto. \\
\hline Número de repetições & 30 \\
\hline Grau de confiança & $95 \%$ \\
\hline
\end{tabular}

Também se deve levar em conta o tamanho da população de cada AG, de acordo com o tamanho do espaço de busca e o deadline; isto pode ser observado na Tabela 10:

Tabela 10: População dos AGs avaliados.

\begin{tabular}{|c|c|c|c|c|c|}
\hline Espaço de busca & Deadline (ms) & \multicolumn{4}{|c|}{ População (em milhares) } \\
\hline & & AG 1 & AG 2 & AG 3 & AG 4 \\
\hline 5 & 1.000 & 1,8 & 23 & 1,75 & 25 \\
\hline 6 & 1.000 & 1,8 & 23 & 1,75 & 25 \\
\hline 7 & 1.000 & 1,8 & 23 & 1,75 & 25 \\
\hline 8 & 1.000 & 1,8 & 23 & 1,75 & 25 \\
\hline 9 & 1.000 & 1,8 & 21 & 1,75 & 21,8 \\
\hline 10 & 1.000 & 1,8 & 21 & 1,75 & 21,8 \\
\hline 5 & 1.500 & 2,6 & 35 & 2,5 & 40 \\
\hline 6 & 1.500 & 2,6 & 35 & 2,5 & 40 \\
\hline 7 & 1.500 & 2,6 & 35 & 2,5 & 40 \\
\hline 8 & 1.500 & 2,6 & 35 & 2,5 & 40 \\
\hline 9 & 1.500 & 2,6 & 32 & 2,5 & 35 \\
\hline 10 & 1.500 & 2,6 & 32 & 2,5 & 35 \\
\hline
\end{tabular}

Observando-se a Tabela 10, nota-se que os algoritmos foram executados com uma população diferente, mesmo tendo o mesmo deadline e o mesmo espaço de busca. Isso ocorreu porque alguns algoritmos são muito mais rápidos do que outros. O operador de seleção torneio com dezesseis participantes mostrou-se muito mais rápido do que o operador de roleta viciada. Além disso, o uso de elitismo também deixou os algoritmos mais lentos, fazendo com que fosse necessário diminuir o tamanho da população para que fosse possível 
continuar atendendo aos deadlines estabelecidos. Isso fica claro quando se observa a população do AG 4, que em todos os casos foi maior do que os demais algoritmos.

\subsubsection{Planejamento de experimentos B}

Neste planejamento de experimentos, os espaços de busca maiores foram abordados, ou seja, do quinto ao décimo. O algoritmo BE não conseguiu atender nenhum dos dois deadlines, mas em alguns casos ele foi executado para que fosse possível comparar seus resultados com os dos demais algoritmos. O planejamento pode ser observado na Tabela 11:

Tabela 11: Fatores e níveis do planejamento de experimentos B.

\begin{tabular}{|c|c|c|}
\hline Espaço de busca & Algoritmo & Deadline (ms) \\
\hline 5 & BE, FU, HG, BA e AGDH. & 1.000 \\
\hline 6 & BE, FU, HG, BA e AGDH. & 1.000 \\
\hline 7 & BE, FU, HG, BA e AGDH. & 1.000 \\
\hline 8 & FU, HG, BA e AGDH. & 1.000 \\
\hline 9 & FU, HG, BA e AGDH. & 1.000 \\
\hline 10 & FU, HG, BA e AGDH. & 1.000 \\
\hline 5 & BE, FU, HG, BA e AGDH. & 1.500 \\
\hline 6 & BE, FU, HG, BA e AGDH. & 1.500 \\
\hline 7 & BE, FU, HG, BA e AGDH & 1.500 \\
\hline 8 & FU, HG, BA e AGDH. & 1.500 \\
\hline 9 & FU, HG, BA e AGDH. & 1.500 \\
\hline 10 & FU, HG, BA e AGDH. & 1.500 \\
\hline
\end{tabular}

Observando-se a Tabela 11, o número de experimentos realizados foi cinquenta e um. Isso ocorreu porque o algoritmo $\mathrm{BE}$ foi executado apenas uma vez, para os dois deadlines diferentes.

No Capítulo 4 foi explicado o procedimento do algoritmo BA. Portanto, da mesma forma que foi apresentada as populações de cada AG na seção anterior, serão apresentados os números de tentativas do algoritmo BA para cada espaço de busca e deadline estabelecido; isso pode ser visto na Tabela 12. 
Tabela 12: Número de tentativas do algoritmo BA.

\begin{tabular}{|c|c|c|}
\hline Espaço de busca & Deadline (ms) & Número de tentativas (milhares) \\
\hline 5 & 1.000 & 80 \\
\hline 6 & 1.000 & 80 \\
\hline 7 & 1.000 & 80 \\
\hline 8 & 1.000 & 80 \\
\hline 9 & 1.000 & 75 \\
\hline 10 & 1.000 & 75 \\
\hline 5 & 1.500 & 145 \\
\hline 6 & 1.500 & 145 \\
\hline 7 & 1.500 & 130 \\
\hline 8 & 1.500 & 130 \\
\hline 9 & 1.500 & 125 \\
\hline 10 & 1.500 & 125 \\
\hline
\end{tabular}

\subsubsection{Planejamento de experimentos $\mathrm{C}$}

Esse planejamento de experimentos foi realizado apenas para comparar o desempenho do HG com o HG2. No caso em que apenas um vetor de pesos é informado e uma restrição local é definida, o tempo de execução do HG2 não deve ser estatisticamente superior ao tempo de execução do HG. Portanto, os experimentos definidos para comprovar essa hipótese podem ser observados na Tabela 13:

Tabela 13: Fatores e níveis do planejamento de experimentos C.

\begin{tabular}{|c|c|}
\hline Espaço de busca & Algoritmo \\
\hline 1 & HG \\
\hline 7 & HG \\
\hline 1 & HG 2 \\
\hline 7 & HG 2 \\
\hline
\end{tabular}




\subsubsection{Influência dos fatores}

O cálculo da influência dos fatores é uma técnica importante que visa identificar a forma com que os fatores de um experimento influenciam a variável de resposta. Foram realizados três cálculos de influência dos fatores, todos eles focados na variável de resposta QoS. Primeiramente, foi calculada a influência dos fatores dos quatro algoritmos genéticos desenvolvidos; buscou-se identificar a forma que os operadores de seleção e elitismo influenciam no QoS da composição obtida. As combinações analisadas são as mesmas dos doze grupos de experimentos definidos na Tabela 8 .

Os algoritmos FU e HG também foram avaliados, nesse caso, variando-se os fatores: quantidade de Web Services abstratos e quantidade de Web Services concretos por Web Service abstrato. As combinações analisadas podem ser observadas na Tabela 14. A variável de resposta foi a diferença entre o ótimo global e a resposta obtida pelo algoritmo em questão. Por exemplo, se para o caso " 2 - 100" o ótimo global foi dez e o algoritmo FU obteve nove, a variável de resposta é um. Dessa forma, buscou-se descobrir qual fator faz com que os algoritmos fiquem mais distantes do ótimo global.

Tabela 14: Fatores e níveis usados no cálculo da influência dos fatores dos algoritmos FU e HG.

\begin{tabular}{|c|c|c|}
\hline Web Services abstratos & Web Services concretos & Algoritmo \\
\hline 2 & 100 & $\mathrm{FU}$ \\
\hline 2 & 200 & $\mathrm{FU}$ \\
\hline 4 & 100 & $\mathrm{FU}$ \\
\hline 4 & 200 & $\mathrm{FU}$ \\
\hline 2 & 100 & $\mathrm{HG}$ \\
\hline 2 & 200 & $\mathrm{HG}$ \\
\hline 4 & 100 & $\mathrm{HG}$ \\
\hline 4 & 200 & $\mathrm{HG}$ \\
\hline
\end{tabular}

\subsection{Considerações finais}

Neste capítulo foi apresentado o ambiente de testes, bem como as ferramentas utilizadas para a realização dos experimentos. Foi esclarecido como os atributos de QoS dos Web Services foram criados, normalizados e recuperados. Os planejamentos dos experimentos de 
todos os algoritmos desenvolvidos citados no Capítulo 4 foram apresentados e justificados. Por fim, explicaram-se os motivos que levaram ao cálculo da influência dos fatores em alguns algoritmos. No próximo capítulo, serão apresentados os resultados obtidos em todos os experimentos realizados e a análise de seus motivos e implicações. 


\section{Análise dos Resultados}

\subsection{Considerações iniciais}

Este capítulo apresenta os resultados dos experimentos realizados neste trabalho de mestrado. As duas variáveis de resposta definidas no capítulo anterior (QoS e tempo de resposta) são analisadas, bem como os cálculos de influência de fatores que foram definidos.

\subsection{Análise do tempo de resposta}

Nesta seção são apresentados os resultados dos experimentos em relação ao tempo de resposta dos algoritmos, agrupados pelos planejamentos de experimentos definidos no capítulo anterior.

\subsubsection{Análise do tempo de resposta do planejamento de experimentos A}

Nestes experimentos, os três algoritmos avaliados conseguiram cumprir os deadlines estabelecidos. Como pode ser observado na Figura 21, o algoritmo BE teve um tempo de resposta significativamente maior do que os outros dois, mas mesmo assim ficou abaixo dos deadlines definidos. Levando-se em conta que os três algoritmos conseguiram cumprir os dois deadlines a melhor opção seria utilizar o BE, pois é o único que garante o ótimo global para qualquer conjunto de atributos de QoS que seja definido. 


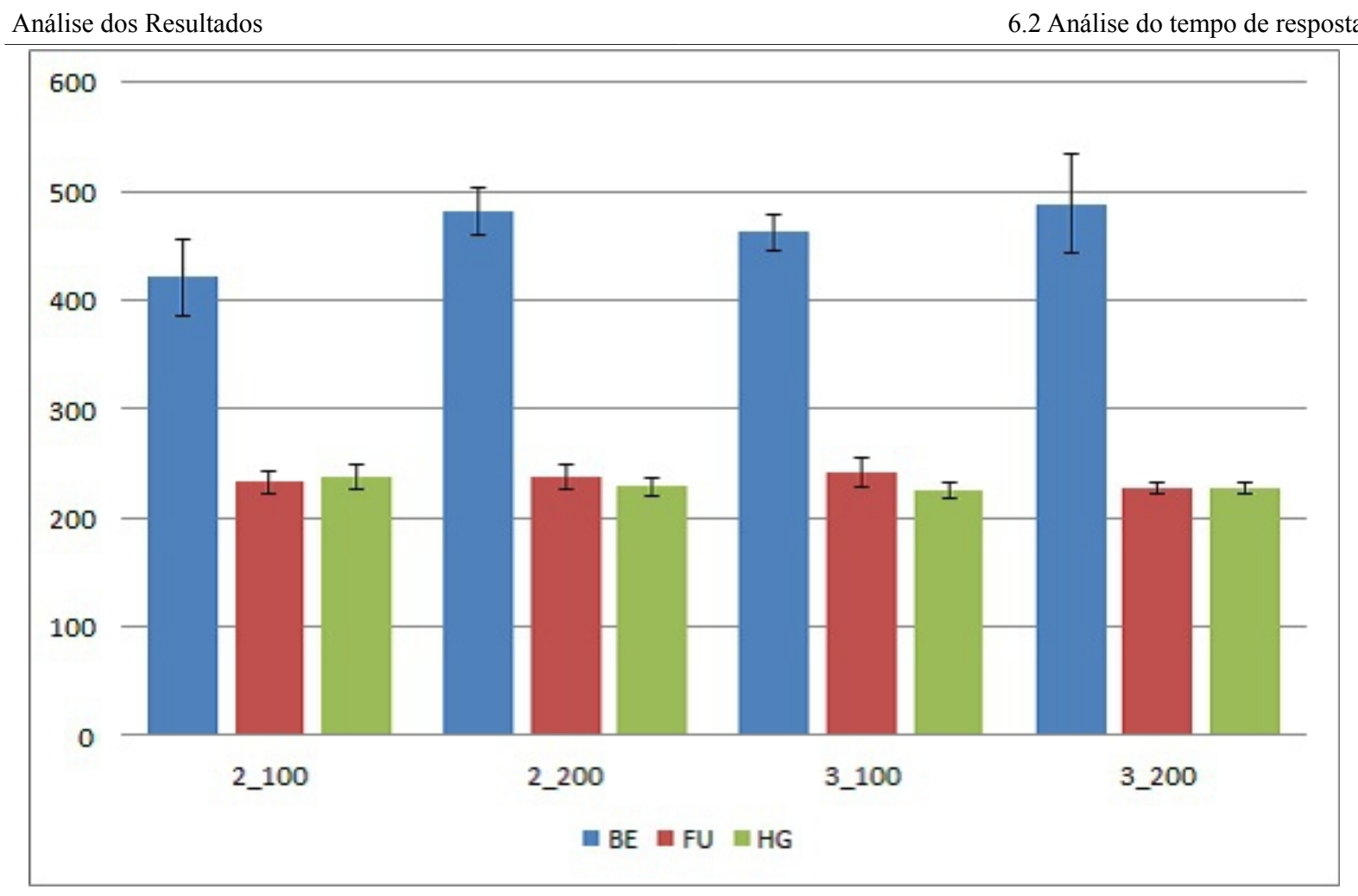

Figura 21: Tempos médios de resposta (em ms) dos algoritmos avaliados no planejamento de experimentos A.

\subsubsection{Análise do tempo de resposta do planejamento de experimentos dos AGs}

Como são algoritmos estocásticos, aumentando-se o deadline pode-se aumentar o tamanho da população, de forma a tentar obter um melhor QoS. Sendo assim, devem-se avaliar separadamente os tempos de resposta dos AGs de acordo com cada deadline e garantir que para cada grupo de experimentos, eles sejam estatisticamente equivalentes, para não favorecer algum algoritmo dando-o mais tempo para encontrar uma boa resposta.

A Figura 22 mostra os tempos de resposta de acordo com o deadline de mil milissegundos. Pode-se observar que para cada espaço de busca, os quatro AGs estão com seus intervalos de confiança sobrepostos, o que significa que são estatisticamente equivalentes. 


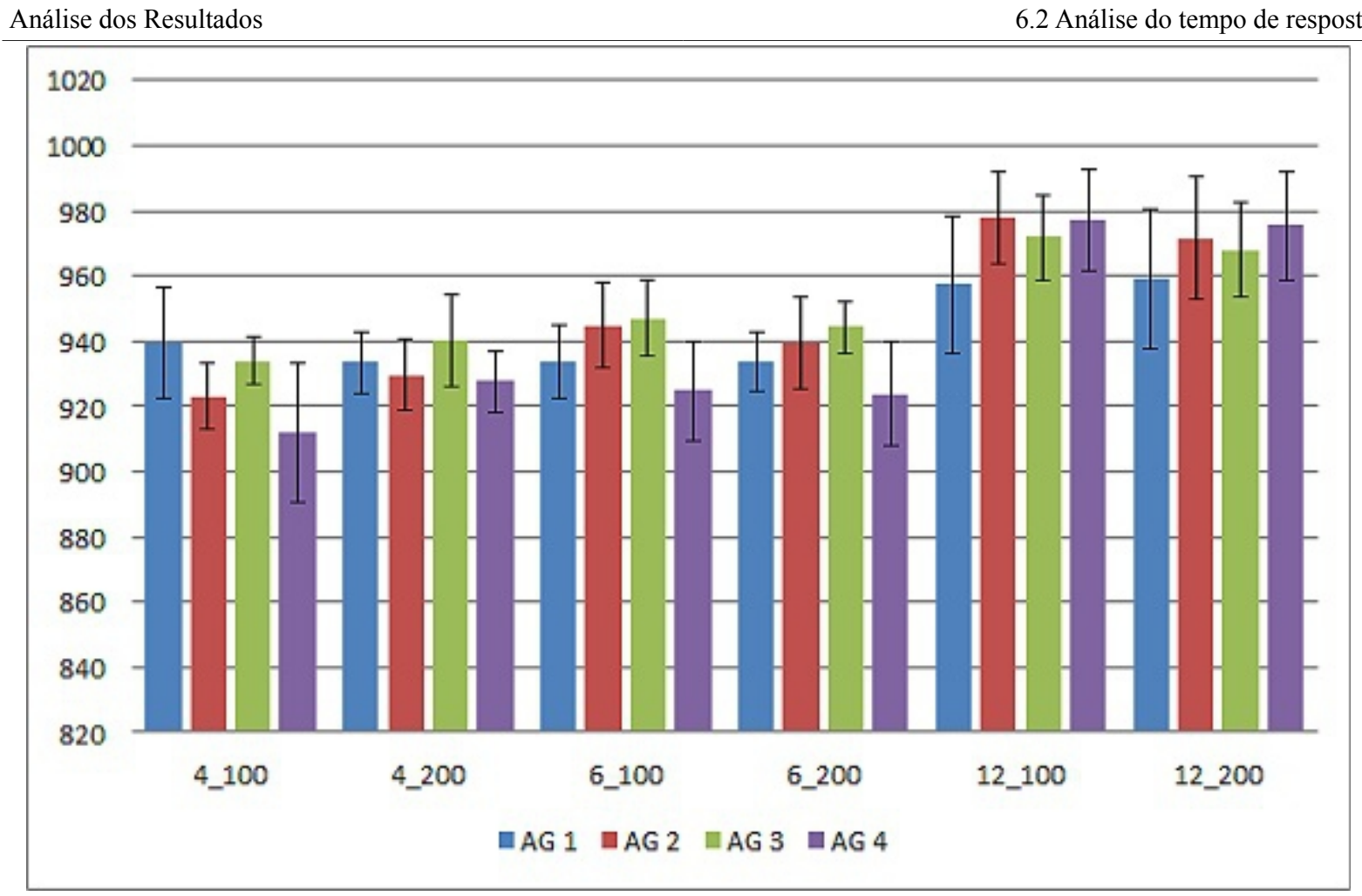

Figura 22: Tempos médios de resposta (em ms) do planejamento de experimentos dos AGs, com deadline de mil milissegundos.

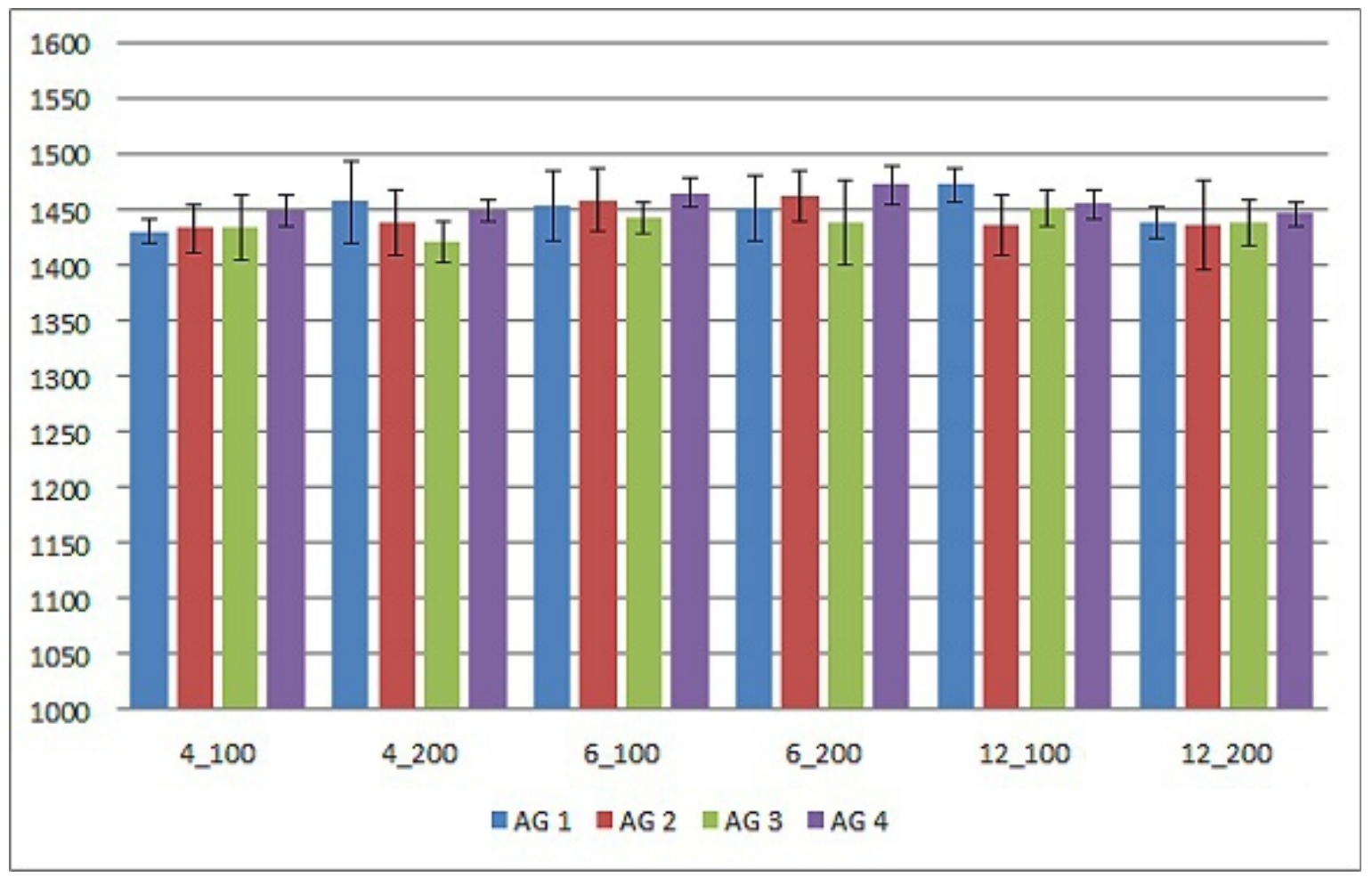

Figura 23: Tempos médios de resposta (em ms) do planejamento de experimentos dos AGs, com deadline de mil e quinhentos milissegundos. 
O mesmo foi feito para o deadline de mil e quinhentos milissegundos, sendo que seus resultados podem ser observados na Figura 23. Do ponto de vista do cumprimento dos deadlines estabelecidos, todos os AGs podem ser utilizados, bastando apenas definir um número de gerações e tamanho da população apropriada.

\subsubsection{Análise do tempo de resposta do planejamento de experimentos $B$}

Neste planejamento de experimentos, os maiores espaços de busca foram avaliados. $\mathrm{O}$ algoritmo BE não conseguiu cumprir nenhum dos dois deadlines estabelecidos, sendo que para o espaço de busca "4 - 100" obteve uma média de tempo de resposta de 1.733 milissegundos e no caso do espaço de busca " 6 - 100" cerca de quarenta horas. Entretanto, ele foi executado para que fosse possível comparar o ótimo global com o QoS obtido pelos demais algoritmos avaliados.

Os algoritmos FU e HG são determinísticos e não podem se beneficiar de um deadline maior. Já os algoritmos BA e AGDH são probabilísticos e quanto maior o deadline, maiores as chances de conseguirem boas respostas. Sendo assim, da mesma forma como ocorreu em relação aos experimentos com os AGs, o tempo de resposta dos algoritmos BA e AGDH devem ser estatisticamente equivalentes. A Figura 24 exibe os resultados para o deadline de mil milissegundos e a Figura 25 exibe os resultados para o deadline de mil e quinhentos milissegundos. 


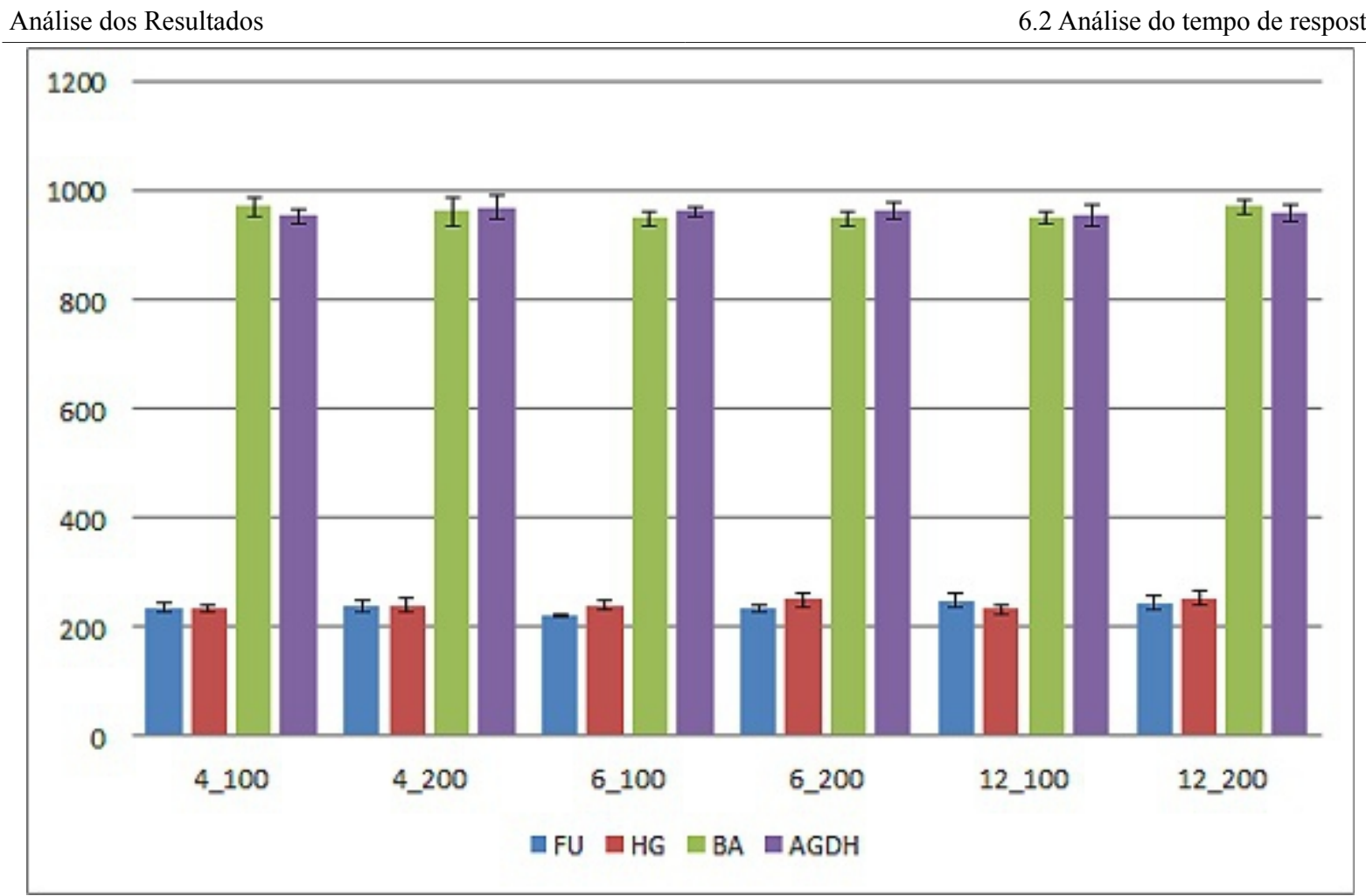

Figura 24: Tempos médios de resposta (em ms) para o Planejamento de Experimentos B, com deadline de mil milissegundos.

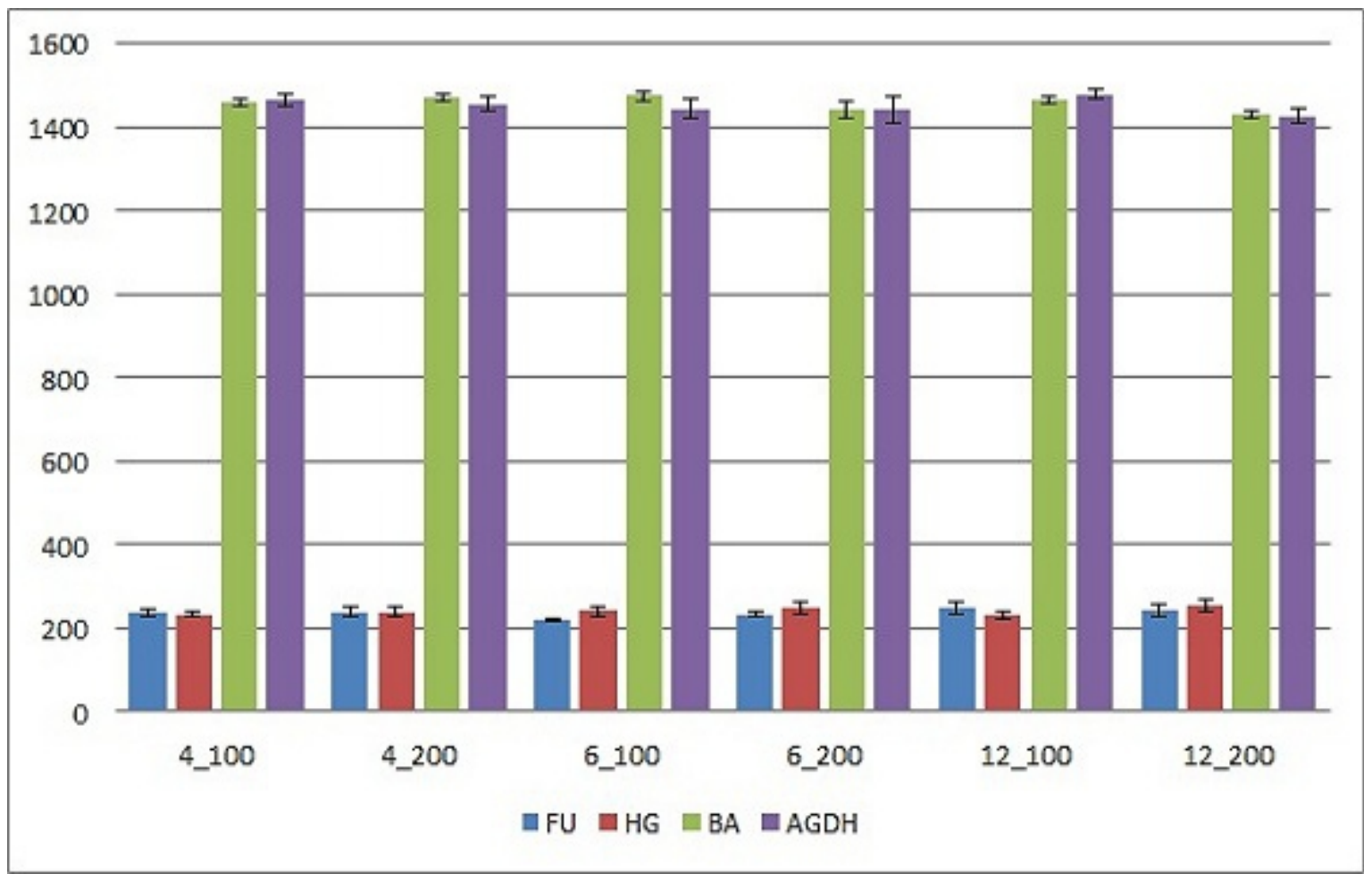

Figura 25: Tempos médios de resposta (em ms) para o Planejamento de Experimentos B, com deadline de mil e quinhentos milissegundos. 
Pode-se concluir que do ponto de vista dos deadlines estabelecidos, os quatro algoritmos citados podem ser utilizados. No caso do BA e AGDH, necessita-se apenas definir corretamente o número de tentativas e o tamanho da população, respectivamente.

\subsubsection{Análise do tempo de resposta do planejamento de experimentos $\mathrm{C}$}

Este planejamento de experimentos visou apenas a comparar os tempos de resposta dos algoritmos HG e HG2, quando o segundo recebe um vetor de pesos para seus atributos de QoS e uma restrição local. Esse vetor de pesos e essa restrição local não deveriam afetar significativamente o desempenho do algoritmo, pois são procedimentos rápidos. Para os espaços de busca avaliados, isso se mostrou correto e os resultados podem ser observados na Figura 26.

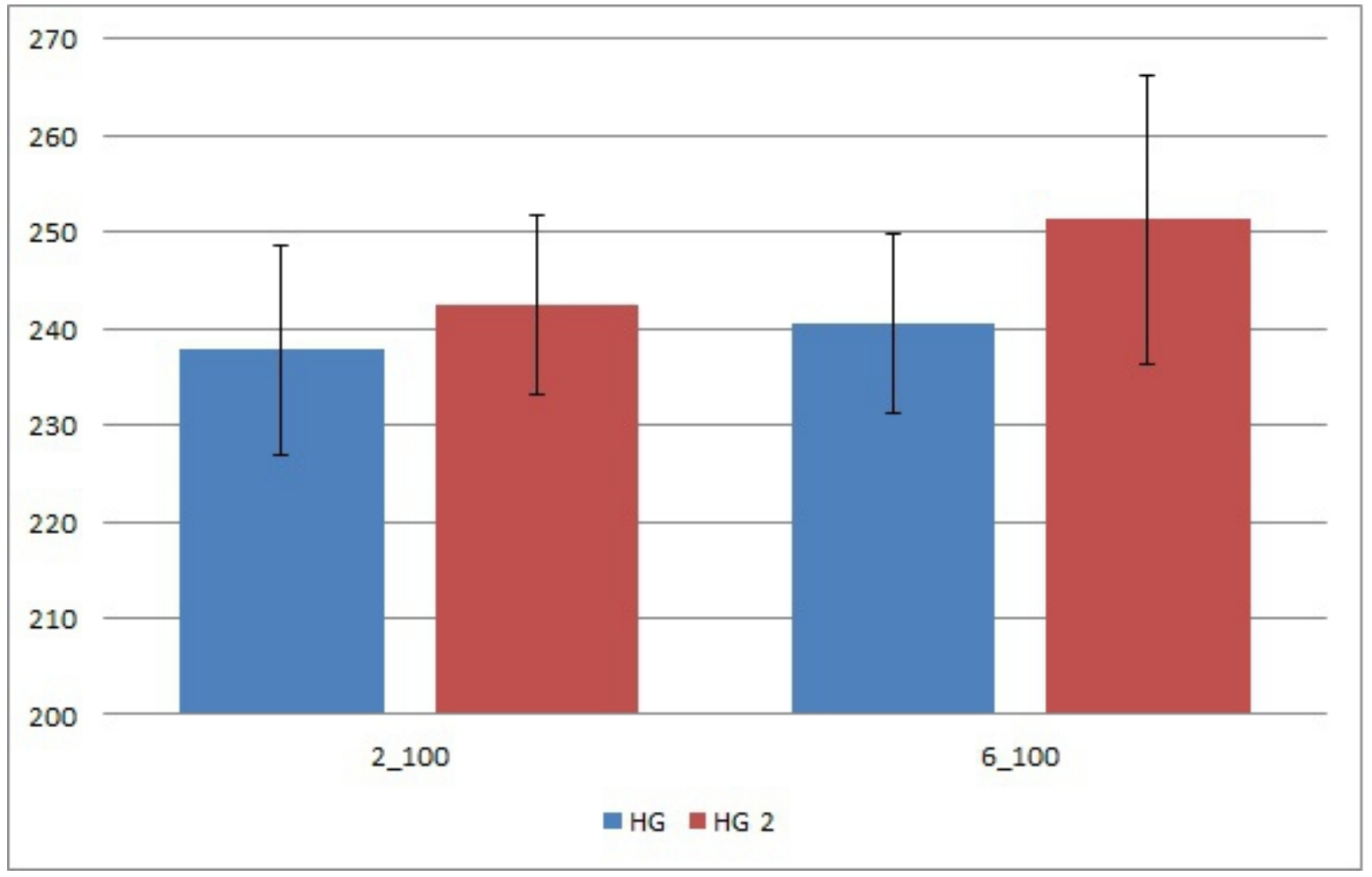

Figura 26: Tempos médios de resposta (em ms) para o Planejamento de Experimentos C

Mesmo que para espaços de busca maiores o aumento seja mais significativo, nota-se que o tempo de resposta médio está bem abaixo dos dois deadlines estabelecidos, o que significa que é provável que o HG2 possa ser utilizado em qualquer um dos tamanhos de 
espaço de busca definidos, mesmo sendo um pouco mais lento do que o HG.

\subsection{Análise do QoS}

Nesta seção são apresentados os resultados dos experimentos em relação ao QoS obtido pelos algoritmos, agrupados pelos planejamentos de experimentos definidos no capítulo anterior.

\subsubsection{Análise do QoS do planejamento de experimentos A}

Os três algoritmos avaliados nesse planejamento de experimentos são determinísticos, portanto o desvio-padrão e intervalo de confiança do QoS é nulo. O algoritmo BE, como já foi dito sempre encontra o ótimo global, portanto foi superior ou igual aos demais algoritmos nos quatro tamanhos de espaço de busca avaliados. Nos casos " 2 - 200" e " 3 - 200" os algoritmos FU e HG conseguiram encontrar o ótimo global, o que significa o melhor resultado possível nesses casos. Os resultados podem ser observados na Figura 27.

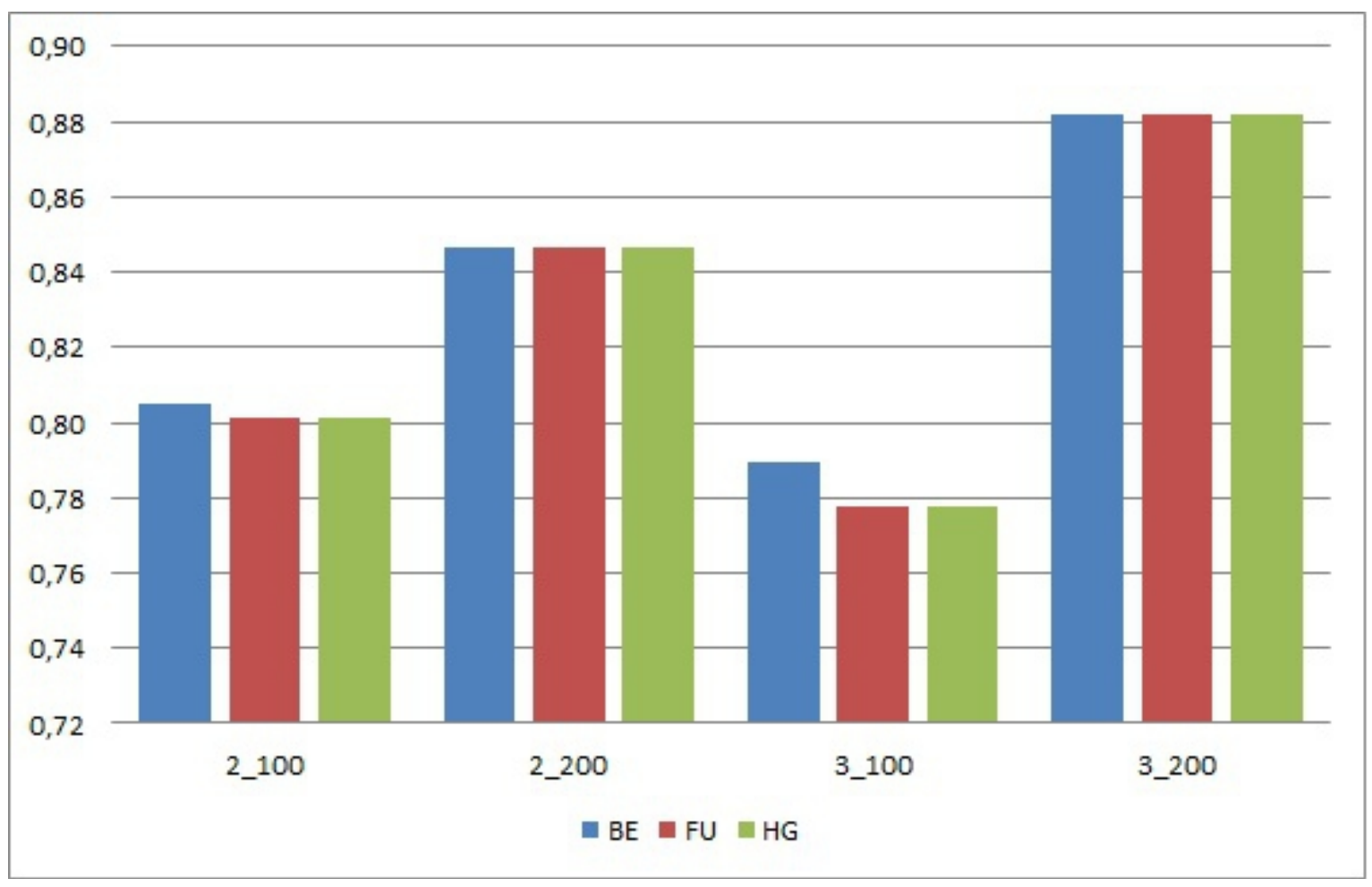

Figura 27: QoS obtido pelo planejamento de experimentos A. 
Por terem encontrado o ótimo global no caso " $2-200 " \mathrm{e}$ " $3-200 "$ e serem mais rápidos do que o $\mathrm{BE}$, pode-se ser levado a crer que o $\mathrm{HG}$ e/ou FU são uma escolha melhor em relação ao BE nesses casos. Entretanto, vale lembrar que o único que realmente garante o ótimo global para qualquer conjunto de atributos de QoS é o BE e já que ele consegue atender aos deadlines estabelecidos (no caso do deadline mil e quinhentos, usa menos da metade do tempo) ele é a melhor opção.

\subsubsection{Análise do QoS do planejamento de experimentos dos AGs}

Neste caso, primeiro serão mostrados os resultados para o deadline de mil milissegundos, posteriormente os resultados para o deadline de mil e quinhentos milissegundos. Os AGs, por serem algoritmos estocásticos, podem fornecer respostas diferentes em cada execução. Dessa forma, cada coluna representa a média do QoS obtido, incluindo também seu intervalo de confiança. A Figura 28 exibe os resultados para o deadline de mil milissegundos.

À primeira vista, observa-se que o AG 2 e o AG 4 obtiveram desempenhos superiores aos outros dois, em todos os tamanhos de espaços de busca analisados. Observando-se o AG 2 e o AG 4, nota-se que exceto pelo espaço de busca " 4 - 100", onde o AG 2 é estatisticamente superior ao AG 4, seus intervalos de confiança estão sobrepostos, o que implica no fato de serem estatisticamente equivalentes. 


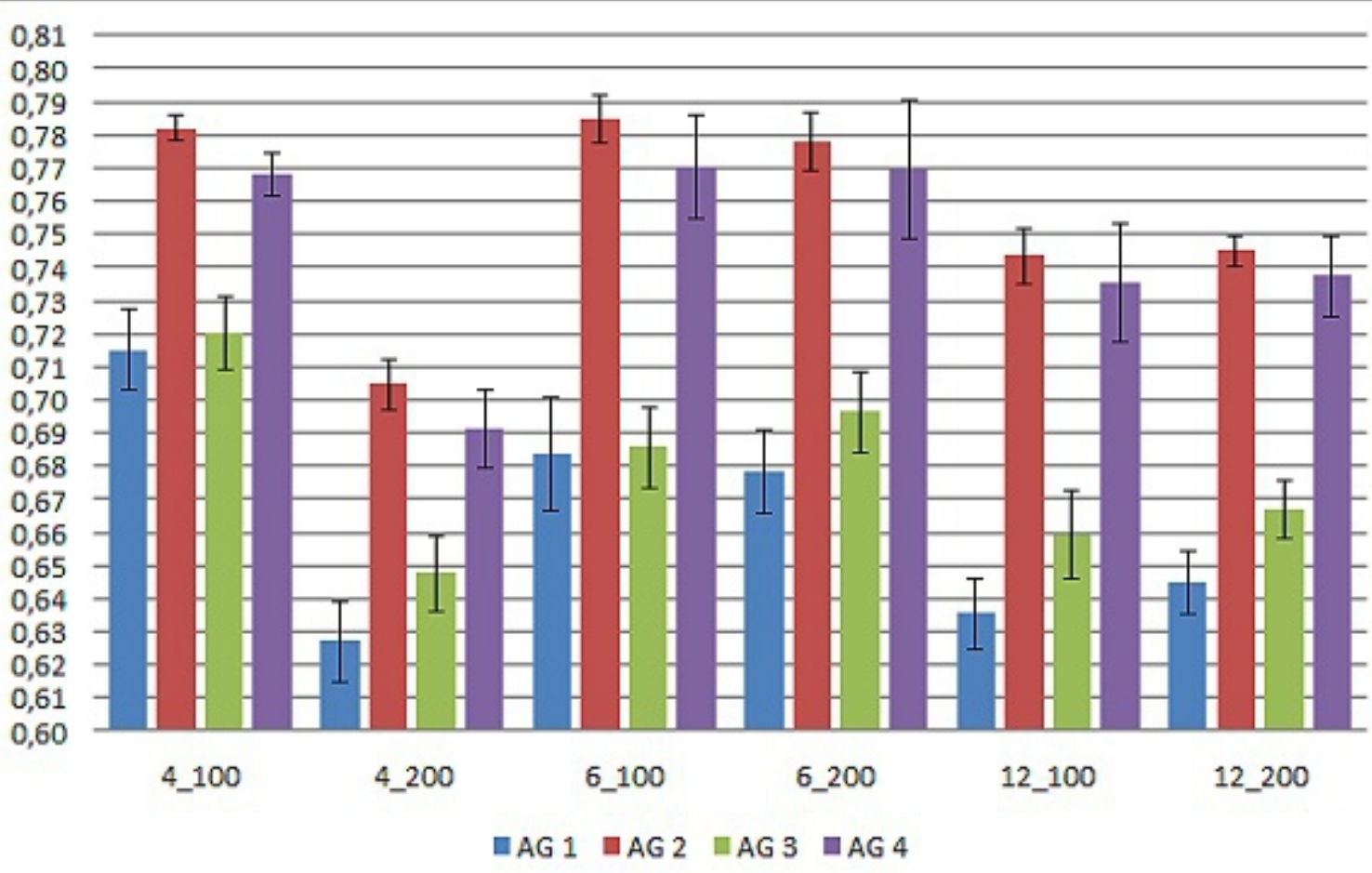

Figura 28: QoS médio dos algoritmos avaliados no planejamento de experimentos dos AGs, para o deadline de mil milissegundos.

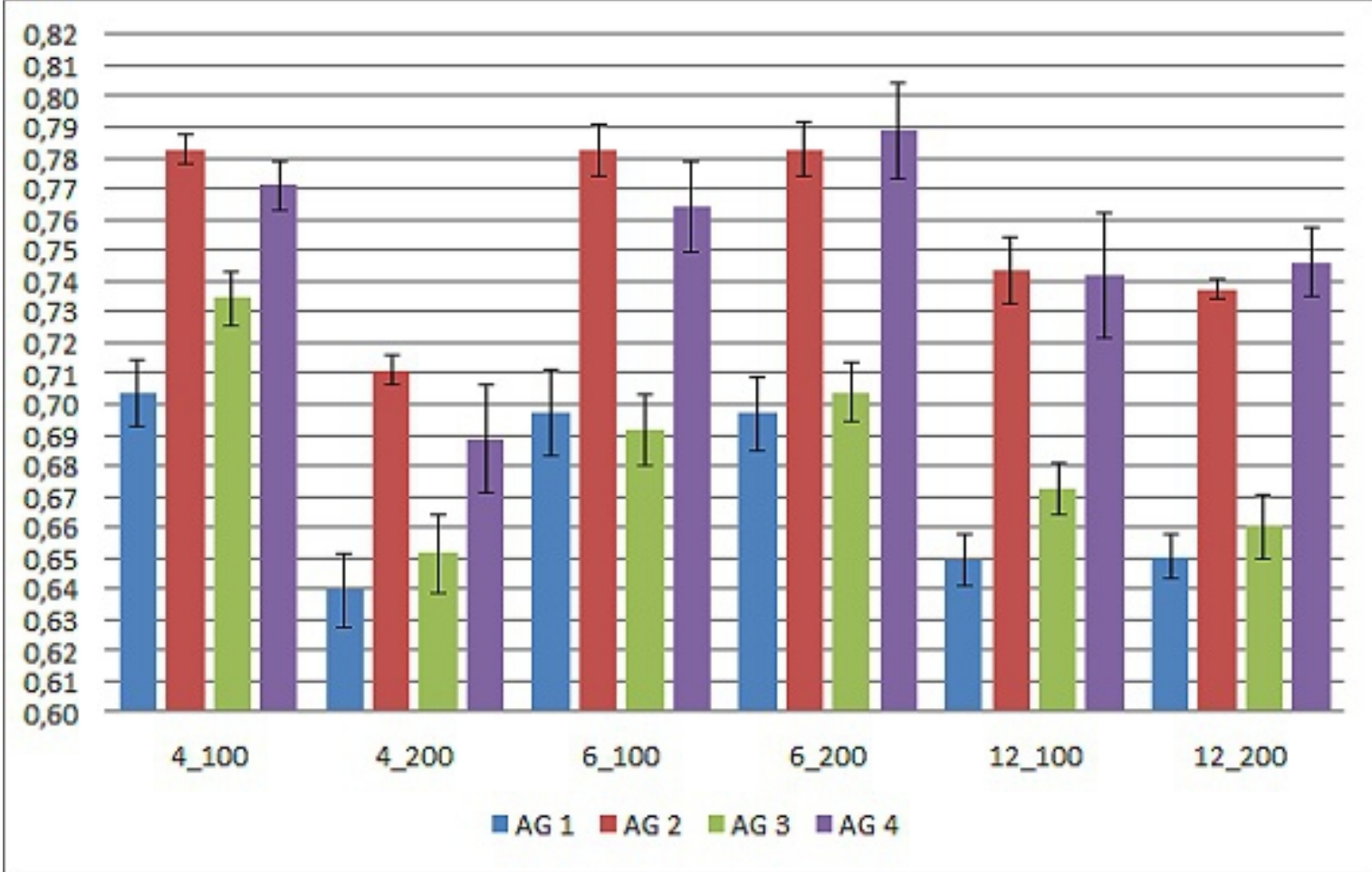

Figura 29: QoS médio dos algoritmos avaliados pelo planejamento de experimentos dos AGs, para o deadline de mil e quinhentos milissegundos. 
O fato do AG 2 ser superior em um tamanho de espaço de busca e equivalente ao AG 4 nos demais, já é suficiente para classificá-lo como a melhor opção. Entretanto, outra característica desejada em AGs é a estabilidade de suas respostas. A estabilidade pode ser medida pelo desvio-padrão e pelo intervalo de confiança. Dentre os quatro AGs avaliados, e nos seis tamanhos de espaço de busca, o AG 2 obteve o menor intervalo de confiança em todos os casos. Combinando essas duas informações obtidas, fica claro que o AG 2 foi o melhor algoritmo nesse conjunto de experimentos. A Figura 29 exibe os resultados dos experimentos com o deadline de mil e quinhentos milissegundos.

Na Figura 29 pode-se observar que os resultados ficaram bem semelhantes com os resultados do deadline de mil milissegundos. Isso provavelmente ocorreu porque o aumento no deadline não foi suficiente para que houvesse uma melhoria significativa das respostas. Todos os experimentos realizados possuem um tempo $k$, que representa a troca de mensagens entre as três máquinas do ambiente de testes, além do tempo necessário para normalizar os atributos de QoS obtidos na máquina que executa o servidor MySQL. Esse $k$ foi registrado em dez repetições e calculou-se a média, desvio-padrão e intervalo de confiança (com grau de confiança de 95\%). Isso pode ser observado na Figura 30.

Da mesma forma que ocorreu com o deadline de mil milissegundos, neste caso os algoritmos AG 2 e AG 4 obtiveram desempenho claramente superior aos outros dois. O AG 2 é superior estatisticamente ao AG 4 apenas no caso " 4 - 200" e os dois são estatisticamente equivalentes nos demais tamanhos de espaço de busca. Novamente isso é suficiente para apontar o AG 2 como o melhor algoritmo e novamente o intervalo de confiança do AG 2 foi o menor dos quatro AGs.

Sendo assim, para os dois deadlines analisados, o AG 2 é a melhor opção, pois é sempre superior ou igual aos outros três AGs. 


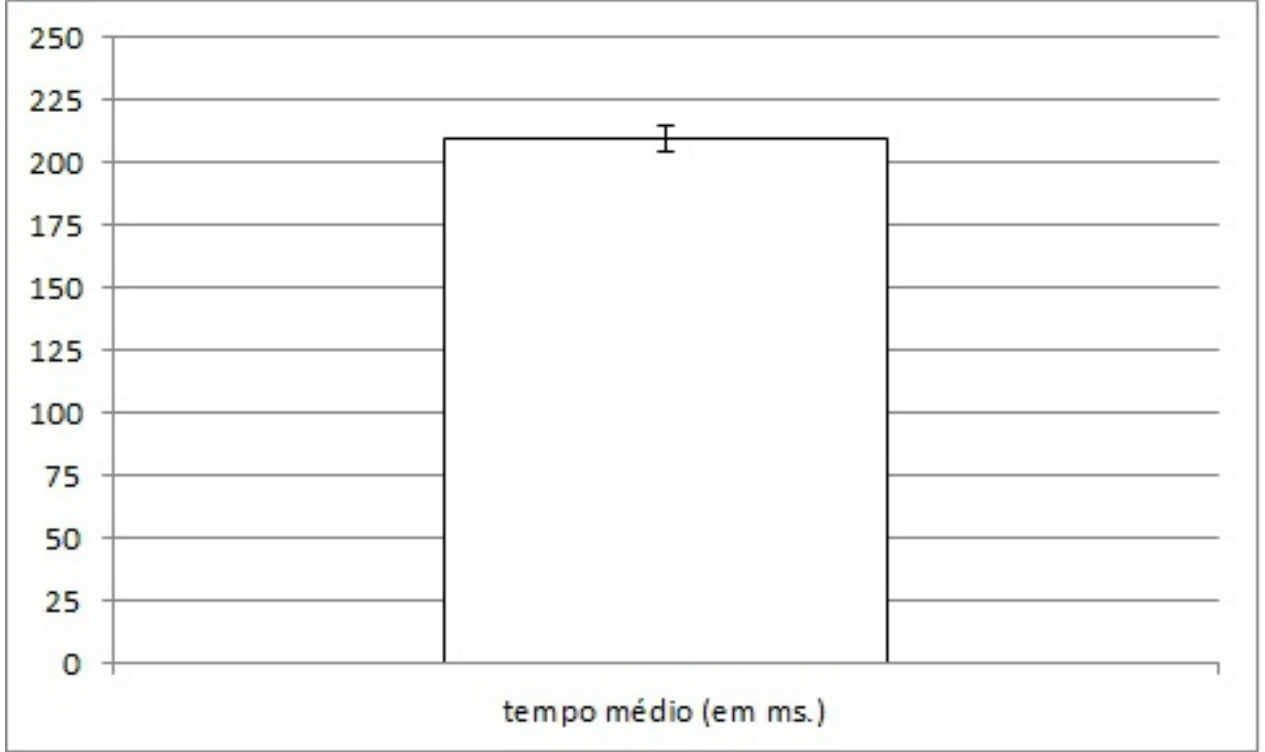

Figura 30: Tempo médio dispendido na troca de mensagens entre as máquinas do ambiente de testes e na normalização de atributos de QoS.

\subsubsection{Análise do QoS do planejamento de experimentos B}

Como foi citado no capítulo anterior, o algoritmo BE não conseguiu atender a nenhum dos dois deadlines definidos. Portanto, ele não é uma alternativa viável. Entretanto, ele foi executado, pois como encontra o ótimo global, podem-se comparar seus resultados com os demais algoritmos, permitindo assim determinar a distância entre as respostas obtidas pelos algoritmos e o ótimo global. Os resultados para o deadline de mil milissegundos podem ser observados na Figura 31.

No primeiro tamanho de espaço de busca $(4-100)$, observa-se que o algoritmo BA e o AGDH obtiveram os melhores resultados (com exceção do BE) e são estatisticamente equivalentes; também se pode afirmar que chegaram próximos do ótimo global. No segundo tamanho de espaço de busca, novamente os algoritmos BA e AGDH obtiveram os melhores resultados e são equivalentes, mas desta vez ficaram distantes do ótimo global. Como os atributos de QoS foram gerados aleatoriamente, provavelmente para esse espaço de busca em específico os atributos gerados devem ter tido valores bem abaixo dos demais espaços de busca, sendo o ótimo global praticamente um outlier desse conjunto de dados. Mesmo o ótimo global sendo maior do que as respostas encontradas pelos outros três algoritmos nota-se que é significativamente menor em relação aos ótimos globais dos espaços " $4-100$ " e "6 $100 "$. 
A partir do terceiro tamanho de espaço de busca, nota-se que o algoritmo BA deixa de ser uma boa opção. Isso acontece porque os espaços de busca são grandes e uma estratégia de Random Walk torna-se ineficaz (ao menos para os deadlines definidos).

No terceiro tamanho de espaço de busca, o algoritmo FU obteve um resultado superior ao HG e próximo ao ótimo global. O algoritmo AGDH obteve o mesmo resultado do FU. No quarto e no quinto tamanho de espaço de busca, os algoritmos FU, HG e AGDH empataram. Finalmente no quinto tamanho de espaço de busca, o FU foi superior ao $\mathrm{HG}$ e empatou com o AGDH.

Levando-se em conta os seis tamanhos de espaço de busca avaliados, o algoritmo AGDH é a melhor opção, pois sempre obteve respostas superiores ou iguais aos demais algoritmos.

Os resultados para o deadline de mil e quinhentos milissegundos podem ser observados na Figura 32.

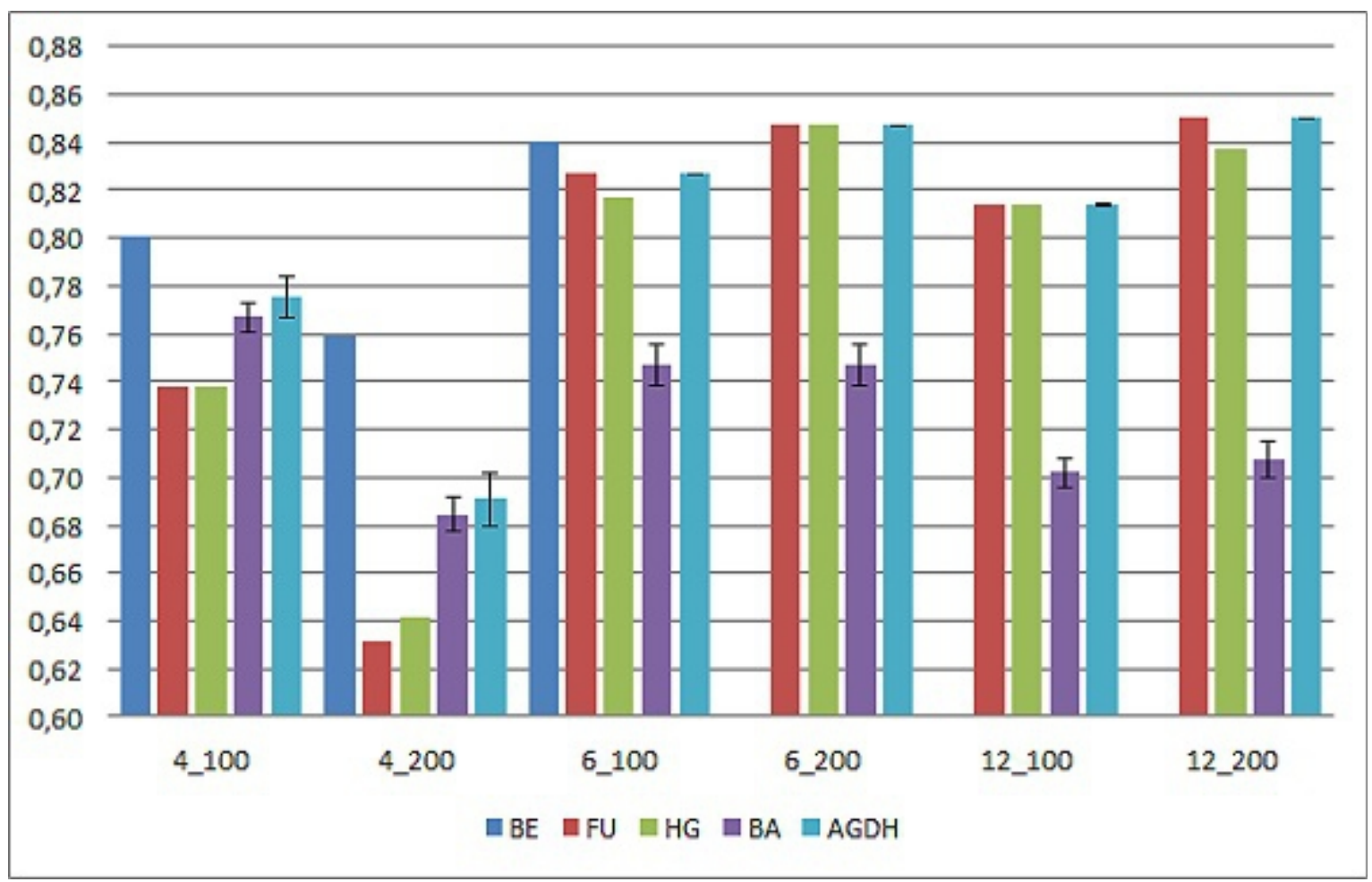

Figura 31: QoS médio dos algoritmos avaliados no planejamento de experimentos B, para o deadline de mil milissegundos. 


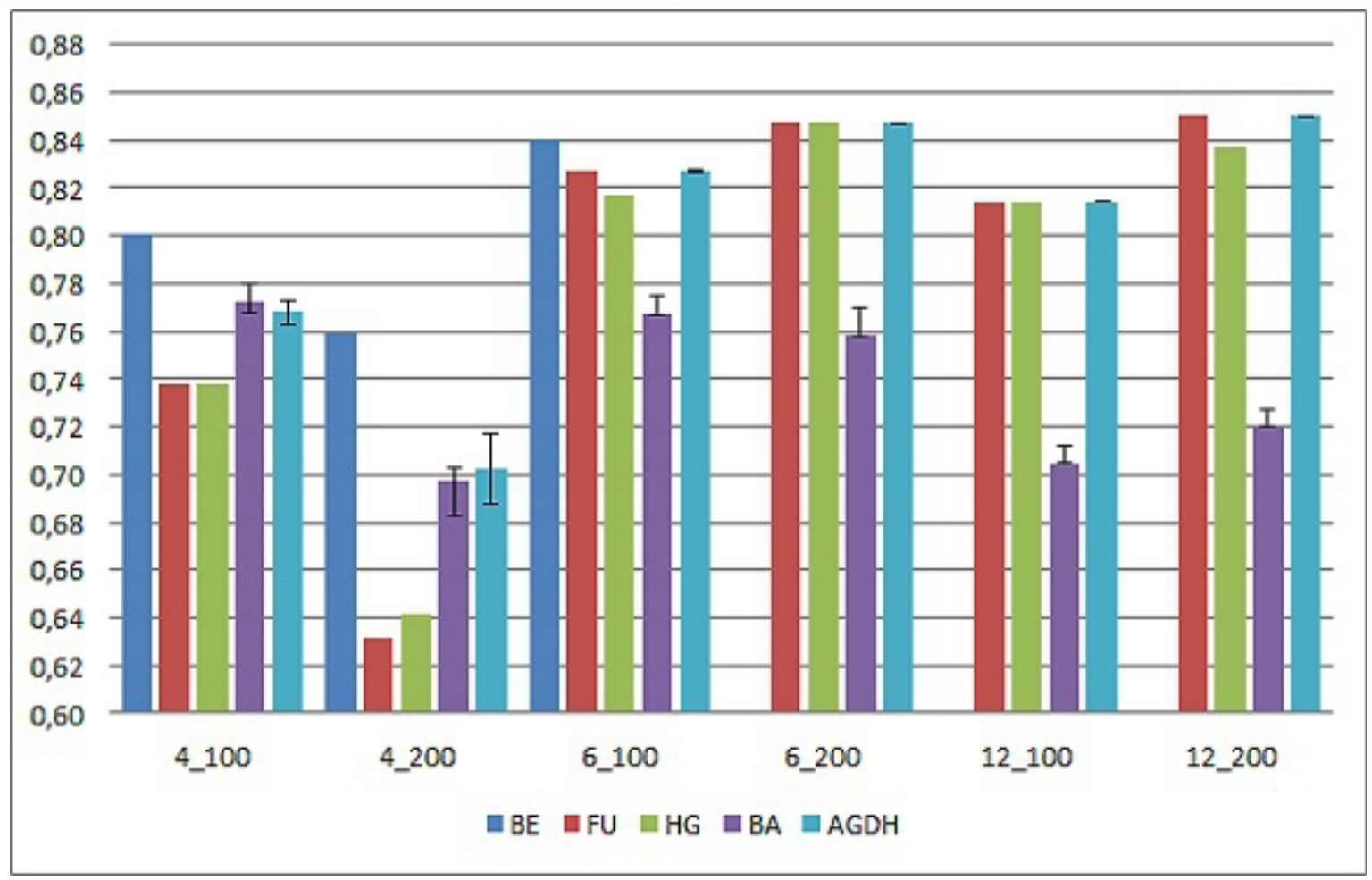

Figura 32: QoS médio dos algoritmos avaliados no planejamento de experimentos B, para o deadline de mil e quinhentos milissegundos.

Com esse deadline, os algoritmos BA e AGDH não obtiveram um aumento significativo dos seus resultados. As diferenças que não são estatisticamente equivalentes podem ser observadas na Tabela 15.

Tabela 15: Diferenças no QoS do algoritmo BA para os dois deadlines definidos.

\begin{tabular}{|c|c|c|c|c|c|}
\hline Algoritmo & $\begin{array}{c}\text { Espaço de } \\
\text { busca }\end{array}$ & Deadline & Média & Média + IC & Média - IC \\
\hline BA & 6_100 & 1.000 & 0,747 & 0,756 & 0,739 \\
\hline BA & 6_100 & 1.500 & 0,767 & 0,775 & 0,759 \\
\hline
\end{tabular}

De forma semelhante ao que ocorreu nos experimentos com o deadline de mil milissegundos, neste caso os algoritmos BA e AGDH também foram equivalentes nos dois primeiros tamanhos de espaço de busca; sendo também melhores do que os algoritmos FU e HG. Novamente a partir do terceiro tamanho de espaço de busca, o algoritmo BA torna-se uma escolha indesejada. 
$\mathrm{O}$ algoritmo AGDH é novamente a melhor escolha, pois obteve desempenho sempre superior ou igual aos demais algoritmos, em todos os tamanhos de espaço de busca avaliados.

\subsection{Influência dos fatores}

\subsubsection{Influência dos fatores dos AGs}

Primeiramente foram calculadas as influências dos fatores: operador de seleção e elitismo, dos quatro AGs desenvolvidos e avaliados. As influências dos fatores foram calculadas em todos os doze grupos de experimentos, representados na Tabela 8 da Seção 5.3.3. Os resultados podem ser observados na Tabela 16 .

Tabela 16: Análise da influência dos fatores para o planejamento de experimentos dos AGs.

\begin{tabular}{|c|c|c|c|c|}
\hline \multicolumn{5}{|c|}{ Influência dos fatores (\%) } \\
\hline$\#$ & A - Operador de Seleção & B - Elitismo & AB & Total \\
\hline 1 & 96,65 & 2,79 & 0,56 & 100 \\
\hline 2 & 92,45 & 7,26 & 0,30 & 100 \\
\hline 3 & 98,76 & 0,78 & 0,46 & 100 \\
\hline 4 & 97,44 & 2,27 & 0,29 & 100 \\
\hline 5 & 96,42 & 2,94 & 0,64 & 100 \\
\hline 6 & 96,34 & 2,92 & 0,74 & 100 \\
\hline 7 & 86,07 & 11,55 & 2,38 & 100 \\
\hline 8 & 90,05 & 9,06 & 0,89 & 100 \\
\hline 9 & 97,15 & 0,64 & 2,21 & 100 \\
\hline 10 & 99,38 & 0,00 & 0,62 & 100 \\
\hline 11 & 96,16 & 2,18 & 1,66 & 100 \\
\hline 12 & 98,82 & 0,01 & 1,18 & 100 \\
\hline
\end{tabular}

Observando-se a Tabela 16, se pode notar que em todos os doze grupos de experimentos, o fator que teve a maior influência foi o operador de seleção. Isso é fácil de perceber quando se leva em conta os resultados obtidos pelo AG 2 e AG 4, que foram superiores aos outros dois em todos os tamanhos de espaço de busca e deadlines avaliados. 


\subsubsection{Influência dos fatores do FU e HG}

Também foi calculada a influência dos fatores nos algoritmos FU e HG. Como foi citado no capítulo anterior, essa análise buscou descobrir qual fator influencia mais na queda do QoS do algoritmo. Os resultados do algoritmo FU podem ser observados na Figura 33 e os resultados do algoritmo HG podem ser observados na Figura 34.

Observa-se que a maior influência está no número de Web Services abstratos. Isso já era esperado, pelo fato de que aumentando o número de Web Services abstratos o tamanho do espaço de busca aumenta exponencialmente.

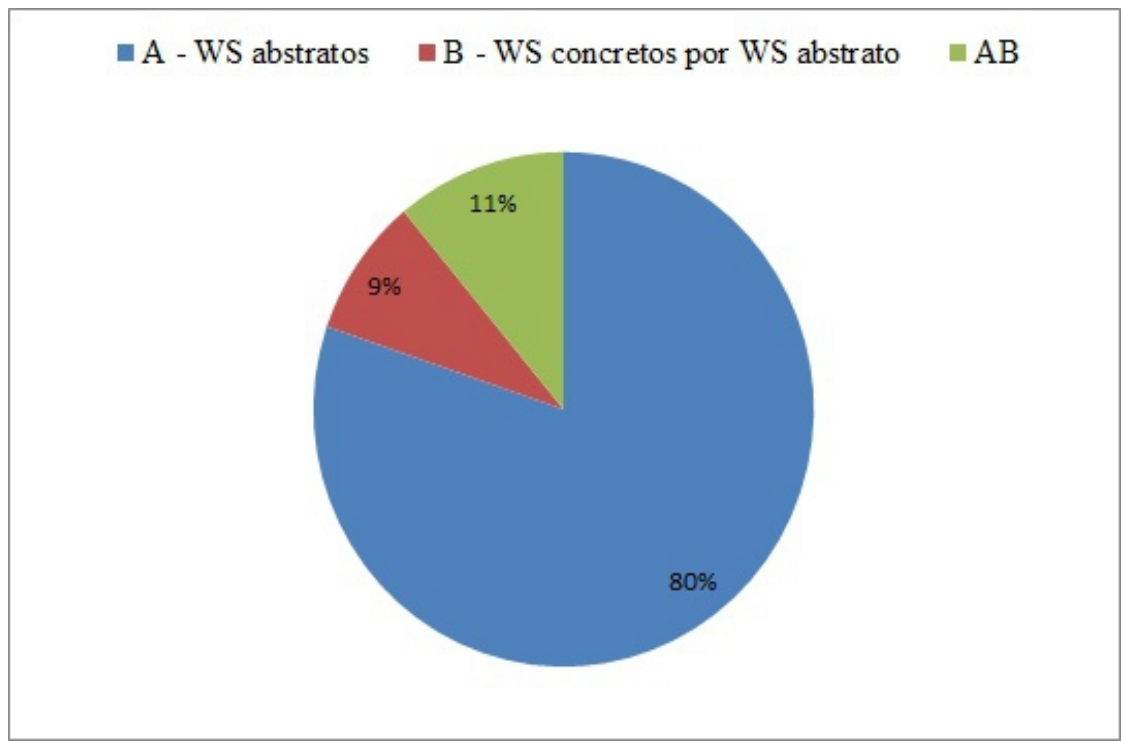

Figura 33: Influência dos fatores do algoritmo FU.

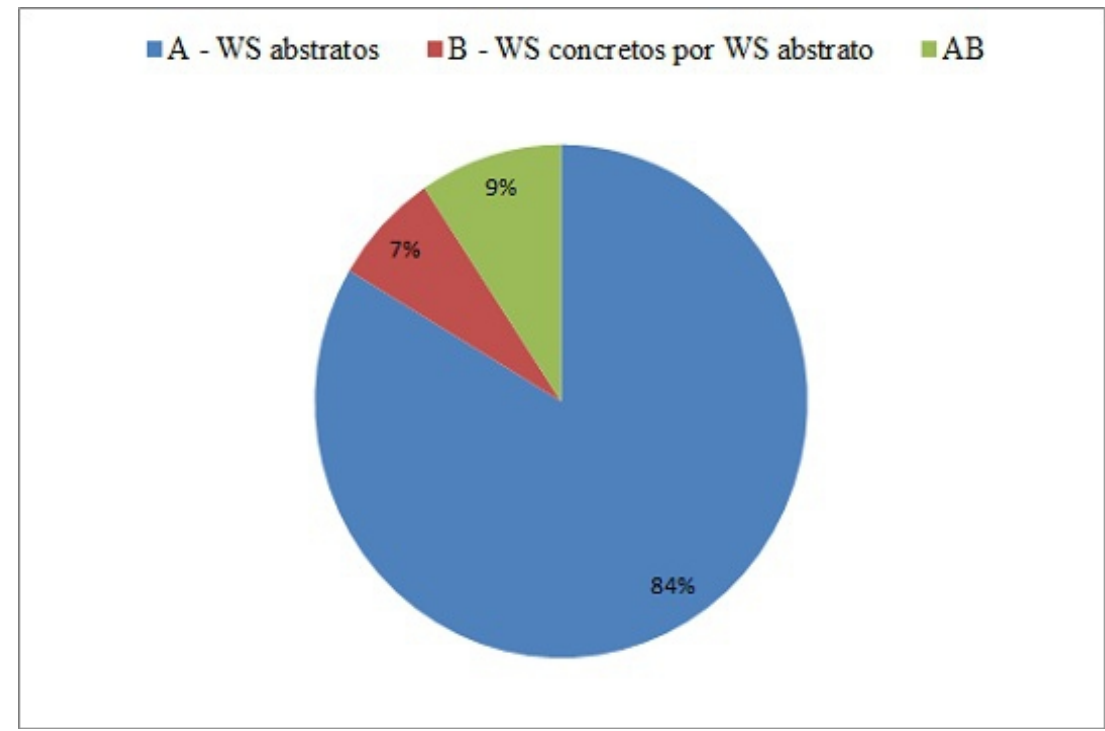

Figura 34: Influência dos fatores do algoritmo HG. 


\subsection{Considerações finais}

Este capítulo apresentou os resultados dos experimentos dos dez algoritmos desenvolvidos e avaliados, tanto em relação ao tempo de resposta como ao QoS obtido. Como havia sido suposto, o algoritmo BE se torna inviável a partir do tamanho de espaço de busca “4-100”, levando-se em consideração os deadlines pré-determinados.

O algoritmo BA mostrou-se como uma alternativa viável para tamanhos de espaço de busca pequenos (4-100 e 4-200), superando os algoritmos determinísticos (FU e HG) e sendo equivalente ao algoritmo híbrido AGDH.

Nos experimentos relacionados aos AGs, ficou clara a superioridade do operador de seleção torneio com dezesseis participantes em relação ao operador roleta viciada. Em todos os tamanhos de espaço de busca e nos dois deadlines definidos, o QoS dos AG 2 e AG 4 foram estatisticamente superiores ao dos outros dois AGs. Além disso, a análise da influência dos fatores também apontou o operador de seleção como o responsável pela maior influência no QoS dos AGs.

A análise da influência dos fatores dos algoritmos FU e HG apontou para o número de Web Services abstratos no fluxo como o maior responsável pela queda da qualidade do QoS obtido. Isso é de se esperar, tendo em vista que se aumentando o número de Web Services abstratos implica que o tamanho do espaço de busca aumente exponencialmente. Como os dois algoritmos só percorrem um subespaço de busca, a probabilidade de não encontrar o ótimo global aumenta. No próximo capítulo serão apresentadas as conclusões e finalmente os trabalhos futuros. 


\section{Capitulo}

\section{Conclusões e Trabalhos Futuros}

\subsection{Considerações iniciais}

Este capítulo tem o intuito de discorrer sobre as conclusões obtidas a partir dos dez algoritmos desenvolvidos e avaliados, as dificuldades que surgiram no decorrer do projeto, as contribuições obtidas e sugestões para possíveis trabalhos futuros.

\subsection{Conclusões}

Como foram citados anteriormente, os sistemas de e-commerce realizam transações entre diferentes empresas, fazendo com que seja provável que sistemas desenvolvidos em diferentes linguagens de programação e para diferentes plataformas tenham que interagir. $\mathrm{O}$ uso de Web Services é uma maneira já bastante utilizada para resolver tais problemas de interoperabilidade.

Além disso, os clientes de sistemas de e-commerce insatisfeitos deixam de usar tais sistemas e não retornam mais, o que causa perdas tangíveis (perda de receitas) e algumas perdas intangíveis (má reputação).

Os Web Services são desenvolvidos para serem concisos e fracamente acoplados, portanto um sistema de e-commerce tem de utilizar uma combinação de vários Web Services para atender às demandas de seus clientes. Dessa necessidade surgiu a composição de Web Services.

Combinando-se a necessidade de interoperabilidade, a necessidade de fornecer um serviço de qualidade para os clientes (e algumas vezes essa qualidade deve ser personalizada, por exemplo, permitindo diferentes pesos para os atributos de QoS ou restrições) e a necessidade de realizar a composição de Web Services, surgiu à solução denominada Composição de Web Services baseada em QoS (CWSbQ). 
Entretanto, como foi citado na Seção 3.6, vários trabalhos relacionados abordam esse problema de forma muito limitada. É preciso levar em consideração os vários aspectos do problema, de forma que seja possível uma solução que possa ser aplicada nos sistemas do mundo real.

Esse problema está relacionado com as áreas de: sistemas distribuídos, otimização combinatória e soft real-time. Além disso, para que seja possível comparar diferentes algoritmos, deve-se levar em conta o uso de técnicas de avaliação de desempenho, como o planejamento de experimentos e a análise da influência dos fatores.

Como já foram citados, alguns trabalhos não dão a devida atenção à característica soft real-time do problema, o que faz com que os algoritmos desenvolvidos não possam ser aplicados em sistemas usados no mundo real. Outro fato observado nos trabalhos relacionados é o uso de tamanhos de espaço de busca muito pequenos. Isso tem grande influência no tempo necessário para se executar um algoritmo determinístico e provavelmente também influencia no QoS obtido.

Portanto, neste trabalho foram atacados esses pontos que tem potencial para serem melhorados, tomando-se as seguintes medidas:

- Definição de deadlines realistas para os algoritmos desenvolvidos e avaliados;

- Criação de tamanhos de espaços de busca desde pequenos até grandes, mas que estão mais próximos de ser o que realmente se encontra no mundo real;

- Uso de técnicas de avaliação de desempenho, usando ferramentas estatísticas como: média, desvio-padrão, intervalo de confiança e análise da influência dos fatores, para comparar os algoritmos desenvolvidos e

- Uso de avaliação de desempenho para avaliar diferentes operadores genéticos dos AGs desenvolvidos, algo que se mostrou eficiente e que não foi observado em nenhum dos trabalhos relacionados citados nesta dissertação.

Outro ponto interessante a ser observado, está relacionado com o que foi citado na Figura 18, do Capítulo 3. Nos trabalhos relacionados citados, não houve uma tentativa de descobrir quais algoritmos são melhores para cada situação (diferentes deadlines, diferentes preferências em relação aos atributos de QoS, diferentes tamanhos de espaço de busca) que podem induzir a preferência ou necessidade de utilizar-se diferentes algoritmos.

Por meio dos experimentos conduzidos e dos resultados obtidos, ficou claro que é 
possível estudar essa adequação dos algoritmos, mesmo que ainda não de forma completa. De qualquer forma, estudar essa adequação sem dúvida fornece melhores resultados do que simplesmente adotar um único algoritmo para qualquer situação (o que é feito por grande parte dos trabalhos relacionados).

Não foram realizados experimentos supondo que o sistema estivesse sobrecarregado. Portanto, num sistema real e sobrecarregado, as populações definidas para os AGs para o algoritmo AGDH e para o algoritmo BA talvez ocasionassem um não cumprimento dos deadlines definidos. Isso comprometeria a característica soft real-time dos algoritmos.

Entretanto, alguns fatos devem ser considerados. Primeiro, os sistemas soft real-time por definição aceitam um relaxamento no deadline quando estão sobrecarregados. Segundo, nem todos os aspectos de um sistema do mundo real podem ser incorporados a um protótipo, pois o escopo seria demasiadamente grande. Terceiro esse problema poderia ser resolvido definindo-se um tempo máximo de execução permitido (provavelmente um pouco maior do que o deadine real) para cada thread que atenderia a uma requisição. Se a thread atingisse o tempo máximo e ainda estivesse executando, a thread "pai" invocaria o método que retorna o melhor indivíduo da população descoberto até o momento e finalizaria a thread "filha".

Apesar do problema de CWSbQ estar sendo pesquisado há alguns anos, fica claro que ainda há muitas melhorias que podem ser desenvolvidas, ainda mais quando se leva em conta a composição automática de Web Services, uma técnica mais autônoma do que a composição manual e dinâmica abordada neste trabalho de mestrado.

\subsection{Dificuldades relacionadas ao projeto}

O desenvolvimento deste trabalho envolveu uma série de conceitos. Primeiramente, trata-se de um problema de otimização combinatória (discreta), portanto foi necessário estudar os conceitos referentes à otimização combinatória, levando em conta seus diferentes aspectos, para que fosse possível identificar todas as características relacionadas ao problema abordado.

Foi necessário estudar os conceitos de algoritmos evolutivos, pois como se constatou estudando os trabalhos relacionados, os algoritmos evolutivos são uma abordagem largamente utilizada no problema de CWSbQ e juntamente com os algoritmos híbridos tem mostrado bons resultados. 
Também foi necessário estudar os conceitos de Web Services, pois foi o padrão de comunicação utilizado entre as máquinas do ambiente de testes.

O conceito de sistemas de tempo-real foi estudado, porque se descobriu que o problema de CWSbQ é um problema soft real-time. Apesar de alguns trabalhos não levarem essa característica em conta, neste trabalho essa importante característica do problema foi considerada.

Por fim, foram estudados os conceitos relacionados à avaliação de desempenho, algo pouco utilizado pelos trabalhos relacionados ao problema estudado.

Descobrir como todas essas coisas podem ser utilizadas e integradas, foi um grande desafio enfrentado durante o desenvolvimento deste trabalho.

\subsection{Contribuições}

Este trabalho trouxe uma série de contribuições para a área, são elas:

- Desenvolvimento e avaliação de vários algoritmos diferentes para a CWSbQ (busca aleatória, busca exaustiva, busca heurística, busca meta-heurística e algoritmos híbridos);

- Novos algoritmos desenvolvidos: HG, HG 2 e AGDH;

- Uso de avaliação de desempenho para aperfeiçoar os AGs utilizados para a CWSbQ;

- Estudo da adequação de cada algoritmo, de acordo com a situação (diferentes deadlines, diferentes tamanhos de espaço de busca, diferentes preferências e/ou restrições dos atributos de QoS).

\subsection{Trabalhos futuros}

- Seria interessante avaliar mais níveis para o fator deadline. Por exemplo, poder-se-ia utilizar além dos dois deadlines adotados neste trabalho, também os deadlines três mil milissegundos e seis mil milissegundos. Como o deadline desejado pode ser selecionado pelo usuário, isso não faria com que os usuários que desejam um deadline menor ficassem insatisfeitos.

- Outro possível trabalho futuro interessante seria hibridizar o algoritmo AGDH adicionando um algoritmo de busca local. A combinação de AGs com algoritmos de busca 
local tem mostrado bons resultados nos trabalhos relacionados. Isso provavelmente faria com que o algoritmo ficasse mais lento, mas poderia trazer melhores resultados (QoS maiores) nos casos de deadlines maiores, como por exemplo, 3 segundos e 6 segundos. Esse novo algoritmo seria denominado Algoritmo Genético Triplamente Híbrido (AGTH).

- Neste trabalho não foram desenvolvidos algoritmos paralelos. Um trabalho futuro interessante seria paralelizar o algoritmo AGTH. Na verdade existem diferentes técnicas para paralelizar AGs e se poderia estudar qual delas traz um melhor resultado para o problema estudado. Esse novo algoritmo seria denominado Algoritmo Genético Triplamente Híbrido Paralelo (AGTHP).

- A última e talvez a mais interessante sugestão para trabalhos futuros é desenvolver um mecanismo que automaticamente seleciona o melhor algoritmo (ou pelo menos um bom algoritmo) para cada requisição feita ao compositor de Web Services. Isso seria feito baseando-se nos resultados de experimentos realizados e nas seguintes características das requisições: deadline, número de Web Services abstratos no fluxo, número de Web Services concretos por Web Services abstrato, preferências do usuário em relação aos atributos de QoS e/ou restrições selecionadas pelo usuário aos atributos de QoS. Por exemplo, usando-se os resultados dos experimentos realizados neste trabalho, fica fácil notar que se o número de Web Services abstratos no fluxo for menor do que quatro, o algoritmo BE é a melhor opção. Por outro lado, se o usuário deseja atribuir pesos aos atributos de QoS ou definir uma restrição local, fica claro que o algoritmo a ser utilizado deverá ser o HG2.

\subsection{Considerações finais}

Este capítulo apresentou as conclusões obtidas no decorrer deste projeto, as dificuldades encontradas, as contribuições desenvolvidas e as sugestões para trabalhos futuros. $\mathrm{Na}$ verdade, as sugestões de trabalhos futuros apresentam desafios complexos e não apenas algumas melhorias no que já foi desenvolvido. Portanto, acredita-se que essas sugestões poderiam ser a base para um novo projeto de mestrado ou a primeira parte de um projeto de doutorado. De fato, isso poderia ser uma parte do que mais tarde virá a ser denominado de Composição Super Automática de Web services. 


\section{Referências Bibliográficas}

Alrifai, M.; Risse, T. "Efficient QoS-aware Service Composition". 2008.

Ardagna, D.; Pernici, B. "Global and Local QoS Guarantee in Web Service Selection". LNCS 3812. Springer-Verlag. Berlin. 2006.

Batouche, B.; Naudet, Y.; Guinand, F. "Semantic Web Services Composition Optimized by Multi-Objective Evolutionary Algorithms". In: Proceedings of the Fifth International Conference on Internet and Web Applications and Services. IEEE Computer Society. 2010.

Berners Lee, T.; Fischetti, M. "Weaving the Web - The original design and ultimate destiny of the World Wide Web, by its inventor". $1^{\text {a }}$ Edição. New York: HarperCollins Publishers, 2000. $256 \mathrm{p}$.

Canfora, G.; Di Penta, M.; Esposito, R.; Villani, M. L. "An approach for QoS-aware Service Composition based on Genetic Algorithms". In: Proceedings of ACM GECCO'05. 2005

Claro, D. B.; Albers, P.; Hao, J. "Selecting Web Services for optimal Composition". Université d' Angers. 2005.

CERAMI, E. Web Services Essentials: Distributed Applications with XML-RPC, SOAP, UDDI \& WSDL. O'Reilly. $1^{\text {a }}$ Edição. 2002.

COMER, D. E.. Internetworking with TCP/IP: Principles, Protocols, and Architectures. 4. ed. : Prentice Hall, 2000. 750 p.

Chu, S.; Leung, L. C.; Hui, Y. V.; Cheung, W. "Evolution of e-commerce Web sites: A 
conceptual framework and longitudinal study". In: Jounal of Information and Management. Vol. 44. pp 154 - 164. 2007.

Cui-Mei, B. "Combining Intelligent Agent with Semantic Web Services for Building An eCommerce System". In: Proceedings of the IEEE International Conference on e-Business Engineering. 2009

Dustdar, S., Schreiner, W. “. A Survey on Web Services Composition”. 2004.

Erl, T. “SOA: Principles of Service Design”. Prentice Hall. 573 f. 2008.

Erradi A.; Maheshwari, P. "A Broker-based Approach for Improving Web Services Reliability.", In: Proceedings of the IEEE International Conference on Web Services (ICWS'05) - 2005.

Fanjiang, Y.; Syu, Y.; Wu, C.; Kuo, J.; Ma, S. “Genetic Algorithm for QoS-aware Dynamic Web Services Composition”. In: Proceedings of the International Conference on Machine Learning and Cybernetics. IEEE Computer Society. 2010.

FARKAS, P.; CHARAF, H. Web Services Planning Concepts. Journal Of .net Technologies, p.9-12, 2003.

Feng, L.; Zhen-ming, L. "Research on user-aware QoS based Web services Composition”. In: Journal of China Universities of Posts and Telecommunications. Vol 5. Elsevier. 2009.

FERRIS, C.; FARREL, J. What are Web Services? Communications Of The Acm, New York,n. , p.31-31, jun. 2003. 
Fogel, D. B. "Evolutionary Computation: Toward a New Philosophy of Machine Intelligence". $3^{\text {a }}$ Edição. IEEE Press. 2006.

Foster, I.; Frey, J.; Graham, S.; Tuecke, S.; Czajkowski, K.; Ferguson, D.; Leymann, F.; Nally,M.; Sedukhin, I.; Snelling, D.; Storey, T.; Vambenepe, W. "Modeling Stateful Resources with Web services". Copyright Computer Associates International, Inc., Fujitsu Limited, Hewlet Packard Development Company, International Business Machines Corporation and The University of Chicago, 2003, 2004. All Rights Reserved.

Giusti, R. "Descoberta de regras de conhecimento utilizando computação evolutiva multiobjetivo". Maio/2010. 143 f. Dissertação (Mestrado em Ciências de Computação e Matemática Computacional) - Instituto de Ciências Matemáticas e de Computação, Universidade de São Paulo, São Paulo, 2010.

He, H.; Haas, H. "Web service architecture usage scenarios". W3C Working Group Note. 2003.

Jain, R. "The Art of Computer Systems Performance Analysis: techniques for experimental design, measurement, simulation, and modeling”. Wiley. 1991

Janssen, M.; Cresswell, M. "An enterprise application integration methodology for egovernment.”, In: Journal of Enterprise Information Management Year: 2005 Volume: 18 Issue: 5 Page: 531 - 547 - Published by the Emerald Group Publishing Limited.

KALEPU, S.; KRISHNASWAMY, S.; LOKE, S.W. Verity: A qos metric for selecting web services and providers. In Proceedings of the Fourth International Conference on Web Information Systems Engineering Workshops (WISEW'03). IEEE CS Press. 2003.

Karunamurthy, R.; Khendek, F.; Glitho, R. H. "A novel architecture for Web service composition". In: Journal of Network and Computer Applications. Vol. 35. pp. $787-802$. 
Elsevier. 2012.

Ko, J. M.; Kim, C. O.; Kwon, I. "Quality-of-service oriented web service composition algorithm and planning architecture". The Journal of Systems and Software. vol. 81. 2079 2090 p. 2008.

KREGER, H. et al. Web Services Conceptual Architecture (WSCA 1.0). Disponível em: $<$ http://www.cs.uoi.gr/ zarras/mdw-ws/WebServicesConceptualArchitectu2.pdf $>$. Maio de 2001. Acessado em: 25/04/2012.

Kuehne, B. T. "Modelos e algoritmos para composição de Web Services com qualidade de serviço". Outubro/2009. 96 f. Dissertação (Mestrado em Ciências de Computação e Matemática Computacional) - Instituto de Ciências Matemáticas e de Computação, Universidade de São Paulo, São Paulo, 2009.

Kurose, J. F.; Ross, K. "Redes de Computadores e a Internet: Uma abordagem top-down". $3^{\mathrm{a}}$ Edição. São Paulo: Pearson Addison Wesley, 2007. 634 p.

LEAVITT, N. Are Web Services Finally Ready to Deliver? Computer, p.14-18, 2004.

Li, S.; Chen, M. “An Adaptative-GA Based QoS Driven Service Selection for Web Services Composition". In: Proceedings of the International Conference on Computer Application and System Modeling. 2010.

Liang, W.; Huang, C. "The generic genetic algorithm incorporates with rough set theory - An application of the web services composition". Expert Systems with Applications. Vol. 36. 5549 - 5556 p. Elsevier. 2009.

Lin, C.; Sheu, R.; Chang, Y.; Yuan, S. “A relaxable service selection algorithm for QoS-based 
web service composition". In: Journal of Information and Software Technology. Vol. 53. pp 1370 - 1381. Elsevier. 2011.

Linden, R. "Algoritmos Genéticos: Uma importante ferramenta da Inteligência Computacional”. $2^{\mathrm{a}}$ Edição. Rio de Janeiro: Brasport, 2008.

Liu, H.; Zhong, F.; Ouyang, B.; Wu, J. "An Approach for QoS-aware Web Service Composition based on Improved Genetic Algorithm”. In: Proceedings of the International Conference on Web Information Systems and Mining. IEEE Computer Society. 2010.

Liu, Y.; Miao, H.; Li, Z.; Gao, H. "QoS-aware Web services composition based on HQPSO Algorithm". In: Proceedings of The First ACIS/JNU International Conference on Computers, Networks, Systems, and Industrial Engineering. IEEE Computer Society. 2011.

Ma, Y.; Zhang C. "Quick convergence of genetic algorithm for QoS-driven web service selection". Computer Networks. Vol. 52.1093 - 1104 p. 2008.

Menascé, D. A.; Barbará, D.; Dodge, R. "Preserving QoS of E-commerce Sites Through SelfTuning: A Performance Modelo Approach”. In: Proceedings of the ACM Conference on Ecommerce. 2001.

Moraes, N. A. "Avaliação de Desempenho de algoritmos para composição de Web Services". Novembro/2010. 55 f. Trabalho de Conclusão de Curso (Engenharia de Computação) Instituto de Ciências Matemáticas e de Computação, Universidade de São Paulo, São Paulo, 2010.

Nakamura, L. H. V. "Utilização de Web semântica para seleção de informações de web services no registro UDDI: Uma abordagem com qualidade de serviço”. Fevereiro/2012. 150 f. Dissertação (Mestrado em Ciências de Computação e Matemática Computacional) Instituto de Ciências Matemáticas e de Computação - USP, São Paulo, 2012. 
PAPAZOGLOU, M. P.; GEORGAKOPOULOS, D. Service-Oriented Computing. Communications Of The Acm, p.25-28, out. 2001.

PAPAZOGLOU, Mike P.. Service -Oriented Computing: Concepts, Characteristics and Directions. Proceedings Of The Fourth International Conference On Web Information Systems Engineering (wise'03), 2003.

Peltz, C. "Web Services Orchestration and Choreography". Computer. IEEE Computer Society. 2003.

Rothlauf, F. "Representations for Genetic and Evolutionary Algorithms". $2^{\mathrm{a}}$ Edição. Springer. 2006.

Siblini, R.; Mansour, N. "Testing Web Services", Computer Science and Mathematics Division, Lebanese American University, Mme Curie St., Beirute, Leebanon. 2005.

Silva, E. E. “Otimização de Estruturas de Concreto armado Utilizando Algoritmos Genéticos. 2001. Dissertação, USP, 2001.

Snell, J.; Tidwell, P.; Kulchenko, P. "Programming Web Services with SOAP”. O’Reilly Media, 2001. 264 p.

Su, S.; Zhang, C.; Chen J. "An Improved Genetic Algorithm for Web Services Selection". LNCS Vol. 4531.284 - 295 p. 2007.

Tang, M.; Ai, L. "A Hybrid Genetic Algorithm for the Optimal Constrained Web Service Selection Problem in Web Service Composition”. In: Proceedings of the World Congress on Computational Intelligence. Barcelona, Espanha. 2010. 
THOMAS, J. P.; THOMAS, M.; GHINEA, G. Modeling of Web Services Flow. Proceedings

Of The Ieee International Conference On E-commerce (cec'03), 2003.

Tian, M.; Gramm, A.; Naumowicz, T.; Ritter, H.; Schiller, J. “A Concept for QoS Integration in Web Services", In: Proceedings of the Fourth International Conference on Web Information Systems Engineering Workshops (WISEW’03).

VEGESNA, S. IP Quality of Service for ther Internet and Intranets. Indianapolis: Cisco Press, 2000 .

Wang, H.; Lee, C.; Ho, T. "Combining subjective and objective QoS factors for personalized web service selection". Expert Systems with Applications. Vol. 32. 571 - 584 p. 2007.

Wang, P.; Chao, K.; Lo, C. “On optimal decision for QoS-aware composite service selection”. Expert Systems with Applications. N. 37. p. 440 - 449. Elsevier, 2010.

Wang, K.; Tian, N. "Performance Modeling of Composite Web Services". In: Proceedings of the Pacific-Asia Conference on Circuits, Communications and System. 2009.

Weise, T.; Bleul, S.; Comes, D.; Geihs, K. "Different Approaches to Semantic Web Service Composition". In: Proceedings of The Third International Conference on Internet and Web Applications and Services, ICIW. 2008.

Yu, C.; Wang, G.; Liu, Y. “A multi-agent based architecture for Web service Selection in ebusiness". In: Proceedings of The Eight IEEE International Conference on E-business Engineering. IEEE Computer Society. 2011.

Zhang, C.; Ma, Y. "Dynamic Genetic Algorithm for Search in Web Service Compositions Based on Global QoS Evaluations". In: Proceedings of the International Conference on 
Scalable Computing and Communications. IEEE Computer Society. 2009.

Zhang, C.; Su, S.; Chen, J. "DiGA: Population diversity handling genetic algorithm for QoSaware web services selection". Computer Communications. Vol. 30.1082 - 1090 p. 2007.

Zhang, W.; Chang, C. K.; Feng, T.; Jiang, H. “QoS-based Dynamic Web Service Composition with Ant Colony Optimization". In: Proceedings of the 34th Annual IEEE Computer Software and Applications Conference. IEEE Computer Society. 2010.

Zhi-peng, G.; Jian, C.; Xue-song, Q.; Luo-ming, M. "QoE/QoS driven simulated annealingbased genetic algorithm for Web Services Selection". The Journal of China Universities of Posts and Telecommunications. Elsevier. 2009. 